\author{
Universidade de São Paulo \\ INSTITUTO OCEANOGRÁFICO
}

\title{
VARIAÇÕES NA ACUMULAÇÃO DE MATÉRIA ORGÂNICA, AO LONGO DO HOLOCENO, EM SEDIMENTOS DA REGIÃO COSTEIRA DE UBATUBA-SÃO PAULO
}

Simone Sandra Sonvesso

Dissertação de Mestrado apresentada ao Instituto Oceanográfico da Universidade de São Paulo, como parte dos requisitos para obtenção do título de Mestre em Ciências, área de Oceanografia Química e Geológica

Orientador:

Prof.Dr.Michel Michaelovitch de Mahiques

SÃO PAULO

2007 
Perante a complexibilidade das combinações entre o ar, a terra, $e$ o mar, cabe aos "olhos humanos", apenas trilhar um dos infinitos caminhos, no fluxo de uma corrente marinha, que vai para aonde o vento soprar...e paira na brisa suave, em um dia calmo e quente, do inverno do ano em que está. 


\section{Ao men filho, \\ Guilherme Sonvesso Pereira}




\section{PREFÁCIO}

As características dos sedimentos e da matéria orgânica depositados, ao longo dos anos, em um determinado ponto, refletem não só o presente, na época da deposição, mas também guardam em seus aspectos intrínsecos as condições pretéritas, que foram de fundamental importância, pois permitiram a sua deposição, e as condições futuras, que permitiram a sua preservação, ou destruição, e neste caso, o registro não foi contínuo.

Além da importância cronológica dos eventos, existe a importância dos fatores que interferem nas características dos sedimentos e da matéria orgânica depositada e preservada. Aqui, são considerados como fundamentais e interligados: clima, hidrodinâmica e variação do nível relativo do mar. Fatores climáticos alteram a hidrodinâmica, pois influenciam diretamente nos parâmetros fisico-químicos da água do mar, gerando correntes marinhas e ondas que são responsáveis pelo transporte dos sedimentos. A hidrodinâmica, por sua vez, também altera o clima, pois o oceano é uma fonte de calor, e o transporte das águas de um local para o outro modificam a temperatura da atmosfera. A variação do nível relativo do mar é influenciada por vários fatores, entre eles estão os climáticos e os hidrodinâmicos.

A preservação é outro fator fundamental no estudo. Um ponto importante neste tipo de pesquisa, é considerar que a maior ou menor acumulação de matéria orgânica, durante o Holoceno, na região, não é necessariamente relacionada de forma direta com a taxa de acumulação da matéria orgânica no paleoambiente. As condições de baixa e alta preservação da matéria orgânica, e os fatores sedimentológicos podem mascarar a real quantidade de matéria orgânica inicialmente produzida e depositada ao longo dos anos.

O tipo de recorte das praias escolhidas no presente trabalho, junto às áreas de estudo, caracteriza praias de bolso, as quais encontram-se relativamente mais abrigadas. A dinâmica de regiões costeiras, relativamente protegidas, pode ser comparada com a dinâmica de regiões lagunares, que são ambientes onde a preservação da matéria orgânica sedimentar registra os níveis de carbono em uma determinada época. 


\section{AGRADECIMENTOS}

Agradeço a Deus pela vida.

Agradeço a meus pais biológicos Sueli Sandra Torquato Sonvesso e Pedro Geraldo Sonvesso, e a tantos outros que me acompanharam durante o desenvolvimento deste trabalho: meu orientador, Michel Michaelovitch de Mahiques;: Waldenir Furtado, Joseph Hahari, que são pessoas, nas quais, transparece a disciplina, a dignidade e o trabalho . São PROFESSORES, junto a muitos outros, do Instituto Oceanográfico, que zelam pelo funcionamento da Universidade, refletindo responsabilidade. Aos senhores muito obrigada e parabéns pela lealdade que os mantém dignos de serem quem são. Agradeço de coração àquelas pessoas que me ensinaram a dar os primeiros passos neste trabalho, foram elas que me mostraram o $A B C$ dos trabalhos de campo e de laboratório: Edilson, Samara, Clodoaldo, Daniel e Marcelo.

Agradeço a meus companheiros de laboratório que me deram dicas fundamentais: Roberto, Bibiana, Marcelo.

Agradeço a minha avó Luiza Montezano Sonvesso e ao companheiro Rodrigo César de Lima Pereira, pelo incentivo em dar prosseguimentos aos meus estudos.

Obrigada a todos os meus amigos e colegas que de alguma forma, se preocupam com o meu bem estar e desempenho nos meus trabalhos.

Quero dar os agradecimentos especiais a três pessoas que me ajudaram de uma forma imprescindível: meu irmão Allan Torquato e minhas prezadas amigas Camila de "Santos" e Ana Cláúdia.

Obrigada à irmandade pelo equilibrio, verdade e clareza proporcionados para eu finalizar este trabalho.

Agradeço ao caro colega Robson (Soneca)e Abel pelos trabalhos de impressão. 


\section{ÍNDICE}

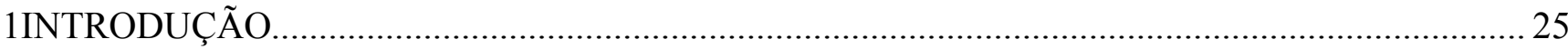

1.1 A importância da matéria orgânica sedimentar ................................................. 25

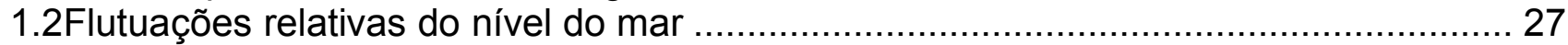

1.3Variações climáticas durante o Holoceno.............................................................. 30

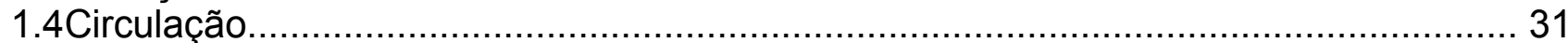

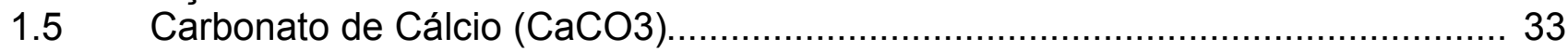

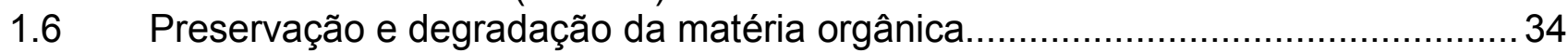

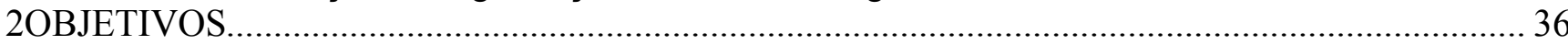

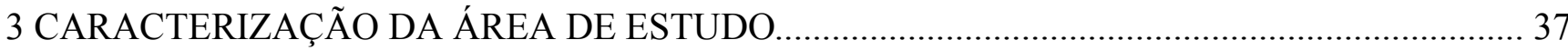

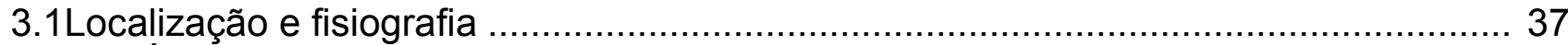

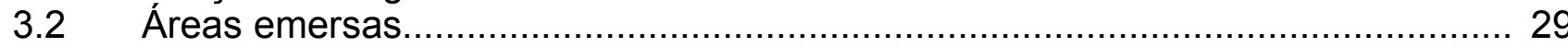

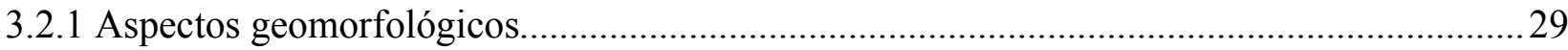

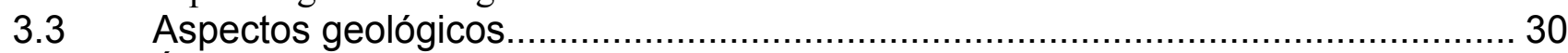

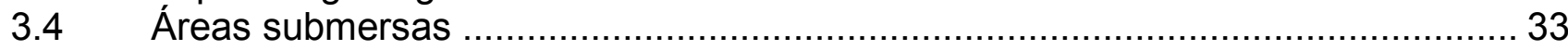

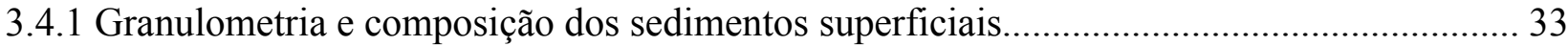

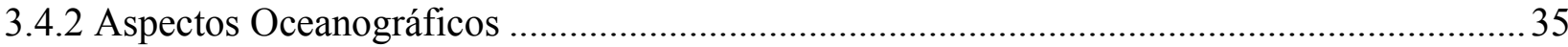

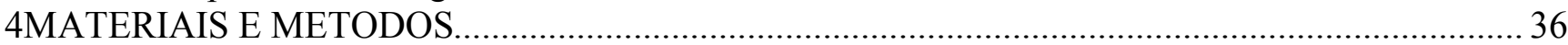

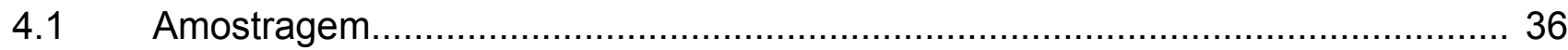

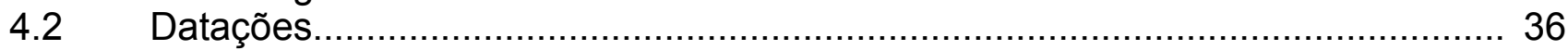

4.2.1 Idade 14C e idade calendário............................................................................................. 36

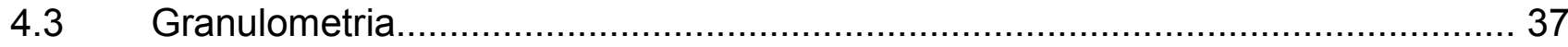

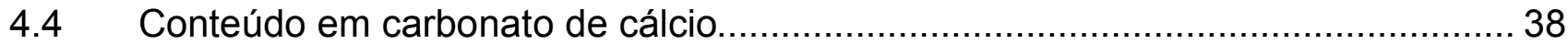

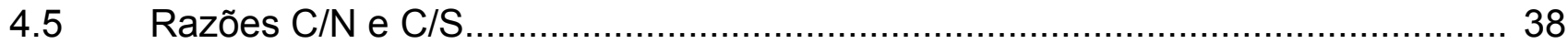

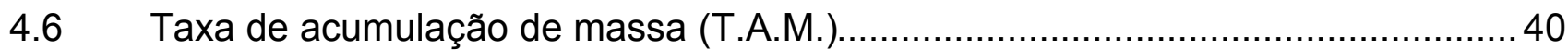

4.7 Taxa de acumulação de matéria orgânica (T.A.C.) ........................................... 40

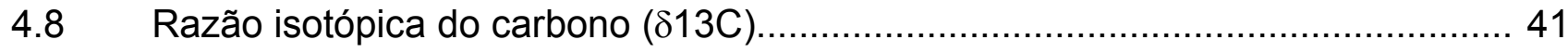

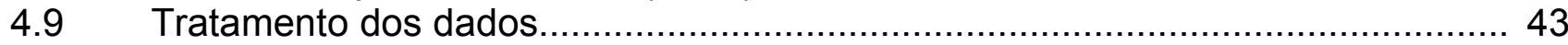

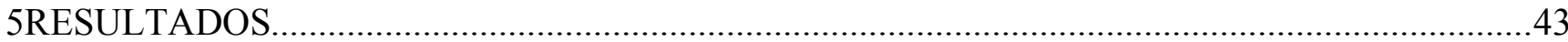

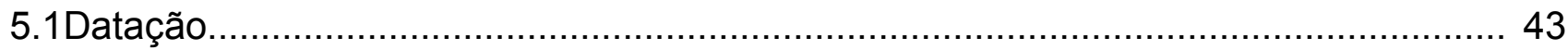

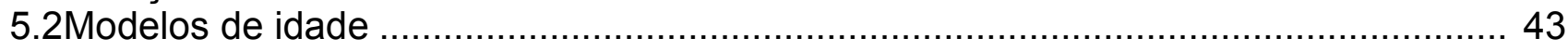

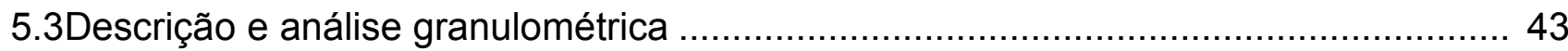

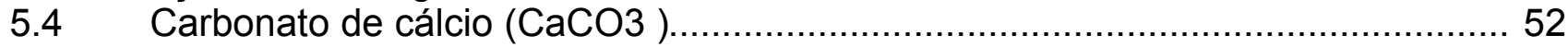

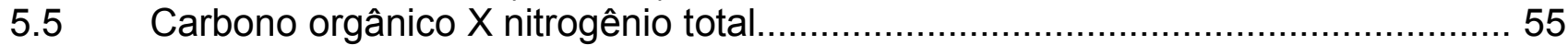

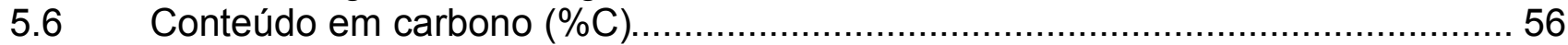

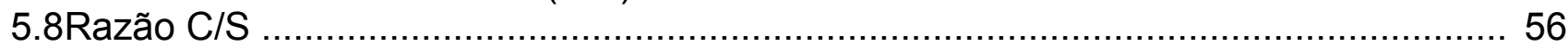

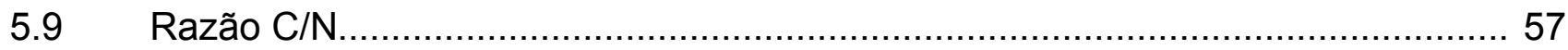

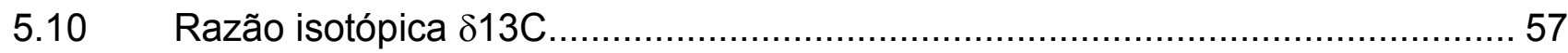

5.11Taxa de acumulação de massa (T.A.M.) e taxa de acumulação de matéria orgânica

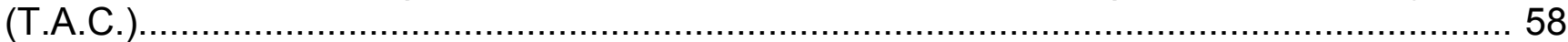

6 DISCUSSÃO

6.1 Modelo de idades.............................................................................. 60

6.2 Origem dos depósitos de areias junto à praia do Lázaro e ao Saco da Ribeira ao

longo do Holoceno ....................................................................................... 60

6.3 Relações entre T.A.C., T.A.M. e conteúdo em carbono (Corg), com variações

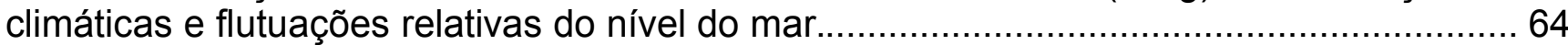

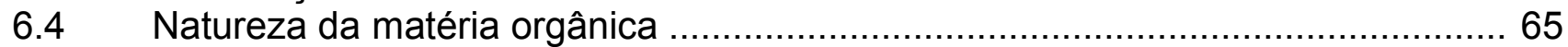

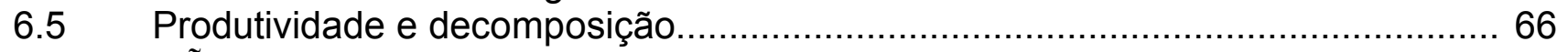

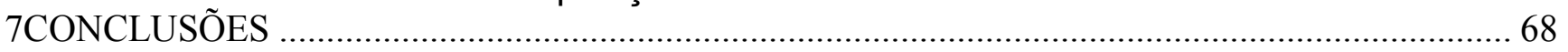




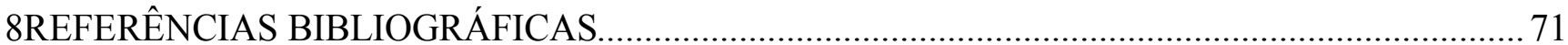




\section{LISTA DE FIGURAS}

Figura 1- Diferentes valores de C/N para materiais distintos (retirada de Bordowskiy -1965 apud Stein, 1991).

Figura 2- Valores de razão isotópica de carbono de diferentes materiais orgânicos (Retirado de Waples, 1981, apud Stein, 1991). 42

Figura 3- Modelos de idades: (A) testemunho UBA 1, (B) testemunho UBA3 ...................................... 45 Figura 4- (A) Carbono org. X nitrogênio total do testemunho UBA1; (B) Carbono org. X nitrogênio total do testemunho UBA3

Figura 5- Conteúdo em Carbono (\%C), taxa de acumulação de massa (T.A.M) e taxa de acumulação de matéria orgânica expressas em $(\mathrm{g} / \mathrm{m} 2 / \mathrm{ano})$ em função da idade $14 \mathrm{C}$ do testemunho UBA1. .59 Figura 6- Conteúdo em Carbono (\%C), taxa de acumulação de massa (T.A.M) e taxa de acumulação de carbono expressas em ( $\mathrm{g} / \mathrm{m} 2 / \mathrm{ano})$ em função da idade $14 \mathrm{C}$ 


\section{LISTA DE TABELAS}

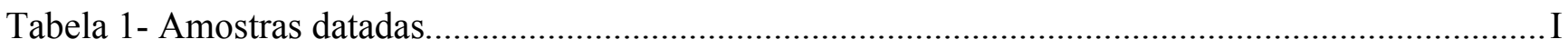

Tabela 2- Idades radiocarbono convencionais (conv.) e calibradas (cal.)........................................... I

Tabela 3- Idades radiocarbono convencionais (conv.) e calibradas (cal.) do testemunho UBA3 (cont.)... IV

Tabela 4- Resultados das análises sedimentares do testemunho UBA1 ............................................... VI

Tabela 5- Resultados das análises sedimentares do testemunho UBA3 ............................................ IX

Tabela 6- Teor de $\mathrm{CaCO} 3$ e das análises da matéria orgânica sedimentar do testemunho UBA1....... XIII

Tabela 7- Teor de $\mathrm{CaCO} 3$ e das análises da matéria orgânica sedimentar do testemunho UBA3.......XVI 


\section{RESUMO}

Mudanças na taxa de acumulação e na natureza da matéria orgânica sedimentar, e suas relações com as variações climáticas e flutuações do nível relativo do mar durante os últimos 8.500 anos cal. A.P. foram investigadas em dois testemunhos provenientes do Saco de Ribeira, Enseada do Flamengo, e junto à praia do Lázaro, Enseada da Fortaleza, na região de Ubatuba, litoral norte do Estado de São Paulo. Para o estudo as amostras coletadas foram submetidas a diversas análises - granulometria, teor de $\mathrm{CaCO}_{3}$, teores de Carbono orgânico, Nitrogênio e Enxofre totais, e razões isotópicas de carbono. Datações ${ }^{14} \mathrm{C}$, calibradas para a idade calendário, permitiram estabelecer um modelo de idades para as variações sedimentares detectadas. Intervalos de clima mais quente, 8.000-6.000 anos cal. A.P., foram acompanhados de um aumento na taxa de acumulação de carbono T.A.C. (10-13 $\mathrm{g} \mathrm{m}^{-2}$ ano-1), seguida de diminuição após 5.000 anos cal. A.P., para valores inferiores a $2 \mathrm{~g} \mathrm{~m}^{-2}$ ano-1. Variações climáticas regionais, possivelmente relacionadas a chuvas torrenciais, próximos ao máximo transgressivo, de 5.100 anos ${ }^{14} \mathrm{C}$ A.P., foram detectadas pelo aumento nos valores de T.A.C. (10-12 g. m 2 ano-1 $^{-1}$, aumento nas taxas de acumulação de massa (T.A.M.) e deposição de sedimentos mais grossos, acompanhados de aumento na tendência continental da natureza da matéria orgânica. As maiores tendências continentais da matéria orgânica sedimentar, registradas aproximadamente entre 1.500-1.200 anos cal. A.P., podem ser decorrentes de uma oscilação negativa do nível do mar. No geral, todos os resultados estão de acordo com as curvas de variação do nível relativo do mar, já descritas na literatura. As análises sedimentares da região estudada revelaram um evento regressivo-trangressivo, que ainda não havia sido referido para o Estado de São Paulo. A partir de $\sim 2.000$ anos cal. A.P., o mar teria atingido um nível mais baixo que o atual, com o mínimo provavelmente entre 1.500-1.200 anos cal. A.P., e encontra-se em ascensão até os dias atuais. As características anóxicas e a matéria orgânica sedimentar de origem planctônica registradas junto à praia do Lázaro, em meio a condições de energia relativamente mais alta, em $\sim 900$ anos cal. A.P., foram consideradas como resultado de condições óxicas das águas, acompanhadas de altas taxas de produtividade, e subseqüente degradação da matéria orgânica, existentes no período anterior. 


\begin{abstract}
Changes in the organic carbon accumulation rates ( $\mathrm{C}_{\text {org }}$ A.R.) and organic matter source characteristics and their relation to climate and relative sea level changes during the last 8.500 cal. yr. B.P. were investigated in two sediment cores from 2 embayments Flamengo and Fortaleza inlets - northern coast of São Paulo State. Sediment samples were analysed for grain size, organic Carbon, total Nitrogen and Sulphur contents, and $\delta^{13} \mathrm{C}$ ratio. Radiocarbon datings provided a model age to the sedimentary deposits. The warm climate interval 8.000-6.000 cal. yr. B.P. was accompanied by an increase in the

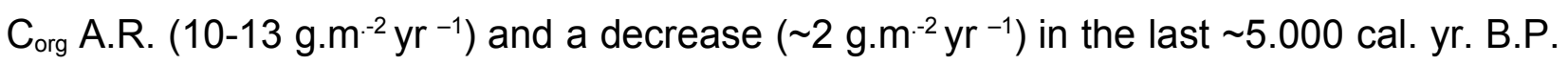
Regional climate changes, as stormy weather, that may have ocurred near the maximum transgressive period called Santos Transgression at $5.100 \mathrm{yr}$. B.P., were recorded in the sedimentary profiles by relatively hight T.A.C. and T.A.M. values, coaser grain size sediment delivery, and enhanced terrestrial organic matter source characteristics. Improvement of terrestrial origin of the sedimentary organic matter recorded between 1.500-1.200 cal. yr. B.P in the studied area was mainly related to a negative sea-level oscillation. All the results are in general agreement with the existing sea level change curves. The sedimentary profiles suggest a negative sea-level fall event, that had'nt been described yet for São Paulo State. It's proposed that the negative oscillation would have begun at $\sim 2.000 \mathrm{cal}$. yr. B.P.and reached a minimum probably between 1.500-1200 cal. yr. B.P. The relative sea level has been rising since then. Anoxic conditions accompanied by algal origins of sedimentary organic matter, observed in the sedimentary profile from Fortaleza inlet at 900 cal. yr. B.P, during a more oxidizing environment are considered as a result of a previous well oxygencontaining water column and high productivity rates.
\end{abstract}





\section{INTRODUÇÃO}

\subsection{A importância da matéria orgânica sedimentar}

Depósitos sedimentares podem desempenhar um papel importante no estudo do conteúdo global de carbono, preservando registros de antigos níveis de carbono em ambientes costeiros como lagunas, estuários e praias semiconfinadas, que podem guardar registros da matéria orgânica acumulada durante o Holoceno (Sampei et al., 1997).

A proporção da matéria orgânica, de origem primária e secundária, preservada em registros sedimentares é pequena em relação ao conteúdo total de sedimento; no entanto, ela pode evidenciar as condições pretéritas da sua origem e ambiente deposicional a partir do registro geoquímico orgânico (Meyers, 1997).

As mudanças climáticas modificam as propriedades físico-químicas da água do mar (temperatura, salinidade, intensidade de correntes, descarga fluvial, etc). Estas alterações são refletidas na produtividade das águas, e podem influenciar no tipo e quantidade de matéria orgânica acumulada.

A produtividade das águas em uma determinada região também pode ser modificada pela variação relativa do nível do mar. Uma relativa queda no nível do mar provocaria a diminuição dos organismos marinhos e avanço dos ecossistemas terrestres.

Segundo Sampei (1999), a variação no conteúdo de carbono orgânico na matéria orgânica sedimentar, e a indicação relativa da variação da influência (marinha ou terrestre) no paleoambiente não dependem exclusivamente da produtividade primária .

Produtividade primária, profundidade da coluna d'água, concentração de oxigênio na camada próxima à superfície de fundo, estrutura e forma da matéria orgânica, taxa de sedimentação, etc, vêm sendo considerados como determinantes importantes na variação da acumulação do conteúdo de carbono orgânico (Stein et al. 1996, Pedersen \& Calvert; 1990; Paropkari et al., 1992). 
Mudanças na importância dos diferentes fatores acima citados determinam o complexo sistema de formação de sedimentos enriquecidos em carbono orgânico (Sampei, 1999).

O carbono está presente em distintas formas isotópicas como constituinte essencial das cadeias de moléculas orgânicas. O conteúdo de ${ }^{13} \mathrm{C}$ é significativamente diferente em plantas de clima quente - as quais possuem compostos de C4 como principais constituintes de seus metabolismos - das plantas de clima frio, que apresentam compostos de C3 em seus processos metabólicos (Coleman \& Fry, 1991). Esta separação básica no sistema fisiológico é estendida e ampliada na distinção entre ecossistemas terrestres e marinhos.

Isótopos estáveis constituem uma ferramenta importante no diagnóstico da origem da matéria orgânica (Meyers, 1997; Coleman and Fry, 1991; Sampei et al., 1997; Mahiques et al. 1999). A partir de diferentes valores da razão de isótopos estáveis de carbono $\left({ }^{13} \mathrm{C}\right)$ é possível verificar a origem da matéria orgânica.

Assim como o carbono, o nitrogênio é um elemento de grande importância na constituição da matéria orgânica dos seres vivos, principalmente como elemento fundamental na estrutura das proteínas. A análise do conteúdo em carbono e nitrogênio, a partir da razão $\mathrm{C} / \mathrm{N}$, constitui uma fonte indicadora da origem da matéria orgânica (Mahiques, 1998).

Em sedimentos marinhos o enxofre é encontrado na forma de sulfetos, e pode dar indicações sobre a concentração de oxigênio, nas condições de deposição próximas à camada de superfície de fundo, a partir da análise do conteúdo de carbono e enxofre dados pela razão C/S (Mahiques, 1998).

A variação da acumulação de matéria orgânica e as mudanças climáticas ao longo do Holoceno podem ser melhor correlacionadas com a datação de amostras de conchas ou de fragmentos orgânicos coletados ao longo da coluna sedimentar pelo método do ${ }^{14} \mathrm{C}$ (Sampei, 1997).

Diferentes frações granulométricas sedimentares costumam apresentar diferentes valores para a razão $\mathrm{C} / \mathrm{N}$, tornando possível a correlação do tipo de matéria orgânica depositada, com a seleção hidrodinâmica sedimentar por 
granulometria (Meyers, 1997). As características da matéria orgânica depositada nos sedimentos superficiais de áreas costeiras vêm sendo empregadas em correlações com processos oceanográficos (Mahiques et al., 1999).

\subsection{Flutuações relativas do nível do mar}

Segundo Mörner (1980), "eustasia" se refere às variações do nível do mar originadas por movimentos verticais na superfície do oceano em um dado ponto, onde suas causas não são consideradas. As flutuações relativas do nível do mar incluem todos os fatores que causam mudanças na superfície da terra e no nível do mar (glacio-eustasia, tectono-eustasia e geoido-eustasia).

Glacio-eustasia é um efeito que se refere aos estágios glaciais e interglaciais, cujas mudanças climáticas são provocadas pela variabilidade dos "Ciclos de Milankovitch". As variações dos parâmetros orbitais e axiais da Terra são mecanismos de baixa frequência conhecidos como "Ciclos de Milankovitch", que possuem as seguintes periodicidades: $\sim 96.000$ anos (excentricidade da órbita da terra), $\sim 42.000$ anos (inclinação axial), $\sim 21.000$ anos (precessão dos equinócios).

Durante os estágios glaciais ocorre o aumento do volume das calotas polares e geleiras, e conseqüente diminuição do volume da água do mar devido ao congelamento das águas. Durante os estágios interglaciais o volume das águas dos oceanos aumenta devido ao derretimento do gelo. As variações de alta freqüência ocorrem dentro de cada ciclo glacial-interglacial. Este último tipo de variação encontra-se relacionado a fatores tais como hidrodinâmica dos oceanos, cobertura de geleiras, variações no conteúdo de gases atmosféricos, vulcanismo, radiação solar, e fatores geodinâmicos, explicados em Lowe \& Walker (1997).

Outros efeitos podem interferir no nível relativo do mar, tais como tectonoeustasia, movimentos da terra que mudam o volume das bacias oceânicas, e geoido-eustasia, efeitos gravitacionais/rotacionais que mudam a distribuição do nível dos oceanos, detalhados por Mörner (1980). 
Os métodos de pesquisa que vêm sendo utilizados na elaboração de hipóteses sobre as flutuações relativas do nível do mar durante os últimos 8.000 anos A.P. baseiam-se na utilização de ferramentas como datações em vermetídeos, beach rocks, sambaquis, terraços costeiros, paleolinhas de costas, dunas eólicas, barras de areia, entre outras (Angulo, 1993; Suguio \& Martin, 1976; Suguio et al., 1984). Contudo, as correlações existentes na literatura não estão isentas da incerteza de cada método utilizado, na limitação de dados, além de basearem-se em parâmetros que muitas vezes refletem padrões particulares, devido às diferenças entre as regiões pesquisadas.

As flutuações relativas do nível do mar durante o Holoceno estão dentro do contexto "Pós- glacial", que segue o Último Máximo Glacial (UMG), no qual o nível do mar teria atingido a cota de $-110 \mathrm{~m}$, no sudeste brasileiro, conforme proposto por Kosmann \& Costa (1974).

A transgressão marinha que sucedeu o UMG possui registros de fases de estabilização na atual plataforma continental e nas áreas emersas. Estas últimas são evidenciadas por paleoníveis marinhos em posição superior ao atual, a partir de 7.000-6.000 anos A.P. ${ }^{1}$ No Estado de São Paulo esta fase é conhecida como "Transgressão Santos" (Suguio \& Martin, 1978), no Rio Grande do Sul como "Barreira IV" (Vilwock et al.,1986) e nos estados do nordeste como "Última Transgressão" (Bittencourt et al., 1979).

No Estado do Rio Grande do Sul foram estabelecidas três fases de estabilização do nível relativo do mar a $11.000,9.000$ e 8.000 anos A.P., com os respectivos paleoníveis: -60/-70 m, -32/-45 m e -20/-25 m, obtidos a partir de análises morfológicas, sedimentares e datações ${ }^{14} \mathrm{C}$ (Corrêa, 1996).

Suguio et al. (1985), apresentou uma revisão de trabalhos sobre variações do nível relativo do mar nos últimos 7.000 anos A.P., na qual mostrou curvas para diversos setores da costa brasileira, as quais apresentam-se semelhantes. A 
$1 \mathrm{~A} . P=$ Antes do Presente. Considera-se presente o ano de 1950 para as datações ${ }^{14} \mathrm{C}$ convencionais

semelhança entre as curvas é explicada pelas variações regionais da superfície do geóide. Tais curvas apresentam dois máximos, um por volta de 5.100 anos A.P., outro por volta de 3.600 anos A.P., e duas oscilações negativas com níveis abaixo ou próximos ao atual por volta de 4.100-3.800 e 3.000-2.700 anos A.P.

Estudos realizados por Angulo \& Lessa (1997) nas regiões de Paranaguá (PR) e Cananéia (SP) contestam as oscilações negativas propostas por Suguio et al. (1985), devido à inconsistência, apontada pelos autores, das fontes para formulação das curvas, que baseiaram-se principalmente em dados de sambaquis. Angulo \& Lessa (1997) utilizaram registros de tubos de vermitídeos nos costões ao longo do litoral brasileiro, compilados da literatura, para formular as curvas. O máximo registrado ocorreu por volta de 5.100 anos A.P. com nível relativo do mar a aproximadamente $+3 \mathrm{~m}$, com tendência de queda suave até os dia atuais.

Ybert et al.(2003) mostram resultados que apontam para um nível do mar mais alto do que o presente entre 4.900-3.470 anos cal. A.P.

Uma exceção em relação à tendência geral de queda do nível relativo do mar, desde $\sim 5.000$ A.P. em direção aos dias atuais, ocorre na curva apresentada para o Rio Grande do Sul, proposta por Tomazelli \& Villvock, 1989 apud Tomazelli (1990), onde mostra que o nível relativo do mar encontrava-se abaixo do atual $(-1,5 \mathrm{~m})$ aproximadamente em 1.500 anos A.P. e subiu nos últimos 1.000 anos. Segundo Angulo \& Lessa (1997), esta curva tem como base um número limitado de datações. Em contraste, os resultados obtidos a partir das datações de tubos de vermetídeos no estudo regional, mostram que os paleoníveis indicam nível relativo do mar mais alto do que o atual durante os últimos 2.000 anos A.P., pelo menos até $190+/-65$ anos A.P. (Angulo et al., 1999). 


\subsection{Variações climáticas durante o Holoceno}

No geral, um clima quente aumenta a evaporação das águas do mar e dos continentes, bem como a precipitação. Com o aumento da precipitação, e o aumento da descarga fluvial, supõe-se que possam ocorrer mudanças relacionadas à acumulação de matéria orgânica.

O Holoceno médio (7.000-5.000 anos A.P.) foi globalmente um período quente, que pode ter alcançado seu pico em 6.000 anos A.P. (o chamado "Ótimo Holocênico"), quando as temperaturas nos meses de verão nas altas latitudes do Hemisfério Norte eram 2 a $4^{\circ} \mathrm{C}$ mais altas do que as dos dias atuais (Folland et al.,1990; Goodness et al., 1992). Um período frio persistiu no Holoceno superior entre 3.000 e 2.500 anos A.P., sendo que, em muitas regiões, houve o aumento da aridez e a diminuição da precipitação (Burney, 1993).

Estudos também revelam que ocorreram mudanças na taxa de precipitação dentro dos períodos relativamente quentes, como é o caso do estudo realizado na China por Jarvis (1993), onde entre 9.100 e 7.800 anos A.P., o clima era quente com contínuo aumento da precipitação, e entre 7.800 a 4.000 anos A.P., a precipitação tornou-se mais sazonal.

A partir de análises de testemunhos sedimentares de lagunas, na região sudeste do Rio de Janeiro, Tasayco - Ortega (1996) apud Ybert (2000) propõe em seu trabalho a ocorrência de 5 episódios de seca, em condições de clima semiárido (3.600-3.500, 3.100-3.000, 1.200-1.100 e 600-500 A.P.), e 2 episódios chuvosos (2.300-2100 e 700-600 A.P.).

Scheel-Ybert (2000) realizou um estudo em 6 sítios arqueológicos na região de Cabo Frio, Rio de Janeiro, onde verificou mudanças climáticas, baseadas na estabilidade da vegetação local, deduzida a partir da análise de caracóis em sambaquis. Neste estudo, a autora, reconheceu em ambientes de manguezais, 2 episódios de clima relativamente mais úmido (4.900-4.500 e $2.300-2.000{ }^{14} \mathrm{C}$ A.P.), intercalados com 2 episódios de clima mais seco (4.900-4.500 a 2.300 e 200-1400 ${ }^{14}$ C A.P.). Segundo a mesma autora, a mudança na variação da vegetação do mangue não poderia ser atribuída a flutuações no nível do mar, pois os três episódios de regressão (5.100-3.900, 3.600-2.700 e após $2.500{ }^{14} \mathrm{C}$ A.P.), 
e dois dos três episódios de transgressão (7.000-5.100, 3.900-3.600 e 2.700$2.500{ }^{14} \mathrm{C}$ A.P.) identificados na costa brasileira para o período segundo Martin et al.(1979/80,1997), estão fora de fase com o desenvolvimento do mangue.

Ybert et al. (2003), em estudo realizado na planície costeira do sudeste do Estado de São Paulo a partir de análises de sedimentos orgânicos incluindo diatomáceas e conteúdo de pólen, inferiu que o clima na região, a partir do Holoceno médio (5.000 anos $\mathrm{cal}^{2}$ A.P.) até o presente, não mudou significantemente, salvo pela ocorrência de três sutis episódios de maior umidade (3.470-2.750, 1.940 e 1.300-675 anos cal. A.P.).

\subsection{Circulação}

A atuação dos fenômenos dinâmicos em águas costeiras proporcionam grande variação espacial e temporal das propriedades físico-químicas da água do mar. Correntes de maior intensidade, que promovem a remobilização dos sedimentos de fundo, atuam disponibilizando nutrientes para a manutenção da biomassa marinha. Desta forma, as correntes marinhas podem influir na produtividade da região, através do controle da concentração de oxigênio no ambiente marinho devido à mistura da coluna d'água que a torna bem oxigenada, contribuindo para a fotossíntese, que é essencial tanto para a formação e crescimento de certos organismos, quanto na oxidação da matéria orgânica produzida e sedimentada.

Levantamentos oceanográficos foram realizados com dados químicos e biológicos na Enseada do Flamengo e em áreas próximas. Dados obtidos a partir do projeto "Utilização Racional dos Ecossistemas Costeiros da Região Tropical Brasileira: Estado de São Paulo" (IOUSP, 1988,1989), indicam uma importante variação sazonal nos parâmetros oceanográficos na plataforma, na região de Ubatuba. Nos meses de verão, ocorre o avanço de uma massa de água fria, Água Central do Atlântico Sul (ACAS), originária do talude continental, sobre as regiões mais internas da plataforma, proporcionando condições de aparecimento da estratificação termohalina. Este fenômeno gera o aumento da produção primária, devido ao enriquecimento da zona eufótica (Mahiques, 1992). 
2 cal $=$ Idade calendário, calibrada .

Gonçalves et al.(1980) constatou, em abril de 1977, a pobreza de nutrientes ao longo da coluna d'água, assim como uma variação das propriedades físico-químicas, da ordem de 12 horas, relativas à movimentação da maré semi-diurna.

Segundo o projeto acima citado, durante os meses de inverno, ocorrem processos de mistura e o conseqüente desaparecimento da termoclina, favorecendo a ressuspensão do sedimento de fundo e das bactérias aderidas ao detrito.

Segundo Pires-Vanin (1989), os mecanismos de avanço e recuo da ACAS parecem ter importante influência no controle da diversidade, densidade e Abiomassa da fauna bentônica e em certos tipos de peixes da região.

Em águas rasas onde a ação de ondas sobre o fundo é superimposta por fluxos unidirecionais (marés, correntes de retorno, etc), o entendimento dos mecanismos de transporte é dificultado (Komar, 1976). Nestas condições, a partícula em repouso pode ser removida pelo movimento bidirecional das ondas e ser transportada por um fluxo unidirecional, mesmo que este não tenha competência para retirar a partícula do equilíbrio.

As correntes geradas por fenômenos meteorológicos podem ter papel importante e complicador, quando associadas a fenômenos anômalos, de natureza não sazonal na influência do transporte de sedimentos (Swift et al., 1971).

Tessler (1988) afirma que o transporte de sedimentos do litoral sul-paulista pode estar intimamente associado às correntes litorâneas de sentido NE, geradas a partir de ondas S-SE, formadas devido a passagem de frentes frias sobre 0 litoral sul de São Paulo, e que tais frentes frias podem ser mais significativas em termos de transporte, do que quando esta região está sob influência do regime de circulação atmosférica associada aos ventos alíseos. 
Segundo Furtado \& Mahiques (1990), o transporte de pelitos para fora da área costeira pode estar relacionado ao avanço da ACAS, nos meses de verão, que induz a movimentação da Água Costeira (AC), contendo material de origem continental em suspensão para as áreas mais externas da plataforma.

Magliocca \& Kutner (1965) correlacionam a intensidade da hidrodinâmica, no caso, correntes de fundo, com a textura e composição dos sedimentos, principalmente os siltes e as areias finas.

Ab'Saber (1982), realizou estudo sobre a fauna de bivalves em região próxima à Enseada do Flamengo (área de estudo), constatando a diferenciação da energia de correntes que pode condicionar os teores de carbonato e a textura dos sedimentos. Tal diferenciação seria responsável por uma maior abundância de bivalves suspensívoros na porção oeste da sua área de estudo.

\subsection{Carbonato de Cálcio $\left(\mathrm{CaCO}_{3}\right)$}

Existem alguns fatores controladores da quantidade de carbonato nas águas, podendo-se citar: quantidade de nutrientes, salinidade e temperatura, taxa de sedimentação, flutuações no nível do mar, penetração de luz, circulação e oxigenação das águas (Bosence \& Wilson, 2002).

A quantidade de nutrientes das águas em regiões costeiras é um dos fatores oceanográficos que pode controlar a quantidade de carbonato na água do mar. Altas taxas de nutrientes provindas da descarga de rios favorecem a produção de algas bentônicas e planctônicas, contribuindo para o aumento da produtividade da área. Desta forma, torna-se possível estabelecer relações entre carbonato $\mathrm{CaCO}_{3}$ e matéria orgânica.

Valores de salinidade e temperatura um pouco mais elevados do que a média dos oceanos, em águas rasas, contribuem para a precipitação de grãos carbonáticos e oóides. Porém, salinidades muito elevadas impedem o desenvolvimento de muitos invertebrados que secretam carapaças de carbonato de cálcio. Baixas salinidades promovem águas insaturadas contribuindo para a dissolução do carbonato de cálcio. 
Devido ao aporte continental, altas taxas de sedimentação de siliciclásticos, inibem a produção de carbonato de cálcio, pois, organismos bentônicos fotossintetizantes tornam-se recobertos pelos depósitos de tração. Desta forma, a luz não consegue penetrar na água devido à alta carga sedimentar em suspensão.

Os carbonatos são produzidos no local, ou próximos de onde eles foram depositados, e são suscetíveis à dissolução ou cimentação, se forem alternadamente lavados por águas doce e salgada, de acordo com a subida e descida do nível do mar. O carbonato previamente depositado durante um evento transgressivo pode ser dissolvido pela acidez das chuvas em um subseqüente evento regressivo, e exposto às alterações subaéreas. Ainda em relação às variações do nível do mar, é esperado que um sistema carbonático opere de forma contrária a um sistema siliciclástico.

As maiores intensidades de luz penetram principalmente acima de 10-20 m de profundidade da coluna d'água. A quantidade de luz afeta os organismos fotossintetizantes, inclusive invertebrados em associação com algas, que contribuem com a calcificação de corais, alguns foraminíferos bentônicos, e alguns bivalves.

Certos organismos dependem da boa circulação das águas para serem formados. Ondas e correntes de maré influenciam na textura dos sedimentos. No geral, águas bem oxigenadas são essenciais para o crescimento de todos invertebrados.

\subsection{Preservação e degradação da matéria orgânica}

As alterações e degradações da matéria orgânica ocorrem na coluna d'água e nos sedimentos depositados no fundo.

A matéria orgânica por ser uma forma reduzida do carbono, é instável em condições marinhas típicas onde, de forma geral, a coluna d'água encontra-se oxigenada, já que a maior parte das águas naturais se misturam rapidamente e resultam em equilíbrio com a atmosfera, no qual a perda do oxigênio dissolvido, utilizado em processos diversos é reequilibrado (Meyers, 1997). 
Condições anóxicas podem se desenvolver quando a coluna d'água possui forte estratificação, ou ainda quando ocorrem períodos de alta produtividade, nos quais os organismos utilizam grande quantidade de oxigênio, além de contribuírem com o incremento da degradação da matéria orgânica pela oxidação microbiana, sob a qual é exposta durante seu afundamento (Meyers, 1997).

Ainda na coluna d'água, os processos típicos de degradação modificam algumas características da matéria orgânica em um período relativamente curto entre produção e soterramento permanente (Hedges et al. 1988; Wakeham, 1990). As frações da matéria orgânica, mais suscetíveis à alteração, são seletivamente degradadas, criando mudanças composicionais durante o afundamento das partículas (Meyers, op cit). Estudos realizados no lago Michigan mostram perdas proporcionalmente maiores nos biomarcadores algais, do que nas plantas terrestres (Meyers \& Eadie, 1993).

A alteração e degradação da matéria orgânica nos sedimentos do fundo dos lagos e oceanos podem provir, tanto do extensivo consumo que ocorre nas camadas sedimentares bioturbadas, onde se processa o metabolismo dos organismos bentônicos, quanto das bactérias metanogênicas (Meyers, 1997).

É comum se dizer que ausência de oxigênio próximo às camadas de fundo contribui para a preservação da matéria orgânica, visto que nestas condições, o desenvolvimento da fauna bentônica é impedido, adicionado ao fato de que a degradação da matéria orgânica pelas bactérias metanogênicas é menos eficiente do que pelos micróbios aeróbicos (Stein, 1991). Porém, alguns autores questionam tais princípios clássicos da geoquímica orgânica. Canfield (1989) concluiu que taxas de degradação da matéria orgânica em ambientes anóxicos e bem oxigenados são similares. Calvert \& Pederson (1992) afirmam que a oxidação da matéria orgânica continua mesmo na ausência de oxigênio dissolvido na água, e que altas taxas de produção de matéria orgânica, melhoram sua preservação e limita a diluição clástica.

Estudos realizados por Meyers \& Eadie (1993) revelaram que as concentrações de matéria orgânica diminuíram aproximadamente $90 \%$ entre a superfície do lago Michigan e os sedimentos de fundo, porém os valores da razão 
$\mathrm{C} / \mathrm{N}$ e ${ }^{13} \mathrm{C}$ não mudaram substancialmente a partir dos valores iniciais de seu conteúdo algal, ou seja, informações provenientes dos biomarcadores moleculares foram retidas.

\section{OBJETIVOS}

O presente trabalho tem como objetivo principal, analisar a variação da acumulação de matéria orgânica ao longo do Holoceno, na região de Ubatuba, Estado de São Paulo, e verificar sua relação com as mudanças, referentes, ao clima e às posições do nível relativo do mar neste período, diferenciando ao longo da coluna sedimentar, a maior influência marinha ou terrestre nos paleoambientes.

Este estudo foi realizado a partir da análise de alta resolução em testemunhos de 2,2 m de comprimento (UBA1), do Saco da Ribeira, na Enseada do Flamengo, e 3,44 m de comprimento (UBA3), da praia do Lázaro, na Enseada da Fortaleza, litoral norte do Estado de São Paulo, Brasil (Fig.1).

Amostras de bivalves, em posição de vida, e fragmentos vegetais, coletados ao longo dos testemunhos, foram datadas na tentativa de estabelecer uma cronologia de eventos, e de correlacionar com as curvas de variações do nível relativo do mar, disponíveis para a costa sudeste do Brasil. Pretende-se identificar as características da matéria orgânica dos sedimentos e seus aspectos sedimentológicos, a fim de contribuir para o esclarecimento da relação entre o papel da matéria orgânica sedimentar acumulada durante o Holoceno, com as condições dominantes no meio (clima, hidrodinâmica, etc).

Pretende-se verificar se há possibilidade de correlacionar os dois testemunhos sedimentares em um mesmo quadro evolutivo da região, partindo do pressuposto de que há aproximadamente 5.000 A.P. havia uma ligação entre as duas enseadas em questão, através do Saco da Ribeira e da praia do Lázaro (Suguio \& Martin, 1978). 


\section{CARACTERIZAÇÃO DA ÁREA DE ESTUDO}

\subsection{Localização e fisiografia}

A área de estudo localiza-se no litoral norte do Estado de São Paulo Ubatuba, nas enseadas do Flamengo e da Fortaleza (Fig.1), mais precisamente no Saco da Ribeira (Fig.2) e na área adjacente à praia do Lázaro (Fig.3), limitadas respectivamente ás seguintes coordenadas: latitudes $23^{\circ} 30.078^{\prime} \mathrm{S}$ e $23^{\circ} 30.260^{\prime} \mathrm{S}$ e longitudes $45^{\circ} 07.014^{\prime} \mathrm{W}$ e $45^{\circ} 08.163^{\prime} \mathrm{W}$.

A Enseada do Flamengo é caracterizada como um embaiamento de formato trapezoidal, com sua desembocadura voltada para sul, onde as profundidades variam entre 10 e $14 \mathrm{~m}$ (Mahiques, 1992).

O Saco da Ribeira (Fig.2) apresenta um canal natural com profundidades mínimas de 3 metros, alongado para oeste. Observa-se que a capacidade das drenagens é fortemente dependente do regime pluvial, e que a única fonte fluvial mais expressiva na Enseada do Flamengo é o Rio Perequê Mirim que deságua na praia de mesmo nome (Mahiques, 1992).

A Enseada da Fortaleza constitui uma reentrância da costa, de formato triangular, com profundidades máximas, da ordem de $11 \mathrm{~m}$, na desembocadura (Mahiques, 1992). A enseada recebe descarga das águas da bacia do Rio Escuro. A praia do Lázaro, no interior da área de estudo, é uma das praias de bolso individualizada pelos pontões do embasamento (Fig.3). 


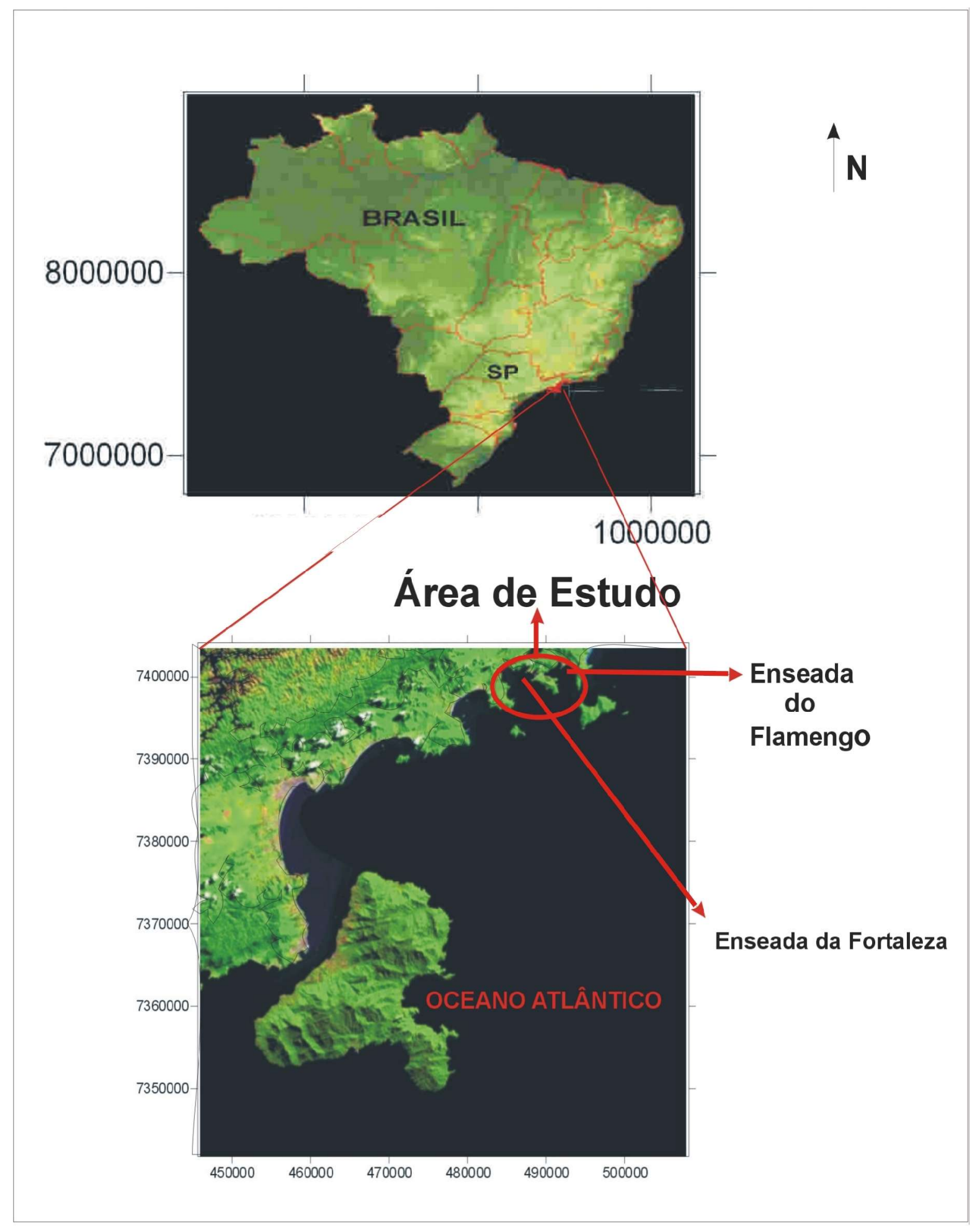

Figura 1- Mapa de localização da área de estudo 



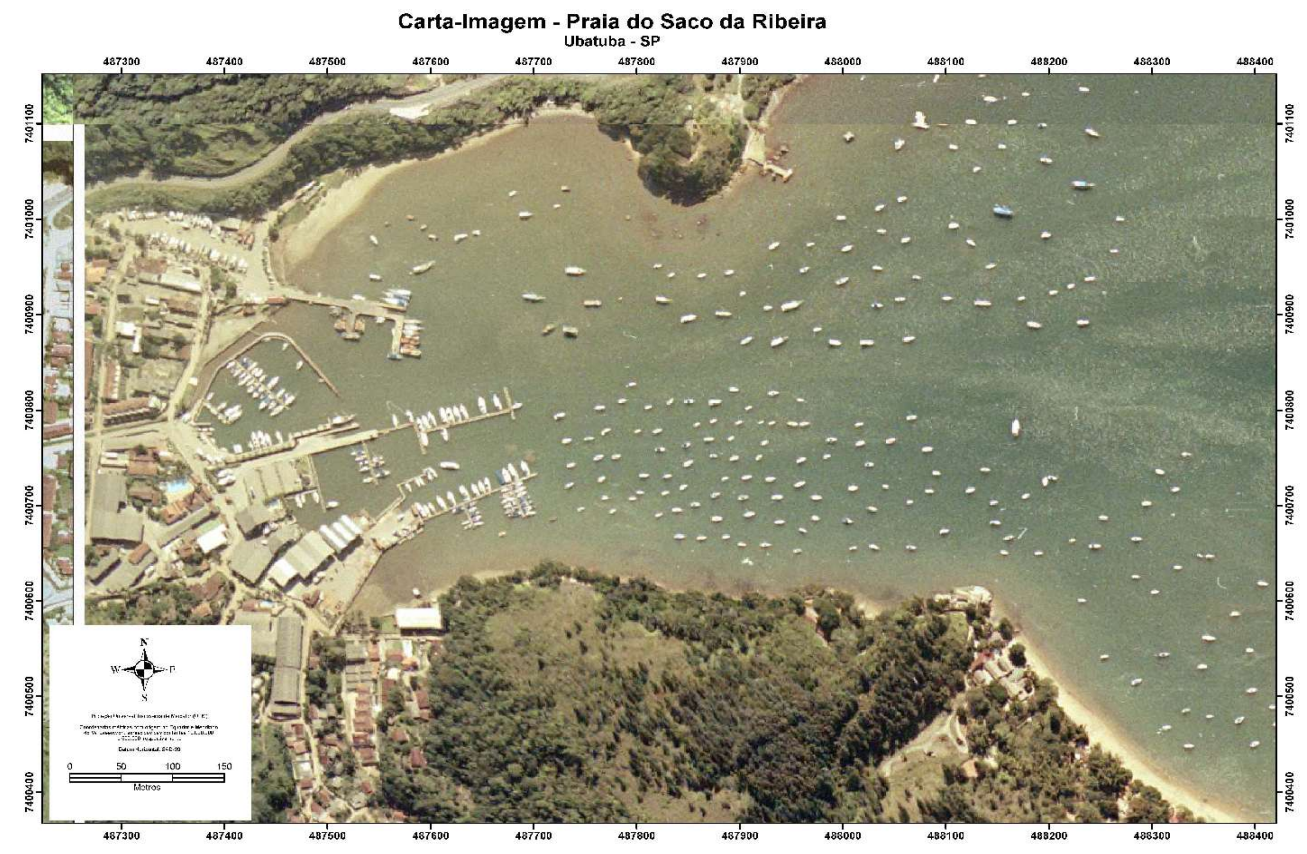

Figura 2 - Saco da Ribeira, adjacente ao local de coleta do testemunho UBA3

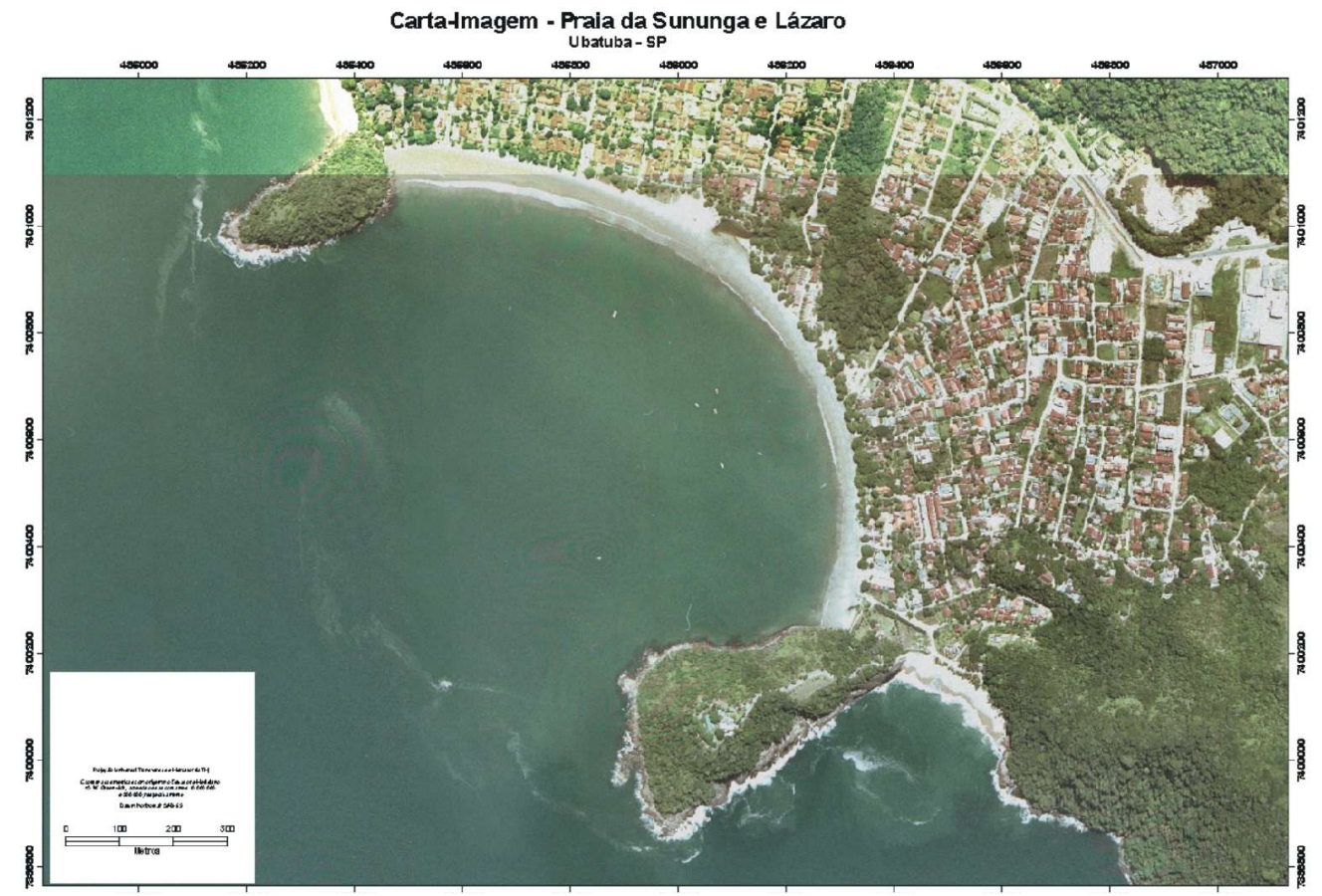

Figura 3 - Praia do Lázaro (centro da figura), adjacente ao local de coleta do testemunho UBA3 


\section{2 Áreas emersas}

\subsubsection{Aspectos geomorfológicos}

As primeiras propostas de caracterização das diferenças geomorfológicas entre litoral norte e sul paulista consiste basicamente de descrições de paisagem, que datam da primeira metade do século 20. Parte destes trabalhos não consiste na caracterização geográfica regional, mas baseia-se na descrição de feições particulares (Deffontaines, 1935; Ruellan, 1944; Almeida, 1947; Florençano \& França, 1951).

Ponçano et al. (1981) realizaram um trabalho baseado em critérios morfoestruturais, onde caracterizaram sistemas de relevo no Estado de São Paulo, considerando aspectos morfológicos para reunir sistemas de relevo em unidades maiores: Províncias, Zonas e Subzonas, detalhadas no mapa geomorfológico do Estado de São Paulo, elaborado pelos autores.

Segundo Ponçano et al. (op cit), feições importantes na caracterização do litoral paulista nas proximidades da área de estudo pertencem a Província Costeira: parte da Serra do Mar inserida na Serrania Costeira, e parte das Baixadas Litorâneas (Fig.4).

Ab'Saber (1955) realizou os primeiros trabalhos de caracterização geomorfológica na região de Ubatuba, no qual descreve terraços de abrasão marinha, correlacionado-os a períodos transgressivos.

A Serra do Mar é o relevo predominante na região de Ubatuba, no geral é caracterizada por relevos de transição (escarpas onde predominam declividades altas, acima de $30 \%$, e amplitudes maiores que $100 \mathrm{~m}$ ), bem como por relevos de degradação, morrotes e morros. Na região de Ubatuba predominam as Escarpas Festonadas, Serras Alongadas e Morros Isolados, com declividades predominantes acima de $15 \%$ e amplitudes locais superiores a $100 \mathrm{~m}$. Nas Baixadas Litorâneas predominam os relevos de agradação, tais como: planícies costeiras, terraços marinhos e mangues, de menor significado na área. 


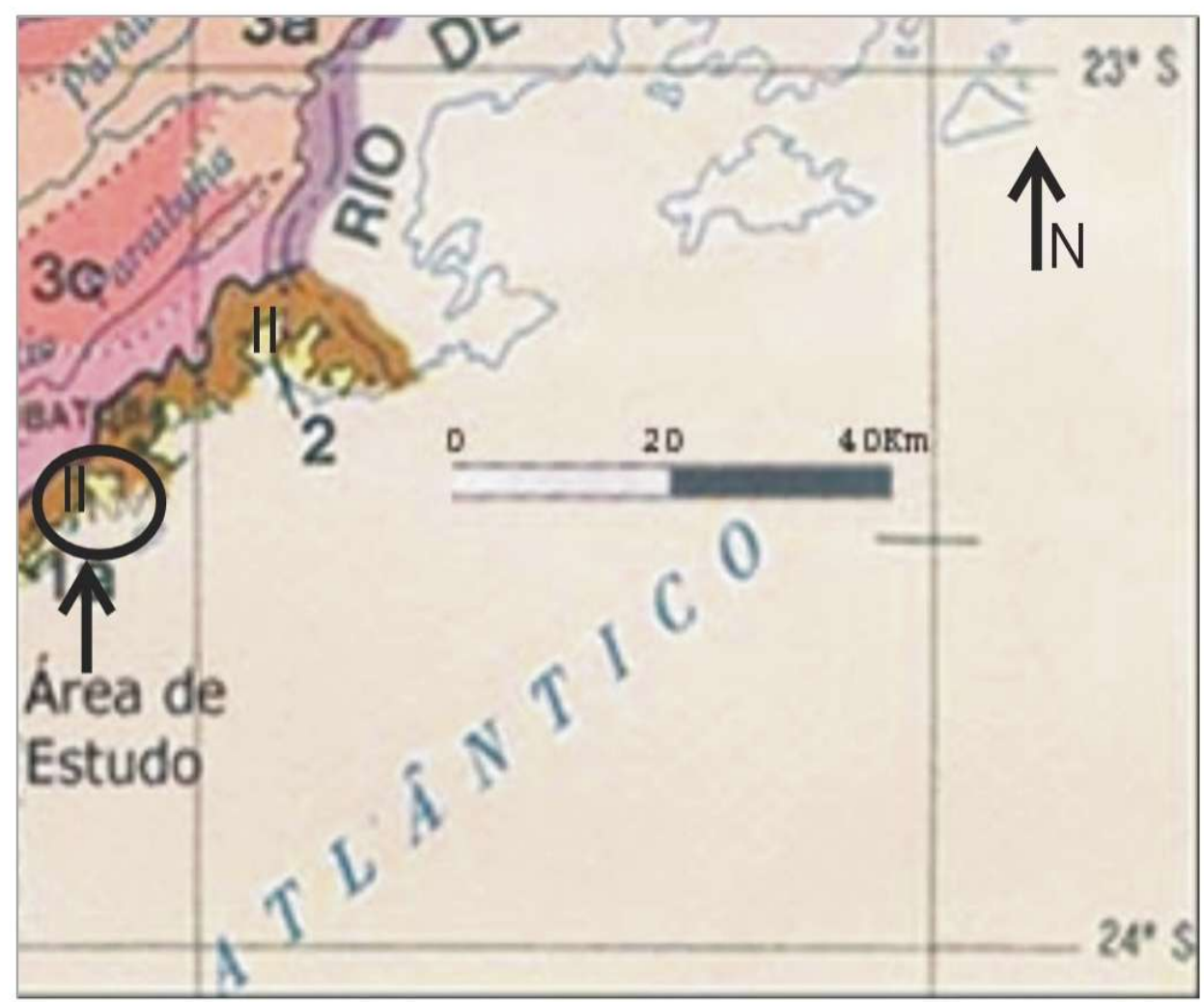

\section{PROVÍNCIA COSTEIRA II}

Serrania Costeira

Serra do Mar

Figura 4 - Recorte do Mapa de Divisão Geomorfológica do Estado de São Paulo (IPT,1981). 



\subsection{Aspectos geológicos}

A geologia regional descrita abrange os limites apresentados no mapa do Estado de São Paulo (Figs.5 e 6). No geral, ocorrem principalmente terrenos do embasamento cristalino (Proterozóico a Eopaleozóico), cujas rochas pertencem ao Domínio Costeiro e ao Domínio Embu, constituindo-se principalmente de rochas gnáissico-migmatíticas, bem como, importantes maciços alcalinos, como o Complexo Sienítico da llha de São Sebastião, charnockitos e enxames de diques básicos do Mesozóico, além de coberturas sedimentares do Cenozóico (CPRM, 1999).

Após diferentes proposições estratigráficas sugeridas por vários autores, na tentativa de distinguir gnaisses e migmatitos de idades distintas, estas rochas foram consideradas do Arqueano e agrupadas no Complexo Costeiro por Almeida et al. (1981). Machado Filho et al. (1983) inseriu-as no Complexo Paraíba do Sul, também de idade arqueana. Segundo Dias Neto (2001), as rochas gnáissicomigmatíticas do Complexo Costeiro constituem-se, predominantemente, por paleossomas de hornblenda-biotita gnaisse e neossoma de composição granodiorítica; subordinadamente ocorrem quartzitos arcoseanos.

$\mathrm{Na}$ região de Ubatuba ocorrem corpos de charnockito eqüigranular a porfirítico (Charnockito Ubatuba ), que pertence aos metamorfitos de alto grau do Complexo Costeiro (CPRM, 1999).

No contexto evolutivo da região no final do Proterozóico, um regime de compressão produziu a amalgamação do supercontinente Gondwana. Do estágio final de consolidação do Cambro-Ordoviciano originou-se denso arranjo de zonas de cisalhamento, orientadas segundo ENE e E-W. Mais tarde, durante a separação mesozóica, que subdividiu Gondwana e culminou na abertura do oceano Atlântico, inúmeras dessas descontinuidades mais antigas foram reativadas em pulsos descontínuos, representados por centenas de intrusões de diques de rochas básicas, ultrabásicas e intermediárias, de caráter toleítico e alcalino, que ocorreram desde o Juro-Cretáceo até o Terciário (Almeida 1967, Almeida \& Carneiro 1998). 


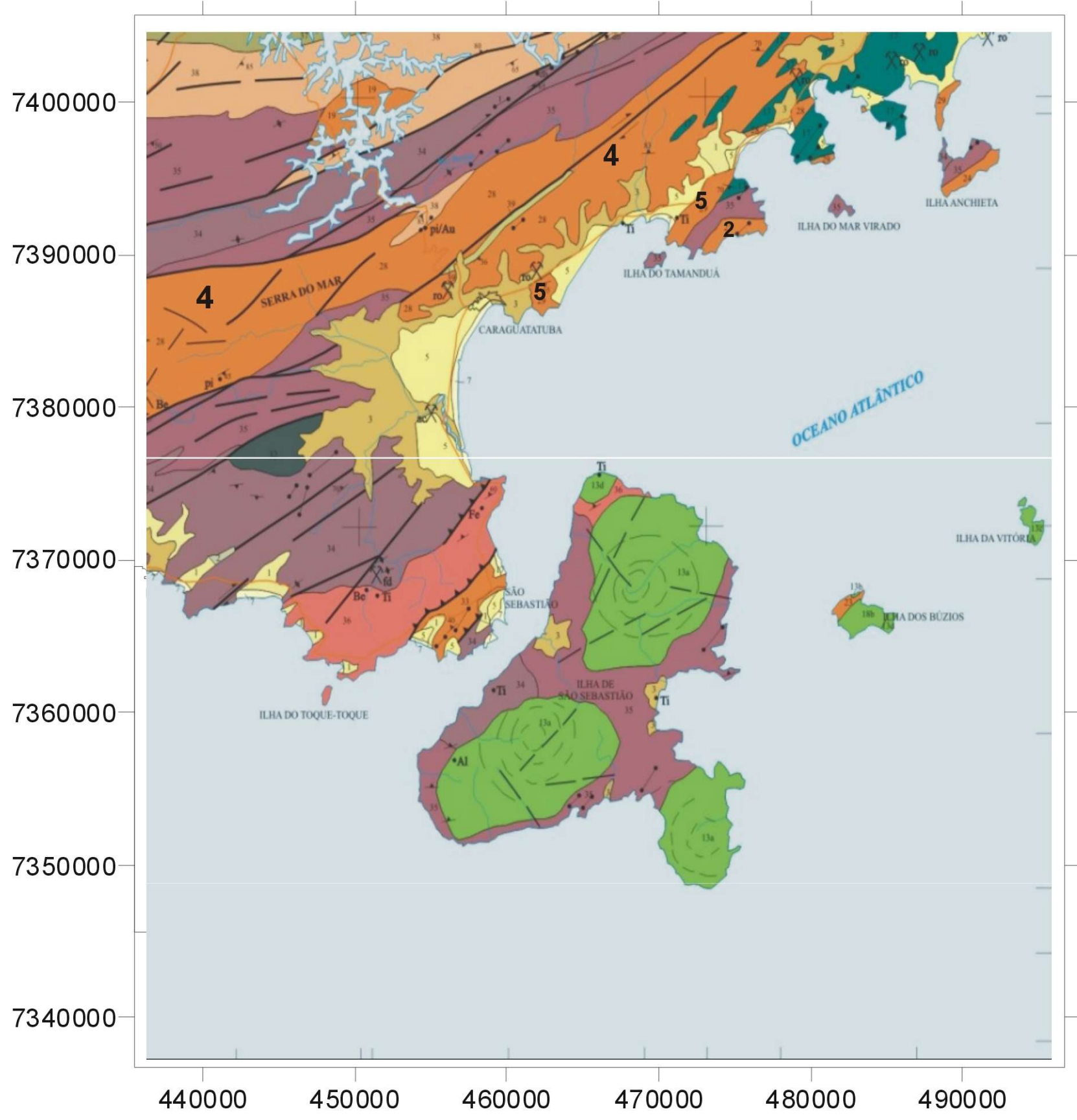

Figura 5- Recorte do mapa geológico do Estado de São Paulo modificado de CPRM (1999), mostrando os aspectos da geologia regional adjacente à área de estudo. 


\section{UNIDADES LITO-ESTRATIGRÁFICAS}

CENOZÓICO

COBERTURAS SEDIMENTARES

Depósitos aluvionares.

Depósitos areno-síltico-argilosos indiferenciados

Depósitos arenosos marinhos

Depósitos arenosos praiais.

\section{MESOZÓICO}

INTRUSIVAS BÁSICAS E ALCALINAS

Intrusivas básico-alcalinas: sienitos, alcalissienitos, nordmarkitos, (biotita) pulaskitos,

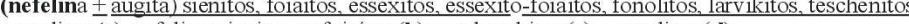
e teralitos (a), nefelina-sienitos ou foiaitos (b), nordmarkitos (c) e teralitos (d)

- Diques básicos e diferenciados: diabásios, microdioritos pórfiros, monzodioritos, monzonitos pórfiros, andesitos pórfiros, traquiandesitos, gabros e lamprófiros; e de traquitos (t), diabásio db) e pegmatitos (pg)

\section{PROTEROZÓICO-EOPALEOZÓICO}

DOMÍNIO COSTEIRO

Biotita granito cinza, porfiritico, com hornblenda; associa-se a charnockitos (Ponte Nova-Paraibuna )

(Hornblenda)-biotita granito a monzogranito róseo porfirítico (Cruz do Alto)

(Hornblenda)-biotita granito porfirititico, por vezes inequiigranular, cinza-rosado, com fảcies a granada e biotita

Metagabros, dioritos, quartzodioritos gnảissicos, enderbitos, anfibolitos e, subordinadamente, migmatitos com estruturas diversas (Com ple xo Ba iro do Ma iisc o).

Granito leucocrático, por vezes com granada

Migmatitos com estruturas diversas, notadamente nebulitica, schlierene estromática.
Charnockito eqüigranular a porfirítico, com quartzomangeritos subordinados (Charnockito Ubatuba)

(Homblenda)-biotita migmatito e/ou granito-gnaisse porfiroclastico.

Biotita gnaisses gradando para migmatitos estromáticos.

Biotita gnaisses e gnaisses peraluminosos com boudins de calcissilicatic quartzitoseanfibolitos

Sillimanita - muscovita quartzitos.

\section{DOMÍNIO EMBU}

uscovita-biotita granito (3b) cinza, porfiritico, com fácies inequigranular, maciço (Tub a rão)

Biotita granito (3a) a monzogranito cinza róseo, inequigranular a porfirítico(Sa nta Ca ta mina)

$+$

Quartzo-micaxistos e quartzitos, por vezes associados a metabasitos. Milonitizados.

\section{CONVENÇÕES GEOLÓGICAS}

Foliaçăo com Mergulho Indicado
Foliação Subvertical
de Empurarrăo ou de Cisalhamento

Figura 6 - Legenda do recorte do mapa geológico do Estado de São Paulo (CPRM, 1999) 
As idades das rochas de composição básica estariam por volta de $120 \mathrm{Ma}$ (Coutinho et al., 1992).

Segundo Riccomini et al. (1989), os processos tectônicos, associados a essa evolução, originada no Mesozóico, acentuaram-se no Paleógeno e perduraram, de forma atenuada, durante o Neógeno até os dias de hoje.

Segundo Pereira (1992), após a transgressão marinha ocorrida na Bacia de Santos, com máximo no Neocenoniano/Eoturoniano, ocorreu erosão subaérea da sequência neoturoniana dando origem a uma discordância com o Eoconiciano. Esta discordância reflete um importante evento tectônico, que resultou em soerguimento pulsativo da área a oeste da Bacia de Santos estendendo-se até o interior do continente. Já Macedo (1991) correlacionou a discordância regional do final do Cretáceo na Bacia de Santos com a superfície de aplainamento do Japi, de Almeida (1964), na área continental. Trabalhos mais recentes, como os de Gallagher et al. (1994), sobre traços de fissão em apatitas, indicam uma taxa de soerguimento significativa da margem continental do sudeste brasileiro desde o Cretáceo.

\section{4 Áreas submersas}

\subsubsection{Granulometria e composição dos sedimentos superficiais}

Segundo estudo realizado por Mahiques (1992) as enseadas do Flamengo e da Fortaleza apresentam as seguintes características sedimentológicas:

- Na enseada do Flamengo ocorre grande variabilidade de tipos sedimentológicos, com diâmetros médios de areias finas a siltes muito finos, porém com o predomínio de silte grosso e médio. O grau de seleção varia de pobremente a muito pobremente selecionados, com valores sempre superiores a 1甲. A análise classificatória multivariante, realizada pelo autor, revela dois domínios bastante distintos. As porções mais abrigadas da Enseada do Flamengo apresentam deposição preferencial de siltes sobre areias muito finas. Nas porções menos abrigadas ocorre o domínio das areias muito finas sobre os siltes. 
No Saco da Ribeira ocorrem termos sedimentológicos mais finos (siltes médios e finos). Na distribuição da relação argila/silte da Enseada do Flamengo, o Saco da Ribeira apresenta-se como zona preferencial na deposição de argilas.

- A Enseada da Fortaleza apresenta maior homogeneidade granulométrica em relação à Enseada do Flamengo. No geral, os sedimentos apresentam unimodalidade, na maioria das amostras ocorre o predomínio de areia muito fina. No que se refere ao diâmetro médio, ocorre uniformidade de tipos sedimentológicos, com o predomínio de areias muito finas no seu interior, que gradam para siltes grossos além de sua desembocadura. A análise classificatória multivariante indica a existência de uma gradação, a partir de termos arenosos muito finos no interior da enseada, passando para silte além da desembocadura. A relação argila/silte indica homogeneidade dos sedimentos da área.

- Os sedimentos superficiais na enseada do Flamengo são predominantemente litoclásticos, com valores relativamente altos em carbonato biodetrítico, carbono orgânico (valores superiores a 1\%) e nitrogênio orgânico (superiores a $0,1 \%$ ) junto ao costão oeste, em relação às áreas a leste da enseada. A razão $\mathrm{C} / \mathrm{N}$ apresenta valores, na maior parte da Enseada do Flamengo, inferiores a 10. O Saco da Ribeira é uma exceção, onde as amostras apresentam valores superiores a 10.

- Na Enseada da Fortaleza ocorrem sedimentos com teor de carbonato biodetrítico superior a $30 \%$ apenas em áreas próximas à Praia do Lázaro e à Ponta Grande. Junto à Praia do Lázaro é um dos poucos locais onde os valores são superiores a $1 \%$ de carbono orgânico e $0,10 \%$ de nitrogênio orgânico. $\mathrm{Na}$ maior parte da área os valores da razão $\mathrm{C} / \mathrm{N}$ são inferiores a 10. A partir da análise dos constituintes da fração $0,500 \mathrm{~mm}$, é verificada que a distribuição dos constituintes biogênicos marinhos é mais homogênea em relação à Enseada do Flamengo, principalmente fragmentos de moluscos. 


\subsubsection{Aspectos Oceanográficos}

Teixeira (1980) realizou estudo dos parâmetros abióticos e produção primária na Enseada do Flamengo que constatou, para os anos de 1978 e 1979, a ausência de variações sazonais consideráveis. Contudo, o autor destacou a importância das variações nictemerais nos valores de oxigênio dissolvido, salinidade, temperatura e nutrientes. Também observa a importância dos fenômenos de ressuspensão dos sedimentos sobre as taxas máximas de produção primária e de clorofila-a, que ocorrem durante períodos de turbulência das águas.

A partir de estudos realizados nas enseadas do Flamengo e da Fortaleza em estações fixas nos anos de 1988 e 1989 por Mahiques (1992), foram verificadas as seguintes condições:

- Na Enseada do Flamengo foram registrados os menores valores de velocidades de corrente e de material em suspensão junto ao fundo nos meses de verão. Em de janeiro os perfis de temperatura e salinidade indicaram a penetração de massa de água fria, promovendo uma variação de temperatura de cerca de $8^{\circ} \mathrm{C}$ entre as águas de superfície e fundo, já os valores de salinidade apresentam-se praticamente homogêneos. Nos meses de inverno, a passagem de frentes frias modifica o padrão de ondas sobre a costa e produz o revolvimento do substrato e o aumento da quantidade de material em suspensão. Os perfis de termossalinometria nos meses de julho apresentaram estratificação suave, e homogeneização da coluna d'água nos meses de agosto. Os perfis de temperatura e salinidade nos meses de abril indicam o desaparecimento da estratificação termohalina devido ao recuo da água fria.

- Nos meses de janeiro, na Enseada da Fortaleza, foi registrada uma marcante estratificação dos parâmetros hidrográficos. Os perfis de hidrografia apresentaram forte estratificação de temperaturas, com amplitudes da ordem de $8^{\circ} \mathrm{C}$ para o período. Já os valores de salinidade apresentaram forte homogeneização, com amplitude de $0,5 \times 10^{-3}$. Nos meses de abril foi verificada a homogeneização da coluna d'água, no geral, tal característica também foi registrada de forma semelhante para os meses de agosto. $O$ conjunto de valores 
mais altos de temperatura e salinidade registrados na Enseada da Fortaleza ao longo de várias campanhas ocorreram nos meses de abril. As estações fixas nos meses de julho revelaram homogeneização da coluna d'água, e valores extremamente baixos de temperatura e salinidade. Os perfis de temperatura e salinidade, executados em outubro, indicam o aparecimento de uma suave estratificação nos parâmetros hidrográficos, com temperaturas variando na ordem de $2^{\circ} \mathrm{C}$.

\section{MATERIAIS E METODOS}

\subsection{Amostragem}

Dois testemunhos foram coletados com a utilização de um testemunhador a vibração nas enseadas do Flamengo e Fortaleza. As análises realizadas nos testemunhos UBA1 e UBA3 consistiram em datação de fragmentos vegetais e conchas de bivalves em posição de vida, pelo método ${ }^{14} \mathrm{C}$, verificação da natureza, taxa de acúmulo e massa da matéria orgânica sedimentar, e análises sedimentológicas.

Os testemunhos foram coletados em dezembro de 2003. As profundidades de coleta da lâmina d'água foram de $3.10 \mathrm{~m}$, UBA1 e $3.80 \mathrm{~m}$, UBA3, sem correção de maré.

\subsection{Datações}

\subsubsection{Idade ${ }^{14} \mathrm{C}$ e idade calendário}

Para um cálculo mais preciso da taxa de acumulação de matéria orgânica, a idade ${ }^{14} \mathrm{C}$ necessita ser calibrada para a idade calendário. $\mathrm{A}$ idade ${ }^{14} \mathrm{C}$ varia da idade calendário a partir do Holoceno médio e inferior (Browman, 1990). As variações de curta escala ocorrem devido às flutuações na modulação heliomagnética da radiação cósmica da galáxia, e recentemente, devido à queima de combustível fóssil em larga escala, além dos testes nucleares. As variações de longa escala são atribuídas às variações geomagnéticas. $\mathrm{A}$ idade ${ }^{14} \mathrm{C}$ convencional é o resultado obtido após a aplicação das correções ${ }^{13} \mathrm{C} /{ }^{12} \mathrm{C}$ na 
idade medida. As calibrações para a idade calendário são apropriadas para materiais orgânicos e carbonatos com idades entre 0 e 20.000 anos A.P.

\subsection{Granulometria}

As partículas sedimentares apresentam dimensões com alta variabilidade. Sua análise permite, entre outras, deduzir indicações sobre os ambientes deposicionais (Meyers, 1997). Por exemplo, a quantidade de argila depositada influencia na acumulação de matéria orgânica em sedimentos marinhos (Mahiques, 1998).

A análise granulométrica consiste na determinação das dimensões das partículas constituintes das amostras e no tratamento estatístico dessa informação. Para sedimentos como areia a análise clássica recorre à separação mecânica em classes dimensionais e à determinação do peso. Para frações menores como silte e argila a determinação da granulometria torna-se mais problemática, levantando-se questões que ainda não foram resolvidas satisfatoriamente. Neste trabalho são utilizadas duas técnicas: pipetagem para a determinação da granulometria dos siltes e argilas, e peneiramento para os sedimentos constituídos por areias, segundo Suguio (1973).

A escala granulométrica aqui utilizada será a escala geométrica $\phi$ (phi), que utiliza potências de 2 como base de uma escala logarítmica, atualmente em uso, segundo a seguinte fórmula:

$$
\phi=-\log _{2} \mathrm{~d}(\mathrm{~mm}) / 1 \mathrm{~mm} .
$$

Torna-se necessário trabalhar com valores de $\phi$ negativos, quando as partículas são maiores que $2 \mathrm{~mm}$, e valores positivos para as de dimensões menores que $2 \mathrm{~mm}$. Exemplo: $0,5 \mathrm{~mm}=2^{-1}$, onde $\phi=-1$. 


\subsection{Conteúdo em carbonato de cálcio}

O Carbonato de cálcio é produzido, principalmente por organismos marinhos, desta forma, seu teor pode indicar maior ou menor influência marinha no aporte sedimentar, ou ainda dar indícios sobre a salinidade das águas, regime de chuvas, e produtividade.

A queima do carbonato de cálcio foi realizada em $25 \mathrm{~g}$ de sedimento, atacado com solução de ácido clorídrico, diluída a 10\%, por cerca de $72 \mathrm{~h}$. Em seguida, as amostras foram lavadas 5 vezes, com água destilada, para que os resíduos pudessem ser eliminados, e secas em estufa a $60^{\circ} \mathrm{C}$ e pesadas.

O conteúdo em carbonato de cálcio foi calculado para cada intervalo amostral a partir da subtração da massa, após a queima do carbonato, da massa total do sedimento

\subsection{Razões $\mathrm{C} / \mathrm{N}$ e $\mathrm{C} / \mathrm{S}$}

A análise da matéria orgânica, a partir de valores da razão $C / N$, tem sido utilizada por diversos autores, na intenção de distinguir entre matéria orgânica sedimentar de origem continental e marinha (Meyers, 1997). Algas apresentam valores de razão $\mathrm{C} / \mathrm{N}$, expressos em massa, entre 4 e 10 , enquanto que as plantas continentais superiores apresentam valores em torno de 20 (Meyers, 1994). O diagrama de Bordowskiy (1965 apud Stein, 1991) (Fig.7) mostra a relação de diferentes valores de $\mathrm{C} / \mathrm{N}$ para materiais distintos.

Segundo Meyers (1994), as diferentes razões de $\mathrm{C} / \mathrm{N}$, estão tipicamente associadas aos constituintes da matéria orgânica; logo a celulose encontra-se em abundância nas plantas continentais superiores, e as proteínas, nas algas.

A presença de enxofre nos sedimentos marinhos ocorre principalmente na forma de sulfetos e indica anoxia nas condições de deposição. Desta forma, a razão C/S é utilizada para indicar se as condições ambientais, na época da deposição, foram óxicas ou anóxicas (Mahiques, 1998). 


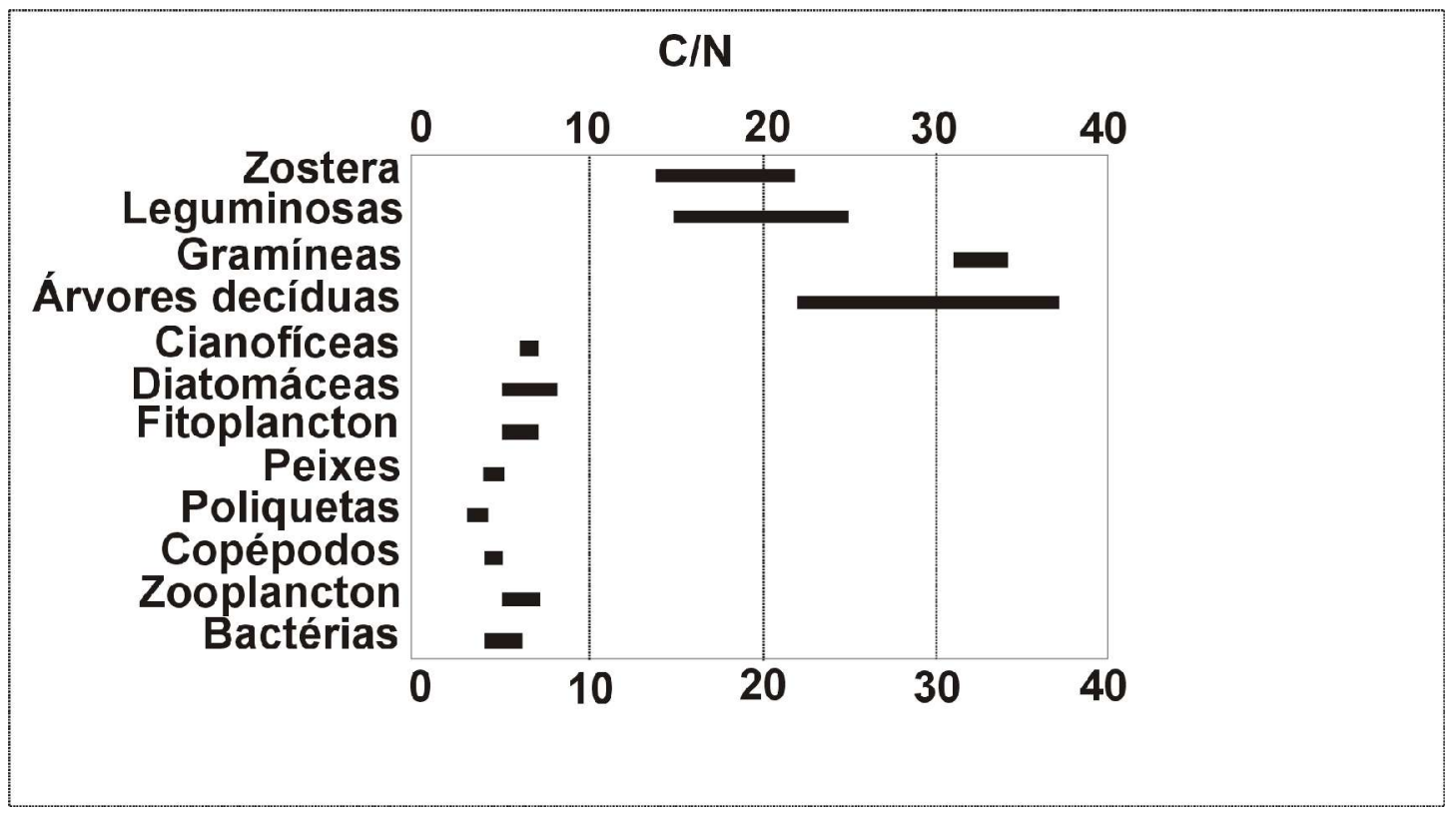

Figura 1- Diferentes valores de $\mathrm{C} / \mathrm{N}$ para materiais distintos (retirada de Bordowskiy -1965 apud Stein, 1991).

O tipo de analisador utilizado, LECO CNS2000, é composto por um forno de combustão e uma unidade de análise. Antes de serem analisadas, as amostras foram liofilizadas, pesadas, atacadas com solução de ácido clorídrico, diluída a $10 \%$, lavadas com água destilada, colocadas em pequenas barcas de cerâmica, e novamente liofilizadas. 
Os teores dos elementos analisados são expressos em $\mathrm{mg}$ do elemento / por $\mathrm{g}$ do peso seco da amostra. Para o cálculo destes teores é necessário definir curvas de calibração para o carbono, nitrogênio e enxofre, utilizando-se 9 amostras de um padrão sulfametazina ( $C=51,78 \%, N=20,13 \%, S=11,52 \%)$, e definido um valor de branco para cada elemento. São analisadas três amostras de sulfametazina e quinze rodadas de branco para calibrar a curva do analisador. Após este procedimento, as amostras podem ser levadas ao forno de combustão, que se encontra a uma temperatura de $1400^{\circ} \mathrm{C}$, onde oxigênio é introduzido por 20 segundos para potencializar a oxidação da matéria orgânica. Os gases liberados neste processo são transportados, com auxílio de uma bomba a vácuo, para o analisador que homogeniza e retira 3 alíquotas dos gases para a análise. $\mathrm{O} \mathrm{N} \mathrm{N}_{2}$ é medido a partir de um sensor de termocondutividade e os gases $\mathrm{CO}_{2} \mathrm{e}$ $\mathrm{SO}_{2}$ são analisados a partir de células de infravermelho.

\subsection{Taxa de acumulação de massa (T.A.M.)}

A T.A.M. é necessária para o cálculo da taxa de acumulação de matéria orgânica, que pode indicar a origem da matéria orgânica e foi calculada para cada intervalo amostral, segundo a seguinte formulação:

T.A.M $\left(\mathrm{g} / \mathrm{m}^{2} / \mathrm{ano}\right)=($ D.S.H. $)$ X (T.S.) X $1-(\mathrm{W} . \mathrm{C} / 100) \times 10^{4}$

Onde D.S.H. é a densidade do sedimento úmido $\mathrm{g} / \mathrm{cm}^{3}$, obtida a partir da porosidade $(\Phi)$, T.S.é taxa de sedimentação ( $\mathrm{cm} / \mathrm{ano})$, e W.C é o conteúdo de água do sedimento (\%).

A porosidade foi obtida a partir da seguinte formulação:

$\Phi=\left((\mathrm{W} / 100) X \rho_{\mathrm{s}}\right) /\left(\left((\mathrm{W} / 100) \times \rho_{\mathrm{s}}\right)+(1-(\mathrm{W} / 100)) X \rho_{\mathrm{w}}\right)$

onde W é o conteúdo em água, $\rho_{\mathrm{s}}$ é a densidade do sedimento considerada 2,35 $\mathrm{g} / \mathrm{cm}^{3}$ e $\rho_{\mathrm{w}}$ a densidade da água considerada $1.0 \mathrm{~g} / \mathrm{cm}^{3}$.

\subsection{Taxa de acumulação de matéria orgânica (T.A.C.)}

Esta taxa foi calculada para cada intervalo amostral, segundo a seguinte formulação: 
T.A.M. $\left(\mathrm{g} / \mathrm{m}^{2} / \mathrm{ano}\right)=($ T.A.M $) . \times \% \mathrm{C}_{\text {org }} \times 10^{-2}$.

Os diferentes valores foram plotados em gráficos, a fim de mostrar a relação entre taxas de acumulação de matéria orgânica e massa, com características terrestres ou planctônicas, bem como, relações com o conteúdo de carbono orgânico no sedimento e taxas de sedimentação.

\subsection{Razão isotópica do carbono $\left(\delta^{13} \mathrm{C}\right)$}

A análise de isótopos estáveis de carbono permite a caracterização da matéria orgânica quanto à sua origem. A composição isotópica do carbono na matéria orgânica reflete a dinâmica da assimilação do carbono durante a fotossíntese e a composição isotópica da fonte do carbono (Hayes, 1993). As plantas fotossintetizantes podem trabalhar em campos metabólicos distintos. A maior parte das plantas fotossintéticas possui o metabolismo do tipo $\mathrm{C} 3$, utilizado para a incorporação do carbono na sua matéria orgânica. Desta forma, também ocorrem diferenças bioquímicas na quantidade de ${ }^{13} \mathrm{C}$, que por sua vez, influencia - $\delta^{13} \mathrm{C}$, possibilitando a distinção entre plantas com diferentes metabolismos (Meyers, 1997).

Existe uma razão padrão o $\delta^{13} \mathrm{C}$, cujo valor se aproxima de $0.00 \%$, para caracterizar os tipos de matéria orgânica. Esta razão é relativa ao PDB, que corresponde a um carbonato do Cretáceo da Carolina do Norte (fóssil Belemnitella americana).

Em áreas temperadas, valores de $\delta^{13} \mathrm{C}$ em torno de $-20.00 \%$, representam o plâncton marinho, sem maiores distinções entre fito e zooplâncton (Stein, 1991). Contudo, são feitas distinções entre diferentes tipos de plantas terrestres (Meyers, 1997). Mangue e gramíneas apresentam valores próximos de $-26 \%$ e $-10.00 \%$, respectivamente. No geral, observa-se que quanto mais negativo o $\delta^{13} \mathrm{C}$, maior é a tendência de o material ser de origem continental. Porém, deve-se ater-se ao fato de que plantas terrestres podem apresentar metabolismos do tipo C3 e C4, como é o caso das gramíneas (metabolismo C4), mesmo sendo de origem continental, podem apresentar valores muito positivos, maiores do que aqueles atribuídos aos 
plânctons. Esta observação aplica-se principalmente nas áreas costeiras. Pode se observar na Fig.8 alguns valores do $\delta^{13} \mathrm{C}$ (Waples, 1981, apud Stein, 1991).

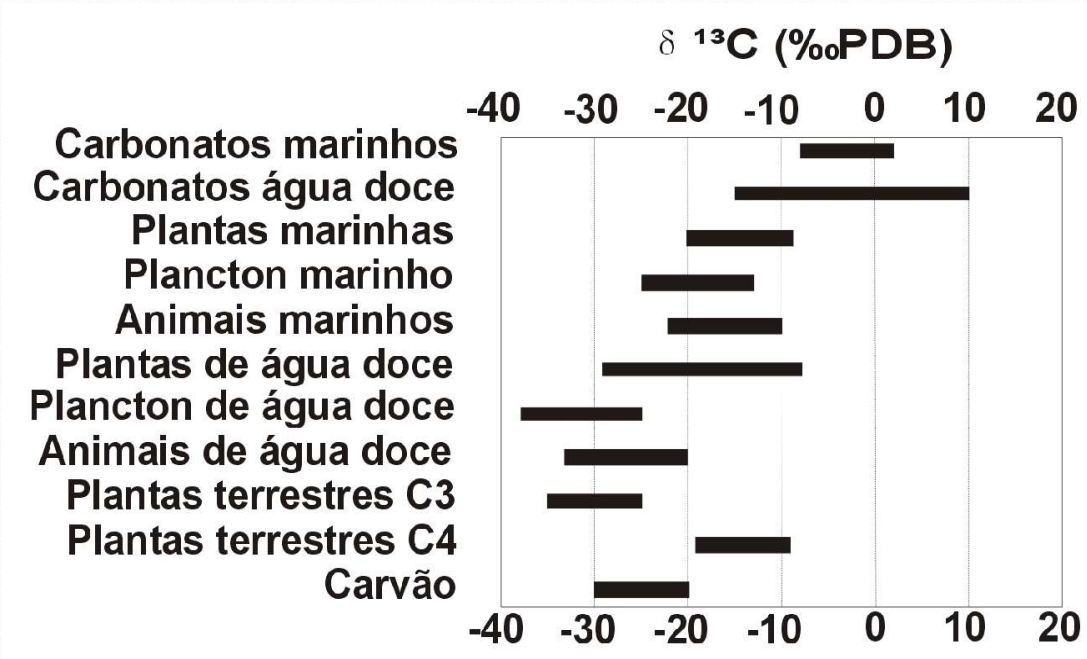

Figura 2- Valores de razão isotópica de carbono de diferentes materiais orgânicos (Retirado de Waples,1981, apud Stein, 1991).

Neste trabalho foram realizadas análises do $\delta^{13} \mathrm{C}$ a cada intervalo amostral dos testemunhos UBA1 e UBA3. Esta análise foi realizada pelo método de combustão em um tubo a vácuo, e as medidas foram feitas por um espectrômetro de massa. Valores de $\delta^{13} C_{P D B}$ do conteúdo da matéria orgânica sedimentar foram obtidos pelo espectrômetro de massa do Coastal Science Laboratories (Austin, TX, USA). As análises isotópicas de carbono foram obtidas pela combustão online em um Analizador Elementar Fisons NA1500 acoplado a um espectrômetro de massa do tipo VG SIRA Modelo 10. O isótopo de carbono foi calibrado utilizando-se o óleo padrão NBS 22 (definido como $-29.60 \%$ relativo ao PDB). A reproducibilidade do isótopo de carbono foi melhor do que $0.2 \%$.

Segundo Meyers (1997), este tipo de análise tem sido utilizada, com sucesso, por diversos autores, para traçar a fonte da matéria orgânica em sedimentos costeiros. 


\subsection{Tratamento dos dados}

Os resultados obtidos foram tratados nos softwares Excel (versão xp), PlanPlot (10.12) e CorelDRAW 9. Para a análise granulométrica foi utilizado Labsed software elaborado pelo Prof. Dr. Jorge K. Yamamoto. O software DEPAGE (versão 3.9) foi utilizado para fazer um modelo de distribuição das idades radiométricas ${ }^{14} \mathrm{C}$, desenvolvido por L.J. Maherr Jr.

\section{RESULTADOS}

\subsection{Datação}

O resultado das datações convencionais e calibradas de radiocarbono encontram-se na tabela 1.

\subsection{Modelos de idade}

Os modelos de idade estão em função da idade calibradada e, no geral, apresentam boa correlação entre os dois testemunhos (Fig.9). Ocorre certa discrepância nas idades próximas ao topo do UBA1 e UBA3.

\subsection{Descrição e análise granulométrica}

O testemunho UBA1 apresenta comprimento total de $221 \mathrm{~cm}$ (Fig.10). A sequência basal é constituída predominantemente por sedimento arenoso, representado por $76 \%$ de areias e $15 \%$ de silte (Fig.11). Este trecho apresenta granodecrescência ascendente até 5.400 anos cal. A.P. Aproximadamente em 7.100 anos cal. A.P. ocorre um contato gradacional, acima do qual, o silte passa a predominar atingindo porcentagens em torno de $93 \%$ em 5.000 anos cal. A.P. Outros contatos gradacionais ocorrem próximos às seguintes idades: 7.600, $6.300,5.450$ e 5.300 anos cal. A.P. (Fig.11). Estes contatos gradacionais ocorrem entre sedimentos mais ricos em areias e sedimentos pelíticos. É importante ressaltar a existência de um contato brusco, entre 5.800-5.750 anos cal. A.P., formado por uma camada de matéria orgânica de coloração (brownish black). 
Existe um segundo contato brusco, aproximadamente em 5.200 anos cal. A.P., entre sedimentos com matriz mais fina e escura (93\% de pelitos) (greenish black) e matriz mais grossa ( $27 \%$ de areias) de coloração mais clara (yellowish brown). A partir de 5.000 anos cal. A.P. o sedimento passa a ter granocrescência ascendente. Em 2.000 anos cal. A.P. ocorre um contato brusco, onde areias finasmuito finas e bem selecionadas dão lugar às areias grossas-muito grossas (78$80 \%$ ) e aos grânulos (9\%). O sedimento mais grosso possui coloração (grayish olive) e está em contato gradacional com a seqüência do topo de coloração (olive black), que volta a apresentar granodecrescência ascendente, a partir de $\sim 1.200$ anos cal. A.P. até os dias atuais. $\mathrm{Na}$ seqüência do topo, o sedimento gradativamente volta a apresentar as mesmas porcentagens anteriores ao contato brusco, com uma tendência de aumento dos finos.

O testemunho UBA3 apresenta comprimento total de $344 \mathrm{~cm}$ (Fig.12). A sequência basal apresenta granodecrescência ascendente até 7.450 anos cal. A.P. Aproximadamente em 7.700 anos cal. A.P., ocorre um contato gradacional, onde a quantidade de pelitos passa a predominar sobre as areias. A partir daí e até 3.200 anos cal. A.P., observa-se um pacote sedimentar praticamente homogêneo, constituído por $85 \%$ de silte médio-grosso (Fig.13). Este trecho apresenta contato gradacional em 6.300 anos cal. A.P. Aproximadamente em 2.600 anos cal. A.P. ocorre um contato brusco com um pacote arenoso, que estende-se até 850 anos cal. AP. Em 2.000 anos cal. A.P., verifica-se a presença pontual de grânulos $(0,1 \%)$. Em seguida e até o topo do testemunho, o silte volta a predominar no sedimento que apresenta coloração (olive gray) e ligeira granodecrescência ascendente (Fig.13). 


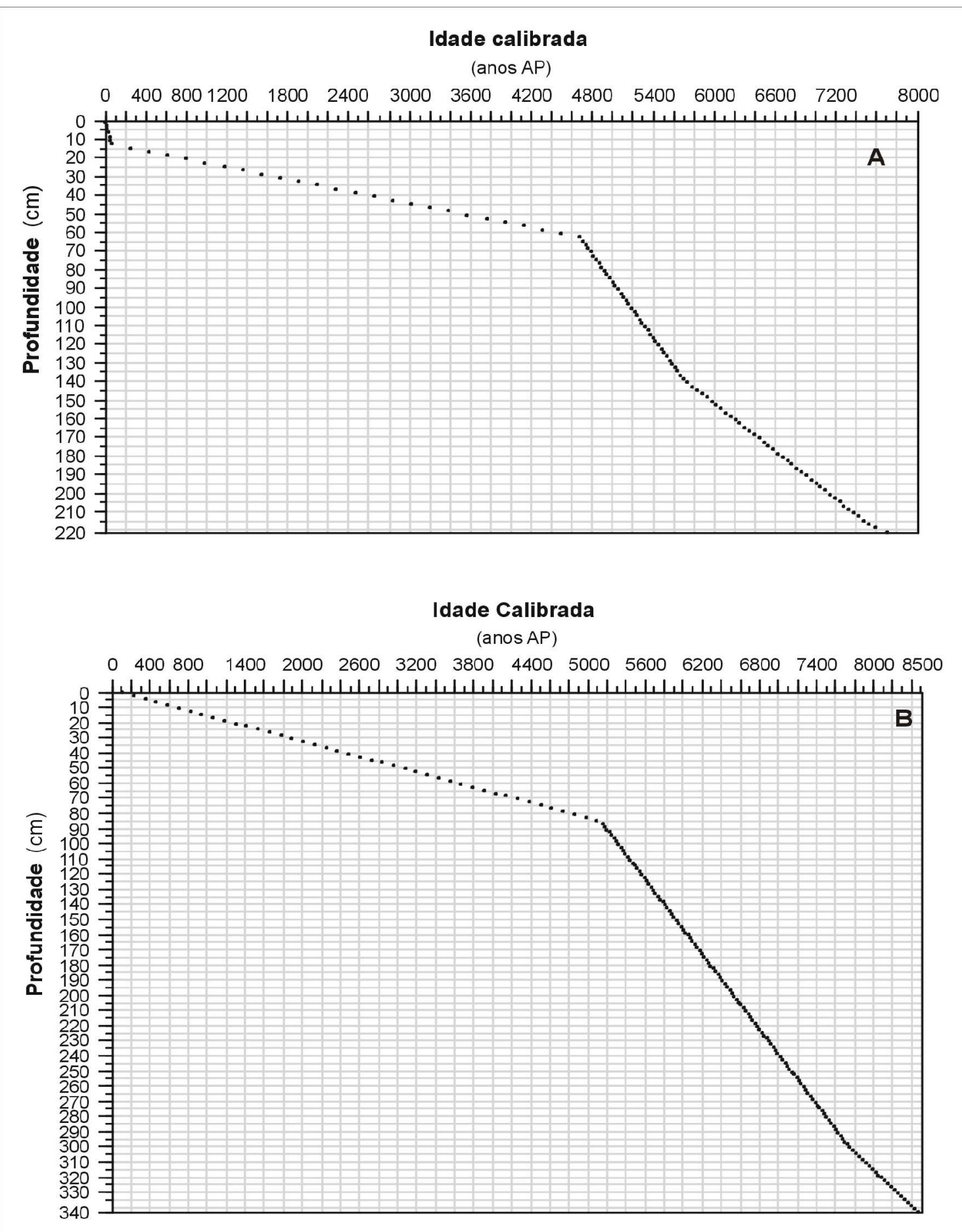

Figura 3- Modelos de idades: (A) testemunho UBA 1, (B) testemunho UBA3 


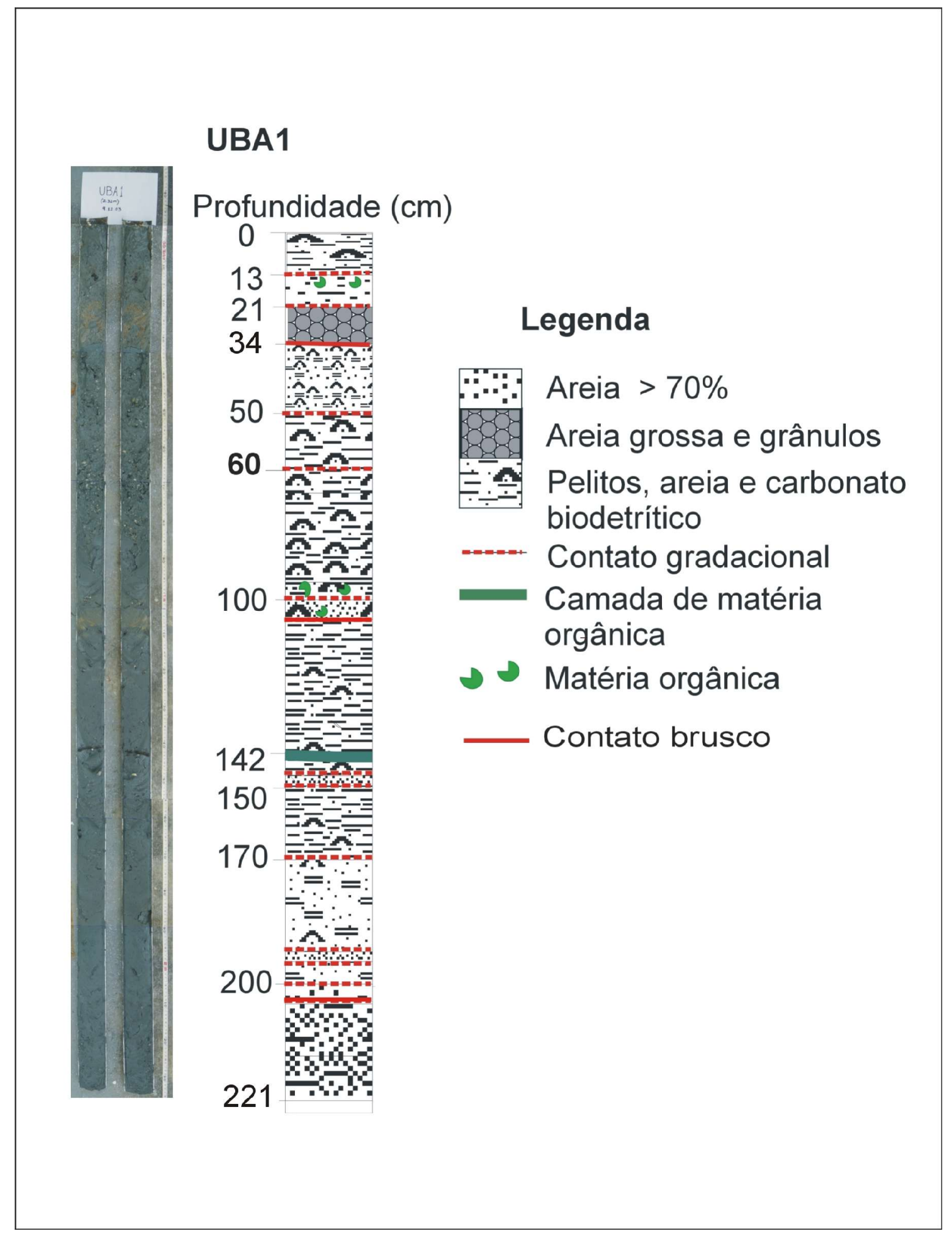

Figura 10 - Descrição macroscópica do testemunho UBA 1 - Saco da Ribeira 


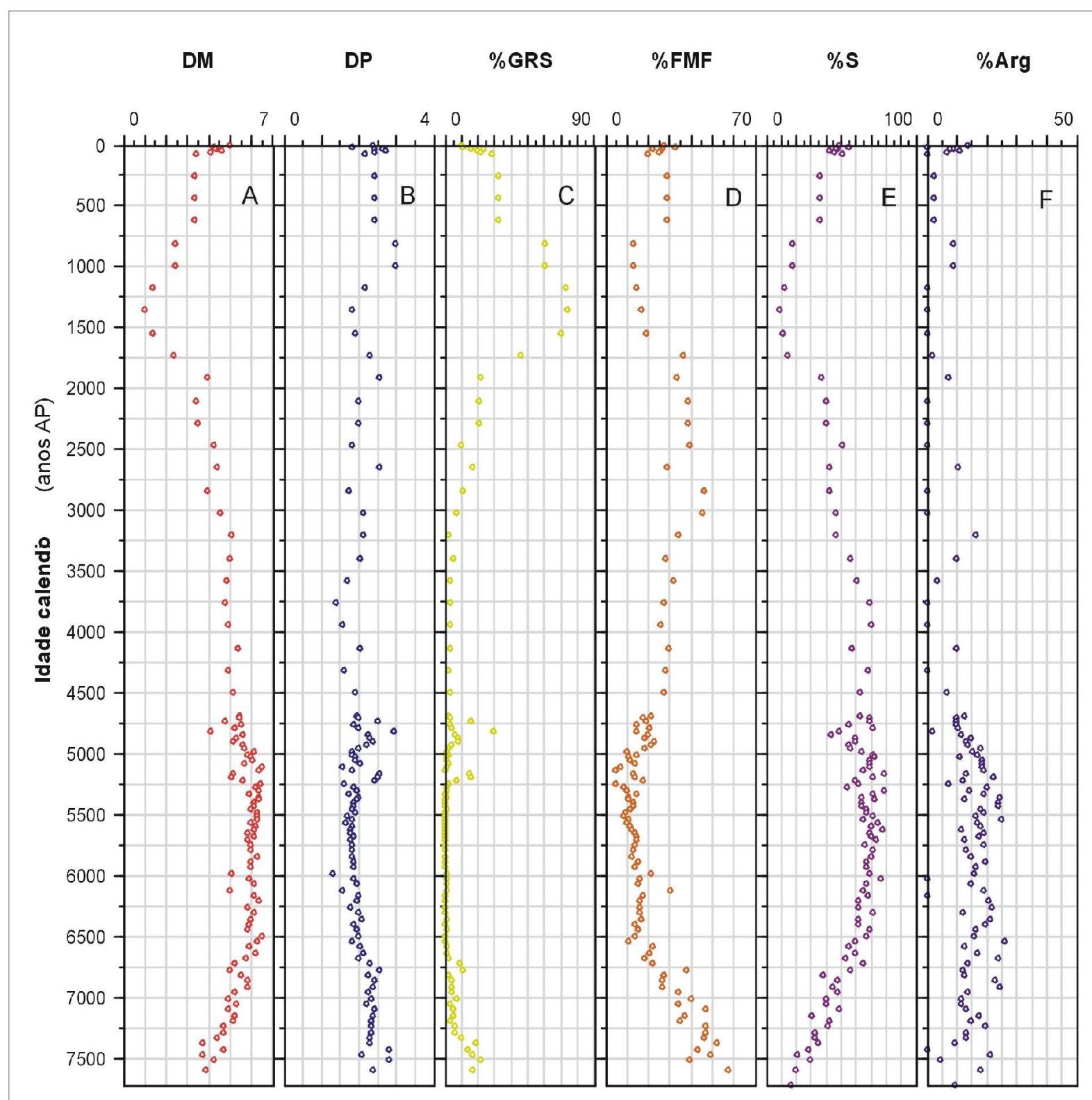

$\max : 7715$ anos AP

Figura 11- Resultados das análises sedimentares do testemunho UBA1, onde $\mathrm{DM}=$ diâmetro médio $(\varphi), \mathrm{DP}=$ desvio padrão, $\mathrm{GRS}=$ grânulos, areia muito grossa, areia grossa e areia média; $F M F=$ areia fina e areia muito fina,.S=silte, $A r g=a r g i l a$ 


\section{UBA3}
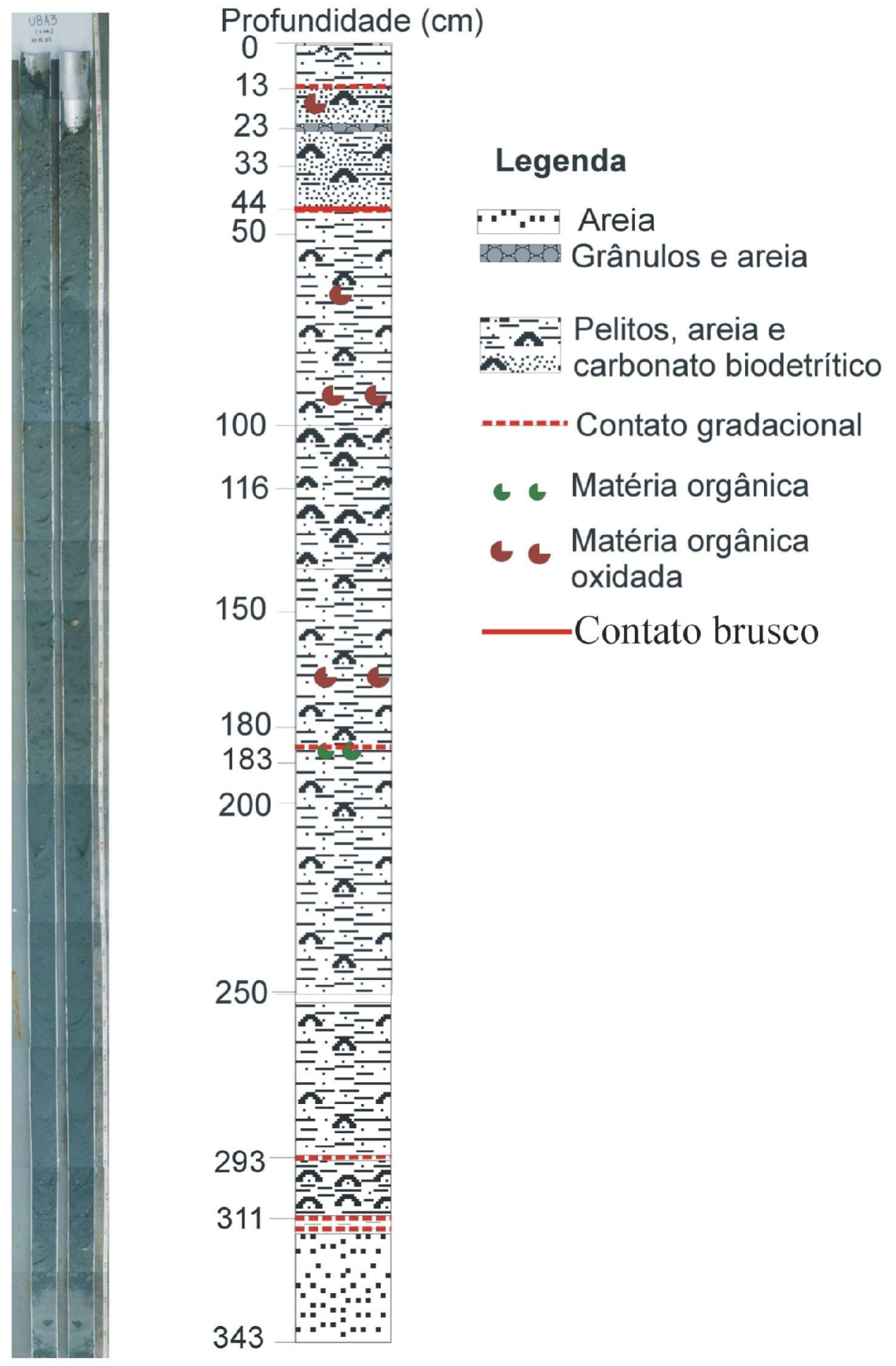

Figura 12 - Descrição macroscópica do testemunho UBA 3- praia do Lázaro. 


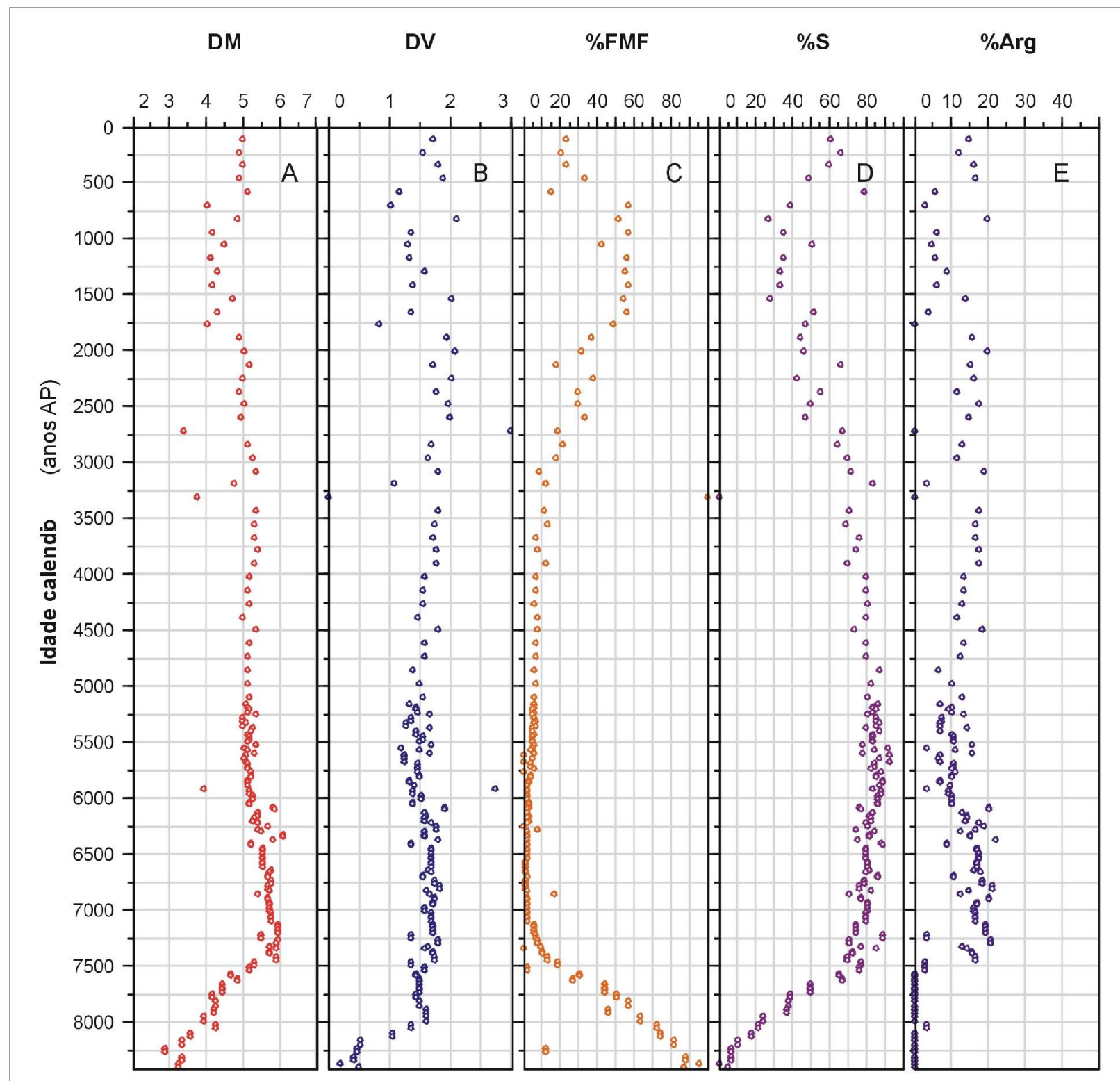

max.: 8410 anos AP

Figura 13 - Resultados das análises sedimentares do testemunho UBA3, onde $\mathrm{DM}=$ diâmetro médio $(\varphi)$; $\mathrm{DP}=$ desvio padrão; $\mathrm{GR}=$ areia muito grossa, areia grossa e areia média; FMF=areia fina e areia muito fina; $\mathrm{S}=$ silte; Arg=argila. 


\subsection{Carbonato de cálcio $\left(\mathrm{CaCO}_{3}\right)$}

De forma geral, a quantidade de $\mathrm{CaCO}_{3}$ apresenta uma tendência de aumento, da base do testemunho UBA1 até aproximadamente 4.900 anos cal. A.P. onde atinge valores máximos, seguidos de diminuição entre $\sim 1.800-1200$ anos cal. A.P., onde são mínimos (Fig.14A).

A base do testemunho UBA1, situada em 7.715 anos cal. A.P., apresenta $13 \%$ de carbonato biodetrítico $\left(\mathrm{CaCO}_{3}\right)$. A partir deste ponto e até 7.100 anos cal. A.P., a quantidade de $\mathrm{CaCO}_{3}$ cai para $8 \%$ e volta a ser $13 \%$ até um contato gradacional em $\sim 6.600$ anos cal. A.P., acima do qual a porcentagem de $\mathrm{CaCO}_{3}$ atinge $20 \%$. Até 5.100 anos cal. A.P. o $\mathrm{CaCO}_{3}$ varia entre $20 \%$ e $10 \%$. A partir daí, aumenta gradualmente de $30 \%$ até atingir $44 \%$ em $\sim 4.900$ anos cal. A.P. Em seguida, a quantidade de $\mathrm{CaCO}_{3}$ decresce até 1.200 anos cal. A.P., diminuindo de $44 \%$ para $17 \%$. Em 50 anos cal. A.P. atinge valores menores que $5 \%$. Durante os últimos 50 anos cal. A.P. os valores de $\mathrm{CaCO}_{3}$ permanecem em torno de $10 \%$

A tendência geral do testemunho UBA3 (Fig.15A) mostra uma concentração de $\mathrm{CaCO}_{3}$ mais homogênea ao longo da coluna sedimentar, se comparada com UBA1.

Na seqüência basal do testemunho UBA3, entre $\sim 8.780-7.550$ anos cal. A.P., ocorrem porcentagens de $\mathrm{CaCO}_{3}$ inferiores a $5 \%$. Aproximadamente em 7.700 anos cal. A.P, observa-se um aumento relevante na quantidade de $\mathrm{CaCO}_{3}$, com valores por volta de $30 \%$, que estendem-se até aproximadamente 6.000 anos cal. A.P., a partir daí, começam a diminuir gradativamente até o topo do testemunho, onde encontram-se em torno de $15 \%$. 


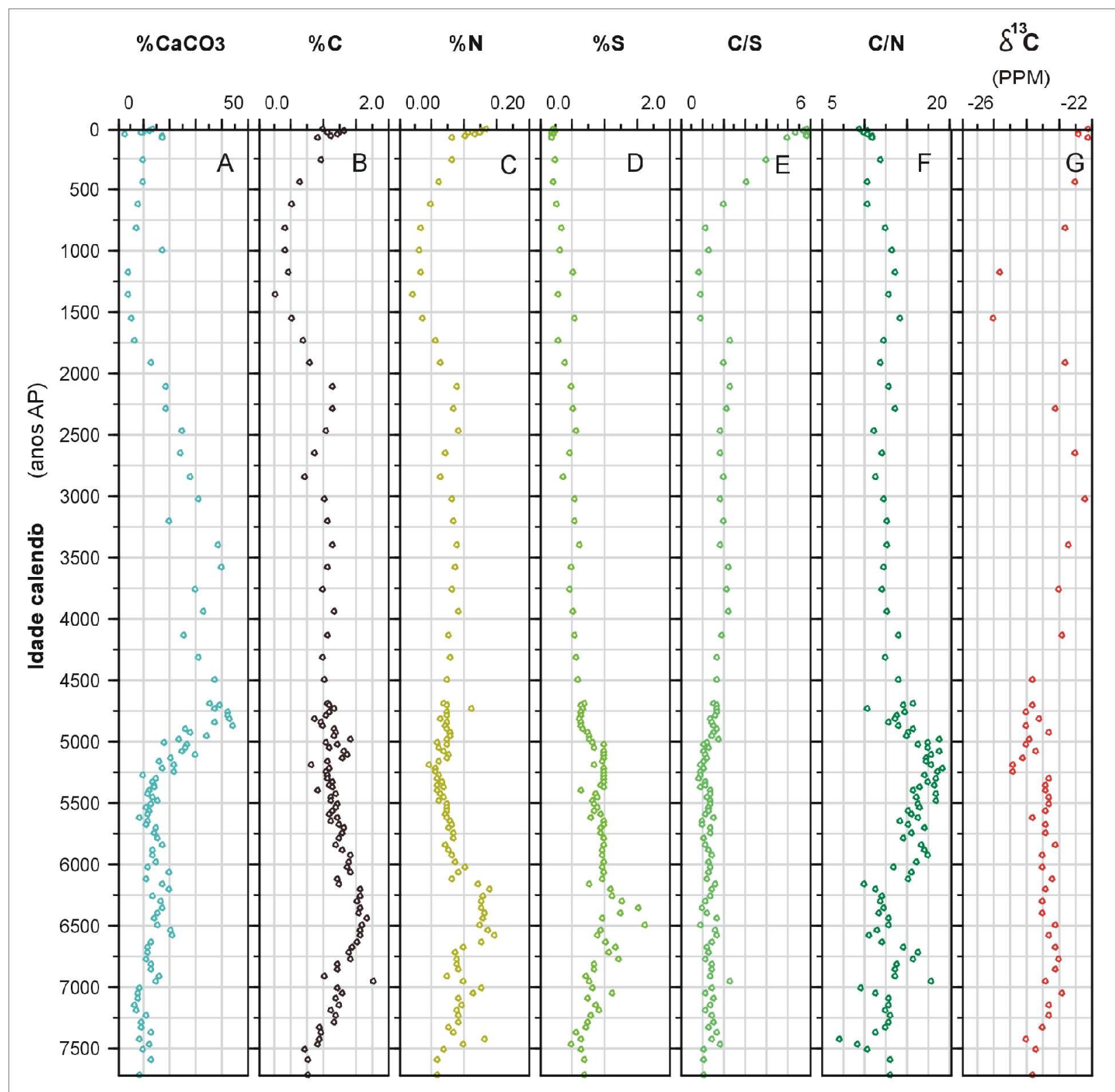

max : 7715 anos AP

Figura 14- Resultados do teor de $\mathrm{CaCO}_{3}$ e das análises da matéria orgânica sedimentar do testemunho UBA1, onde $\mathrm{C}=$ carbono, $\mathrm{N}=$ nitrogênio, $\mathrm{S}=$ enxofre $\mathrm{e}$ $\delta^{13} \mathrm{C}=$ razão isotópica do carbono. 


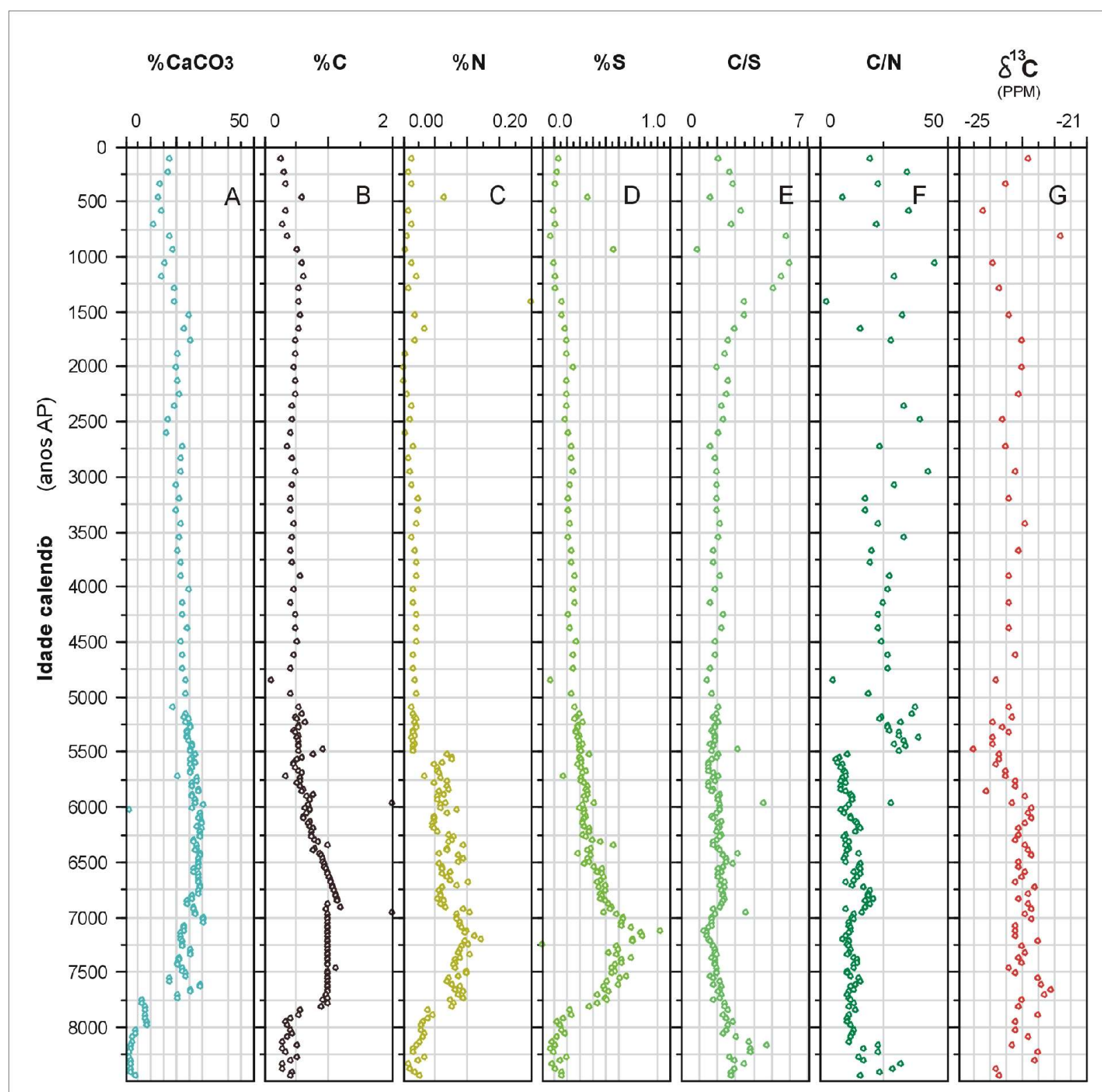

$\max .: 8480$ anos AP

Figura 15- Resultados do teor de $\mathrm{CaCO}_{3}$ e das análises da matéria orgânica sedimentar do testemunho UBA3, onde $\mathrm{C}=$ carbono, $\mathrm{N}=$ nitrogênio, $\mathrm{S}=$ enxofre e $\delta^{13} \mathrm{C}=$ razão isotópica do carbono. 


\subsection{Carbono orgânico X nitrogênio total}

Para checar a confiabilidade dos dados, verificou-se se o material carbono e nitrogênio utilizado para a análise $\mathrm{C} / \mathrm{N}$ era de fato orgânico. Para tanto, os resultados $\mathrm{C}(\%)$ e $\mathrm{N}(\%)$ total do testemunho UBA1 e UBA3 foram plotados em um gráficos (Figs.16 A,B.). Estes gráficos mostram a tendência dos valores de $\mathrm{C}$ e $\mathrm{N}$ nas coordenadas $(0 ; 0)$. Para um valor de $\mathrm{C}=0$ deve-se obter um valor de $\mathrm{N}=0$ para garantir que ambos são orgânicos. Os valores apresentam-se, de certa forma, dispersos, o que deve ser decorrente de conteúdo inorgânico de nitrogênio.

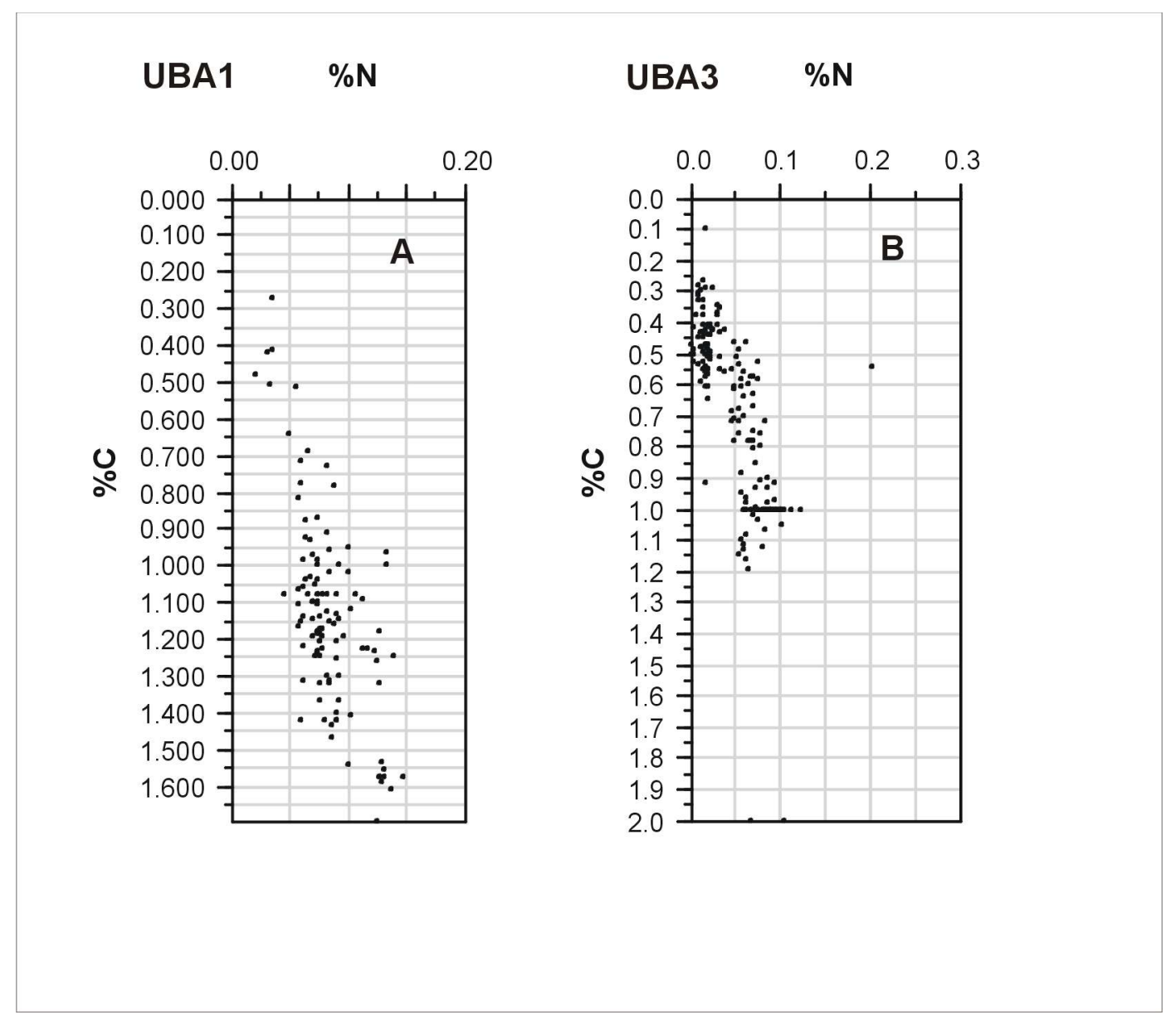

Figura 4- (A) Carbono org. $X$ nitrogênio total do testemunho UBA1; (B) Carbono org. $X$ nitrogênio total do testemunho UBA3. 


\subsection{Conteúdo em carbono (\%C)}

No testemunho UBA1 ocorre uma tendência de aumento no conteúdo em carbono da base $(\sim 0,6 \%)$ até $\sim 6.400$ anos cal. A.P. ( 1,8\%) (Fig.14B). Entre aproximadamente 6.100 e 4.800 anos cal. A.P., observa-se a diminuição gradativa do conteúdo em carbono. Uma diminuição mais acentuada ocorre por volta dos 3.000 anos cal. AP. Os valores mínimos, no conteúdo em carbono, estão em torno de $0,25 \%$, e são observados entre $1.600-700$ anos cal. A.P. A partir daí , verificase aumento dos valores de carbono em direção ao topo. Nos últimos 60 anos, o conteúdo em carbono aumenta de forma mais rápida, variando entre 1,0 e1,3\%.

Da base do testemunho UBA3 até aproximadamente 7.800 anos cal. A.P., o conteúdo em carbono é relativamente baixo, em torno de 0,5\% (Fig.15B). A partir daí, observa-se um aumento relevante, que se estende até $\sim 6.600$ anos cal. A.P., com valores em torno de $1 \%$. Em seguida, o conteúdo em carbono diminui até $\sim 4.800$ anos cal. A.P., (0,5\%). Entre $\sim 2.700$ e 1.200 anos cal. A.P. o conteúdo em carbono sofre um ligeiro aumento, depois diminui para 0,25\%, em 700 anos cal. A.P. Próximo ao topo, encontra-se em torno de $0,25 \%$.

\section{7}

\subsection{Razão $C / S$}

Da base testemunho UBA1 até $~ 5.000$ anos cal. A.P., os valores da razão $\mathrm{C} / \mathrm{S}$ são relativamente baixos, menores que $2 \%$ (Fig.14F). A partir de 5.000 anos cal. A.P. até $\sim 1.650$ anos cal. A.P. apresentam um aumento gradativo, não ultrapassando 2,5\%. Entre 1.650 e 700 anos cal. A.P., ocorre uma diminuição mais brusca, onde os valores da razão C/S ficam em torno de 0,5. entre $\sim 700$ e 55 anos cal. A.P., a razão $\mathrm{C} / \mathrm{S}$ atinge valores em torno de 6,5 , e assim permanecem até o topo do testemunho.

No testemunho UBA3 ocorrem dois trechos onde os valores da razão $\mathrm{C} / \mathrm{S}$ são mais altos (5-6): Entre $\sim 8.250$ e 8.100 anos cal. A.P., e entre $\sim 1.200$ e 600 anos cal. A.P. (Fig.15E). Os valores mínimos são $\sim 1$. Na maior parte do testemunho os valores da razão $\mathrm{C} / \mathrm{S}$ são $\sim 2$. 


\subsection{Razão $\mathrm{C} / \mathrm{N}$}

Da base do testemunho UBA1 até 6.200 anos cal. A.P. ocorre maior variabilidade nos valores da razão C/N, que oscilam entre 5 e 19 (Fig.14F). A partir daí, ocorre um aumento gradativo até $\sim 5.000$ anos cal. A.P. Em $\sim 5.200$ anos cal. A.P., o valor 19 é registrado como o maior do testemunho. Em seguida e até o topo do testemunho, há uma tendência de diminuição gradativa dos valores da razão $\mathrm{C} / \mathrm{N}$, com mínimos em torno de 9.

Da base do testemunho UBA3 até 5.550 anos cal. A.P, ocorrem trechos em que os valores da razão $\mathrm{C} / \mathrm{N}$ são mais altos: entre 8.450 e 8.100 anos cal. A.P. ( 30), e entre 1.200 e 600 anos cal. A.P. ( 50) (Fig.15F).

No testemunho UBA3 a razão $\mathrm{C} / \mathrm{N}$ apresenta uma boa relação de proporcionalidade com a razão $\mathrm{C} / \mathrm{S}$. Quanto maior a razão $\mathrm{C} / \mathrm{S}$, maior é a razão C/N. Porém, ocorre um espalhamento de dados entre 5.550 anos cal. A.P. e o topo do testemunho.

\subsection{Razão isotópica $\delta^{13} \mathrm{C}$}

Os valores de $\delta^{13} \mathrm{C}$ tendem a ficar menos negativos em direção ao topo do testemunho UBA1 $(-23,-22 \%)$, com tendências mais negativas nas idades próximas de $5.200(-24.5 \%)$ e 1.600-750 anos cal. A.P. (-24.8, -25\%) (Fig.14G ).

A partir da base do testemunho UBA1 até 7.000 anos cal. A.P., os valores de $\delta^{13} \mathrm{C}$ aumentam gradualmente de $-23,7$ para $-22,9 \%$. Entre 7.000 e 5.300 anos cal. A.P., permanecem praticamente constantes, variando entre -23 e $-23,4$ $\%$. Por volta de 5.250 anos cal. A.P. diminuem para $-24,3 \%$, chegando a um mínimo de $-24,4 \%$ em 5.150 anos cal. AP. Por volta de 3.000 anos cal. A.P. aumentam para $-22,2 \%$. Os valores de $\delta^{13} \mathrm{C}$ diminuem até alcançar $-25 \%$ em $\sim 1.600$ anos cal. A.P., valor mais baixo do testemunho. A partir de 750 anos cal. A.P., aumentam e ficam em torno de $-22,3 \%$ até o topo do testemunho.

$\mathrm{Na}$ base do testemunho UBA3, ocorre um aumento gradativo nos valores de $\delta^{13} \mathrm{C}$ atingindo $-23 \%$, em 7.500 anos cal. A.P. Em seguida, permanecem em torno 
de $-23 \%$ até 5.300 anos cal. A.P. A partir daí, diminuem gradativamente até ficarem em torno de $-25 \%$ em 5.450 anos cal. A.P. Os valores mais altos de $\delta^{13} \mathrm{C}$ ocorrem entre $\sim 2.300$ e 1.800 anos cal. A.P. Em seguida, ocorre um aumento brusco nos valores de $\delta^{13} \mathrm{C}$ em torno de 900 anos cal. A.P. (-22\%) (Fig.15G) . A partir de 600 anos cal A.P., em direção ao topo do testemunho, há uma diminuição dos valores de $\delta^{13} \mathrm{C}$.

\subsection{Taxa de acumulação de massa (T.A.M.) e taxa de acumulação de matéria orgânica (T.A.C.).}

Os valores de T.A.M. e T.A.C apresentaram boa correlação entre os testemunhos (Figs.17B,C e 18B,C). Observa-se que maiores valores de T.A.M. $\left(1.300\right.$ g. $\mathrm{m}^{-2}$ ano $\left.^{-1}\right)$ e T.A.C $\left(10 \mathrm{~g} \cdot \mathrm{m}^{-2}\right.$ ano $\left.^{-1}\right)$ ocorrem entre a base dos testemunhos até $\sim 5.000$ anos cal. A.P. Os menores valores de T.A.M. (inferiores a 300 g. m. ${ }^{-2}$ ano $^{-1}$ ) e T.A.C. (inferiores a 2.5 g. m. $^{-2}$ ano $^{-1}$ ) ocorrem entre $\sim 5.000$ anos cal. A.P. até os dias atuais, com exceção do topo do testemunho UBA1. As maiores porcentagens de carbono ocorrem por volta de 6.000 anos cal. A.P. 


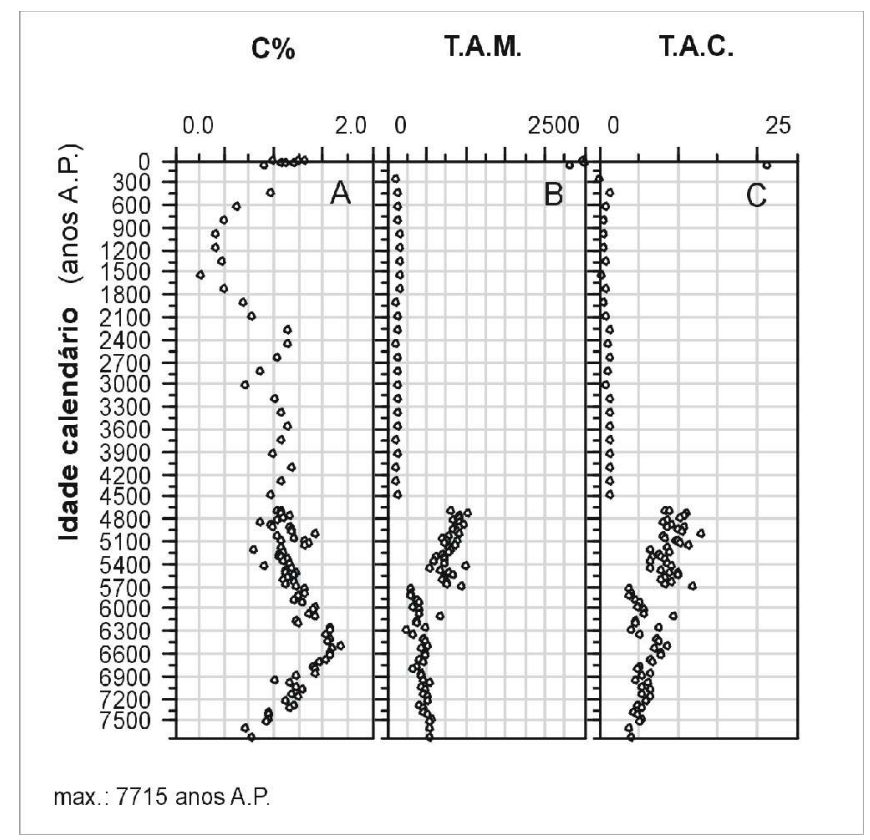

Figura 5- Conteúdo em Carbono (\%C), taxa de acumulação de massa (T.A.M) e taxa de acumulação de matéria orgânica expressas em $\left(\mathrm{g} / \mathrm{m}^{2} / \mathrm{ano}\right)$ em função da idade ${ }^{14} \mathrm{C}$ do testemunho UBA1.

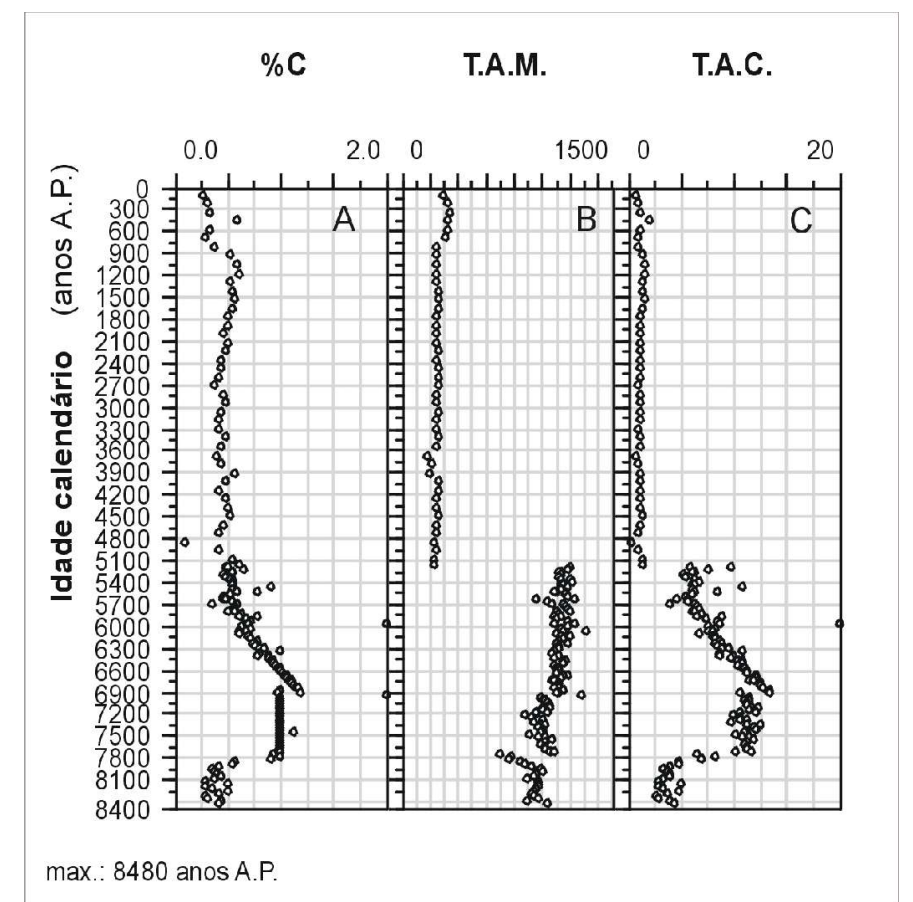

Figura 6- Conteúdo em Carbono (\%C), taxa de acumulação de massa (T.A.M) e taxa de acumulação de carbono expressas em ( $\mathrm{g} / \mathrm{m}^{2} / \mathrm{ano}$ ) em função da idade ${ }^{14} \mathrm{C}$ 


\section{DISCUSSÃO}

\subsection{Modelo de idades}

Os modelos de idade, gerados para os testemunhos UBA1 e UBA3, são muito semelhantes. No geral, apresentaram boa correlação de idades, garantindo confiabilidade nas datações, dentro de uma faixa de erro que não compromete os resultados da pesquisa. Porém, comparando todos os parâmetros analisados, que no geral, apresentam boa correlação entre os dois testemunhos, mostram padrões distintos próximo ao topo dos testemunhos, coincidentes com o trecho em que se observam discrepâncias entre as datações. Tais discrepâncias devem estar associadas a uma possível perda de parte do registro do topo do testemunho UBA3, devido aos erros pertinentes ao tipo de equipamento utilizado na coleta, bem como ao fato de não haver amostra datada próxima ao topo.

\subsection{Origem dos depósitos de areias junto à praia do Lázaro e ao Saco da Ribeira ao longo do Holoceno}

Na base do testemunho UBA3, no geral, o sedimento é bem selecionado, evidenciando que seu transporte deve ter sido realizado por um agente seletivo (Fig.12B). No entanto, por volta de 8.400 anos cal. A.P., ocorre deposição de areias grossas, e diminuição da tendência marinha nas características da matéria orgânica, quando comparada ao trecho seguinte (Fig.12C). Tais condições apontam para um ambiente de transição entre planície e praia. Por tanto, por volta de 8.400 anos cal. A.P., as características sedimentares de um ambiente de planície ainda faziam-se presentes. Entre aproximadamente 8.250-8.000 anos cal. A.P. foram registradas as maiores concentrações de oxigênio, e sedimentação exclusiva de areia muito fina, que podem ser decorrentes de estabilização do nível relativo do mar em um ambiente subaéreo, onde os sedimentos foram predominantemente transportados pelo mar, provavelmente backshore de uma praia. Segundo Klein (2005), houve registro de estabilização do nível do mar, na região de Caraguatatuba, por volta de 8.000 anos A.P., onde o mar situava-se a $13 \mathrm{~m}$, com base em datações feitas em beach rocks. 
A base do testemunho UBA1 é um pouco mais recente (7.700 anos cal. A.P.), apresentando características sedimentares e da matéria orgânica que refletem um nível do mar um pouco mais alto do que na base do testemunho UBA3. Segundo Mahiques \& Souza (1999), depósitos sedimentares, da Enseada do Flamengo, com idade de $\sim 7.500$ anos A.P., foram considerados como indicadores de uma paleopraia.

A seqüência granulométrica inicial granodecrêscente ascendente, da base dos testemunhos, estende-se até $\sim 5.000$ anos cal. A.P., ou seja, reflete sedimentação retrogradacional até um pouco depois do máximo transgressivo de 5.100 anos ${ }^{14} \mathrm{C}$ A.P. Dentro dos depósitos dominados por sedimentos pelíticos, observam-se, no testemunho UBA1, aportes de areia, sendo que o mais expressivo ocorre por volta de 5.200 anos cal. A.P. Estes trechos arenosos podem estar associados a variações climáticas regionais, que promovem períodos de chuvas torrenciais, intensificando a deposição de sedimentos mais grossos, devido ao aumento do aporte sedimentar continental, ou ainda, por correntes marinhas mais efetivas.

No registro sedimentar adjacente à praia do Lázaro (UBA3) a sedimentação é mais homogênea e os sedimentos relativamente mais finos, os grãos mais grossos ocorrem em poucos trechos, em porcentagens menores que $5 \%$. Estas características podem indicar um ambiente de energia mais baixa do que no Saco da Ribeira.

Os depósitos com granocrescência ascendente iniciam-se por volta de 5.000 anos cal. AP e extendem-se até aproximadamente 2.000 anos cal. A.P. (Figs.11 e 13), refletindo uma progradação gradual, provavelmente associada à descida relativa do nível do mar.

A partir de 2.000 anos cal. A.P. ocorre mudança no padrão de sedimentação (Fig.11). Esta mudança é bem marcada no testemunho UBA1 por um contato brusco, provavelmente erosivo, observado na Fig. 10 (prof. $34 \mathrm{~cm}$ ), com idade de $\sim 2.000$ anos cal. A.P., onde os sedimentos tornam-se mais grossos. Estas areias mais grossas e menos selecionadas também poderiam ser resultantes de transporte por sistema torrencial, durante um período de chuvas 
mais intensas, como foi proposto em 5.200 anos cal. A.P. Observa-se que a quantidade de areia muito fina diminui de $50 \%$ em 2.000 anos cal A.P. para $\sim 15 \%$ entre 1.500-900 anos A.P., dando lugar a sedimentos mais grossos, que chegam a 90\% em 1.500 anos AP, mostrando indícios de erosão. Para explicar esta situação, seria cabível assumir que ocorreu erosão e transporte das areias finas e sedimentos pelíticos para regiões mais profundas, associados a um período de hidrodinâmica mais intensa, e ou chuvas torrenciais, que causariam mudanças no registro sedimentar. Porém, variações no clima e na hidrodinâmica regional seriam suficientes, apenas, para explicar parte das características de tais depósitos.

Semelhantes mudanças de padrão também são observadas no testemunho UBA3, de uma forma mais gradual. Os sedimentos tornam-se mais grossos e bem selecionados, a partir de 2.000 anos cal. A.P. até $\sim 600$ anos cal. A.P. (Figs. 11 e 13), afastando a hipótese exclusiva de aumento na intensidade das chuvas e no aporte continental de sedimentos, pois esta situação, além de trazer sedimentos mal selecionados, aumentaria a taxa de sedimentação, fatos estes, que não são observados. Cabe ainda ressaltar, que o aporte sedimentar continental atual tende a ser mais eficiente na Enseada da Fortaleza do que na Enseada do Flamengo, devido às diferenças de extensões das bacias de drenagem que deságuam em cada uma das enseadas, bem como de seus fluxos (Mahiques, 1992). Observa-se que a quantidade de sedimentos mais grossos depositados junto à praia do Lázaro a partir de 2.000 anos cal. A.P. até séculos próximos dos dias atuais, foi menor do que no Saco da Ribeira, contrariando o padrão da dinâmica atual, no que diz respeito à eficiência do aporte sedimentar continental pela rede de drenagem.

A hipótese mais adequada para explicar tais mudanças no registro sedimentar, para o período, seria assumir que o nível do mar desceu, provavelmente, até um nível mais baixo do que o atual, a partir de 2.000 anos cal. A.P., associado a variações no clima e na hidrodinâmica da região de Ubatuba. Padrão semelhante já foi descrito para a costa brasileira, como mostra a curva de variação do nível relativo do mar, proposta para o Rio Grande do Sul, por Villwock \& Tomazelli (1989), onde o nível relativo do mar esteve $-1,5 \mathrm{~m}$ abaixo do atual, por volta de 1.500.A.P., e encontra-se em ascensão desde 1.000 anos A.P. A partir da 
interpretação de linhas sísmicas, Mahiques \& Souza (1999), reconheceram, na enseada do Flamengo, depósitos sedimentares com correspondência no Rio Grande do Sul. É provável que em 1.000 anos A.P. o nível relativo do mar já estaria em ascensão. Assim, seguiu-se um período de transgressão marinha até os dias atuais, com depósitos sedimentares de granodecrescência ascendente (Figs. 11 e 13).

A variação na quantidade de areia fina e muito fina nos trechos onde há aumento no tamanho dos grãos, se comporta de forma variada ao longo do testemunho UBA1. A variação da quantidade de areia fina e muito fina próximo ao topo do testemunho UBA1 é diferente do trecho próximo à base (Fig.11D). Na seqüência arenosa da base os valores de areia fina e muito fina diminuem na medida em que ocorre a deposição de sedimentos mais grossos. Por outro lado, na seqüência próxima ao topo, observa-se uma diminuição considerável nas quantidades de areia fina e muito fina quando ocorre aumento das frações granulométricas mais grossas. Este comportamento pode indicar mudanças na hidrodinâmica da região ao longo do Holoceno, que podem estar associadas às variações climáticas globais. 


\subsection{Relações entre T.A.C., T.A.M. e conteúdo em carbono ( $\left.C_{\text {org }}\right)$, com variações climáticas e flutuações relativas do nível do mar.}

O conteúdo em $\mathrm{C}_{\text {org }}$ é inversamente proporcional à T.A.M. ao longo da maior parte dos testemunhos. No testemunho UBA1 esta relação de proporcionalidade se destaca entre 7.700 anos cal. A.P. até 4.750 anos cal. A.P. (Fig.17A,B) e no testemunho UBA3 entre 7.000 e 5.000 anos cal. A.P. (Fig.18A,B). Portanto, observa-se que a mesma relação entre conteúdo em $C_{\text {org }}$ e T.A.M. ocorre em intervalos muito próximos nos dois testemunhos. O aumento da T.A.M. parece influenciar na diminuição no conteúdo em $\mathrm{C}_{\text {org }}$ nos trechos acima citados. Segundo Sampei et al. (1997), o conteúdo em $C_{\text {org }}$ é inversamente proporcional à T.A.M, devido à diluição clástica, que ocorre dentro de uma determinada faixa de valores da taxa de sedimentação. Por outro lado, a T.A.M. não deve ser o único fator controlador do conteúdo em $\mathrm{C}_{\text {org. }}$, pois este varia em períodos onde os valores de T.A.M. são praticamente constantes.

Fatores como variação do nível relativo do mar, taxa de produtividade e degradação influenciam a natureza da matéria orgânica preservada. O conteúdo em $C_{\text {org }}$ parece apresentar relação com o tipo de matéria orgânica sedimentar preservada. Junto à praia do Lázaro e ao Saco da Ribeira o registro das maiores quantidades do conteúdo em $\mathrm{C}_{\text {org }}$ encontram-se relacionados com matéria orgânica com tendência à natureza relativamente mais marinha, sedimentação pelítica e, altos valores de T.A.M. e T.A.C. Já a diminuição do conteúdo em Corg encontra-se associada à matéria orgânica de origem continental e à sedimentação arenosa.

Observa-se nos dois testemunhos que, no geral, os valores de T.A.M. e T.A.C. são diretamente proporcionais e relativamente altos da base até $\sim 5.000$ anos cal. A.P. No testemunho UBA3 os maiores valores de T.A.M. e T.A.C. ocorrem entre 7.000 e 5.000 anos cal. A.P. (Fig.18B,C). No testemunho UBA1 o comportamento de T.A.M. e T.A.C. é semelhante para o mesmo período. Este comportamento pode ser resposta às variações climáticas globais. Segundo trabalhos já citados, o Holoceno médio foi globalmente um período mais quente, no caso da região estudada, acumulou maior quantidade de carbono, cuja 
natureza é variável, ou seja, dependente de outros fatores, como variações regionais no clima e na hidrodinâmica.

Próximo ao topo do testemunho UBA1 foram registrados valores relativamente mais altos de T.A.C., T.A.M. e conteúdo de $\mathrm{C}_{\text {org, }}$ que devem estar associados às variações climáticas atuais.

A taxa de acumulação de carbono T.A.C. apresentou relação direta com a transgressão marinha com máximo em 5100 anos ${ }^{14} \mathrm{C}$ AP. Foi observado nos dois testemunhos que o aumento da T.A.C. coincidiu com o período de subida relativa do nível do mar (Figs.17C e18C). Os maiores valores de T.A.M. também coincidiram com o período transgressivo acima citado, porém a natureza da matéria orgânica, para o período não é tipicamente marinha.

\subsection{Natureza da matéria orgânica}

Junto à praia do Lázaro e ao Saco da Ribeira destacam-se 3 episódios onde a matéria orgânica apresentou maior tendência às características continentais. Estes episódios ocorreram em épocas muito semelhantes nos dois testemunhos, como mostram as Figs.14F,G e 15F,G: por volta de 7.400 anos A.P., próximo ao máximo transgressivo em 5.100 anos A.P., e novamente entre $\sim 1.500$ e 1.200 anos A.P. No caso da base dos testemunhos o nível do mar estaria mais baixo que o atual, promovendo maior tendência à acumulação de matéria orgânica de origem continental, principalmente no testemunho UBA3, cuja base situa-se em aproximadamente 8.400 anos cal. A.P. (Fig.15G). No caso do trecho próximo ao máximo transgressivo, o responsável pelo acúmulo de matéria orgânica com maior tendência continental deve estar relacionado ao aumento do aporte continental, decorrente de um período de chuvas torrencias, causado por variações climáticas regionais. Os resultados das análises granulométricas (deposição de areias em meio a sedimentos pelíticos) (Figs. 11 e 13), conteúdo em carbonato de cálcio (valores inferiores a 30\%) (Figs. 14A e 15A), e altos valores de T.A.M. e T.A.C (Figs. 17B,C e18B,C) corroboram com esta afirmação. Cabe ressaltar que, no intervalo acima citado, a T.A.C. é inversamente proporcional ao conteúdo em $\mathrm{C}_{\text {org. }}$, podendo ter ocorrido contribuição da diluição clástica, resultante dos mais altos valores das taxas de sedimentação. Por fim, os valores máximos de matéria 
orgânica de origem continental, entre $~ 1.500-1.200$ anos cal. A.P., não devem estar associados apenas a um aumento no aporte continental, devem ter sido influenciados pela descida do nível relativo do mar, porque, apesar do aumento na granulometria dos sedimentos (Figs.11 e 13), não houve registro de aumento na taxa de sedimentação. Entre aproximadamente 1.800-1.000 anos cal. A.P., as quantidades argila e carbonato diminuem no UBA3 (Figs.13F e 15A), e no UBA1, (Figs.11F e 14A), situação semelhante foi registrada quando o nível relativo do mar estava abaixo do atual, num período próximo a 8.000 anos cal. A.P, no UBA3. Por tanto, os dados referentes à natureza da matéria orgânica, corroboram com a hipótese de oscilação negativa do nível relativo do mar, entre 2.000 anos cal. A.P até pelo menos, 1.200 anos cal. A.P.

\subsection{Produtividade e decomposição}

A taxa de produtividade aquática pode ser incrementada por diversos fatores: mudanças climáticas, hidrodinâmica, flutuações no nível do mar, etc. $A$ degradação da matéria orgânica também se dá de diversas formas e intensidades, podendo comprometer o registro da matéria orgânica inicialmente produzida. As diferentes formas de degradação são discutidas em trabalhos como Meyers (1993, 1997), Stein (1991), Canfield (1989), Calvert e Pederson (1992), entre outros.

Para falar claramente da taxa de produtividade e preservação da matéria orgânica na região de Ubatuba, seria necessária a compreensão do ciclo da matéria orgânica do ecossistema costeiro, o que segundo Mahiques (1992) só será possível após realização de muitos estudos sobre o tema.

Neste trabalho é abordada uma hipótese sobre produtividade $\mathrm{e}$

preservação, baseada principalmente na intensidade com que fatores como variação climática, concentrações de oxigênio ao longo da coluna d'água, flutuações do nível do mar e taxas de sedimentação poderiam interferir na natureza da matéria orgânica sedimentar.

Em aproximadamente 900 anos cal. foi registrado, junto à praia do Lázaro, um evento que tornou, águas anteriormente oxigenadas, em um ambiente redutor, coincidente com registro de matéria orgânica de origem marinha, em meio a 
matéria orgânica com maior tendência continental (Fig.15 E,G). Esta situação, em princípio, parece contraditória, pois tal ambiente estaria associado a um período de mar mais baixo que o atual, e, no geral, bem oxigenado. A rigor condições anóxicas podem se desenvolver quando a coluna d'água encontra-se marcadamente estratificada, ou quando ocorrem períodos de elevada taxa de produção primária, assim o oxigênio dissolvido consumido na manutenção da vida não é reequilibrado (Meyers, 1997). Segundo o autor supracitado, condições marinhas típicas apresentam boa oxigenação, já que a maioria das águas se mistura rapidamente para repor os níveis de oxigênio dissolvido consumido.

Uma hipótese para explicar as condições anóxicas registradas por volta de 900 anos cal. A.P., durante um evento com energia suficiente para promover erosão de areia muito fina, como é mostrado na Fig. 11D, é assumir que em um momento anterior a 900 anos cal. A.P., houve altas taxas de produtividade seguida de intensa degradação da matéria orgânica inicialmente produzida, capaz de consumir o oxigênio dissolvido nas águas, mesmo que fossem bem oxigenadas. Calvert e Pederson (1992) postularam que o fluxo crescente de matéria orgânica que acompanham altas taxas de produtividade pode contribuir para a produção de sedimentos ricos em carbono orgânico em colunas de águas oxigenadas, sobrecarregando a capacidade oxidativa do meio, ou seja, matéria orgânica inicialmente produzida é sacrificada para garantir a preservação da matéria orgânica subseqüentemente depositada. O resultado seria o registro de um ambiente anóxico no momento posterior, onde a matéria orgânica poderia apresentar características marinhas, já que segundo Meyers (1984), estudos no lago Michigan mostram perdas proporcionalmente maiores no conteúdo fitoplanctônico do que em plantas terrestres, em ambientes oxidantes.

Cabe ainda ressaltar, que condições aparentemente anóxicas, com baixas razões $\mathrm{C} / \mathrm{S}$, como é o caso do trecho entre $\sim 1.500-800$ anos cal. A.P., no testemunho UBA 1, podem ser resultado de porcentagens de carbono muito baixas, mesmo em ambiente oxigenado. No mesmo período, no testemunho UBA3, ocorrem altas razões C/S indicando ambiente oxidante. 


\section{CONCLUSÕES}

Foram detectadas importantesmudanças relevantes nas taxas de acumulação de carbono e de massa, na região estudada, ao longo do Holoceno. Tais mudanças foram atribuídas às variações climáticas globais, visto que foram observadas num mesmo período em enseadas que apresentaram distinções relevantes, no regime hidrodinâmico, ao longo do Holoceno. Os maiores valores de T.A.C. e T.A.M. foram considerados como decorrentes de um clima mais quente registrado nas enseadas do Flamengo e da Fortaleza entre aproximadamente 7.800-5.000 anos cal. A.P., este período não está muito distante do que é conhecido na literatura como "Ótimo Holocênico". Na região estudada o aumento no regime de chuvas controla o aumento na taxa de sedimentação de terrígenos, causando aumento nas taxas de acumulação de massa, principalmente em períodos quentes e de mar alto. Portanto, o clima, na região de Ubatuba, foi distinto entre, desde pelo menos 8.400 até 5.000 anos cal. A.P., e após 5.000 anos cal. A.P. até décadas próximas à atual.

Nas últimas décadas, houve registro de aumento relevante no conteúdo em carbono, T.A.M., T.A.C. e nas taxas de sedimentação, com valores ainda mais altos do que os detectados durante o Holoceno médio, fatos que podem indicar um novo período de aquecimento global.

No presente trabalho, foi detectada uma oscilação negativa do nível relativo do mar, que ainda não havia sido descrita para a região. As mudanças nas características dos sedimentos, bem como, na matéria orgânica, que ocorreram a partir de 2.000 anos al. A.P., foram consideradas como decorrentes de descida no nível relativo do mar, provavelmente para um posição abaixo da atual.

O significado dado ao aporte de areias mais grossas nas enseadas, ao longo do Holoceno, foram decisivos na interpretação dos paleoambientes. Ao longo das colunas sedimentares, a deposição de areias mais grossas ocorreu em ambientes distintos. As areias mais grossas depositadas por volta de 8.400 anos cal. A.P., estão associadas aos sedimentos da paleoplanície, que ainda estaria influenciando a sedimentação local. Os aportes de sedimentos grossos em 
ambiente de mar alto, por volta de 5.100 anos A.P., foram atribuídos às chuvas torrenciais, decorrentes de variações climáticas regionais. A deposição de areias grossas e grânulos, associada à erosão de areia muito fina, no Saco da Ribeira, a partir de aproximadamente 2.000 anos cal. A.P., foram relacionadas à descida do nível relativo do mar, para um nível mais baixo que o atual. É bem provável, que passagens mais intensas ou mais frequentes de sistemas frontais na região ocorreram durante o intervalo anteriormente citado, influenciando a textura dos sedimentos, pois depósitos de sedimentos mais grossos são observados de forma mais expressiva na Enseada do Flamengo do que na Enseada da Fortaleza, onde, junto à praia do Lázaro, os termos mais grossos também ocorreram, porém em porcentagens muito baixas e a energia dos fenômenos climáticos não foi suficiente para remobilizar as areias muito finas depositadas no paleoambiente, como foi observado no saco da Ribeira.

Quanto à produtividade, com base na natureza e na quantidade de matéria orgânica preservada, associadas ao clima mais quente do Holoceno médio, podese inferir que entre $\sim 7.800-6.600$ anos cal. A.P. deve ter ocorrido um período com altas taxas de produtividade marinha.

Foi detectado um evento de anoxia e preservação de matéria orgânica de origem marinha em 900 anos cal. A.P., durante um período de regressão marinha, acompanhada de baixas taxas de sedimentação. Fato atribuído à ocorrência de altas taxas de produtividade, em um período anterior, inferidas a partir dos maiores valores da razão C/S e ligeiro aumento nas quantidades de carbonato, observados nos dois testemunhos, porém, em intensidades distintas. O oxigênio das águas teria sido consumido a ponto de torná-las mais anóxicas, contribuindo para a preservação da matéria orgânica marinha posteriormente depositada.

As menores porcentagens em conteúdo de carbono são atribuídas, principalmente, às variações negativas do nível relativo do mar, registradas, entre 8400-7800 anos cal. A.P. e em períodos entre $1.400-600$ anos cal. A.P.

No caso de Ubatuba as chuvas de caráter torrencial, que ocorrem durante a passagem de frentes frias, trazem muitas folhas e galhos para o mar, aumentando $o$ aporte de matéria orgânica de origem continental. Desta forma, a natureza da matéria 
orgânica na região estudada, é reflexo das flutuações do nível relativo do mar, asssociada à intensidade com que as variações locais do clima, hidrodinâmica, entre outras, atuam sobre a área. Períodos com altas taxas de produtividade podem não ser devidamente registrados devido à degradação preferencial da matéria orgânica planctônica, principalmente quando ocorre o aumento do aporte de matéria orgânica continental.

Não foram observados nos testemunhos, dados relevantes, que pudessem evidenciar que a Enseada do Flamengo e a Enseada da Fortaleza, tiveram uma ligação por volta de 5.000 anos A.P, através da praia do Lázaro e do Saco da Ribeira.

Em suma, na região estudada os resultados referentes ao conteúdo de carbono e suas taxas de acumulação, guardou registros das variações climáticas globais, de altas taxas de produtividade entre 7.800-6.600 anos cal. A.P., registradas principalmente na enseada do Fortaleza. As características sedimentares registradas ao longo do Holoceno, refletiram, principalmente, variações do nível relativo do mar, além de variações do regime hidrodinâmico local, impressas principalmente nos sedimentos do Saco da Ribeira, no que diz respeito à atuação dos sistemas frontais e chuvas torrencias em épocas de oscilação positivas do nível relativo do mar por volta de 5.100 anos A.P. e de oscilações negativas, a partir de $\sim 2.000$ anos cal. A.P. 


\section{REFERÊNCIAS BIBLIOGRÁFICAS}

Ab' Saber, A.N. 1956. Eat actuel dês connaissances sur les niveaux d'erosion et les surfaces d'aplanissement du Brésil. In: Congress International de Geographie, 18, Rio de janeiro.

Ab' Saber, A.N. 1955. Contribuição à geomorfologia do litoral paulista. Revista Brasileira de Geografia, 17(1): 3-48.

Ab'Saber, A.N. \& Bernardes, N. 1958. Vale do Paraíba, Serra da Mantiqueira e arredores de São Paulo. In: Congresso Internacional de Geografia, 18, Rio de Janeiro, 1958. Guia de Excursões, Rio de Janeiro, (4): 1-303.

Almeida, F.F.M. 1967. Origem e evolução da plataforma brasileira. DGM/-DNPM, Rio de Janeiro. p. 1-36 (Boletim 241).

Almeida, F.F.M. 1964. Fundamentos geológicos do relevo paulista. Bol. Inst. Geogr.Geol., São Paulo, (41): 169-263

Almeida, A.P. 1947. O litoral Norte. Revista Arquivo Municipal, São Paulo, (112): 3540.

Almeida, F.F.M. de \& Carneiro, C.D.R. 1998. Origem e evolução da Serra do Mar. Revista Brasileira de Geociências, 28 (2): 135-150.

Angulo , R.J. 1993. Indicadores biológicos de paleoníveis marinhos quaternários na costa paranaense. Bol. paranaense de Geoc. 41, 1-34.

Angulo, R.J.\& Lessa, G.C. 1997. The Brazilian sea-level curves: a critical review with emphasis on the curves on Paranaguá and Cananéia regions. Marine Geology.140: 141-166.

Angulo, R.J. \& Giannini, P.C.F. 1996. Variações do nível relativo do mar nos últimos 2.000 anos na Região sul do Brasil: uma discussão. Bol. Paranaense de geociências , 44: 67-76.

Angulo, R.J.; Giannini, P.C.F; Suguio, K.;Pessenda, L.C.R. 1999. Relative sea -level changes in the last 5500 years in southestern Brazil (Laguna Imbituba region, Santa Catarina State) based onvermitids ${ }^{14} \mathrm{C}$ ages). Marine Geology 159:323-339.

Bittencourt, A.C.S.P.; L. Martin; G.S., Vilas-boas \& G.S., Flexor 1979. Quaternary marine formation of state of Bahia, Brazil. Proceedings,1978. In: Int. Symp. On Coastal Evolution in the Quaternary, São Paulo. P. 232-253.

Bistrich, C.A.; Carneiro, C.D.R.; Dantas, A.S.L.; Ponçano W.L.; Campanha,G.A.C.; Nagata, N.; Almeida, M.A.; Stein, D.P.; Melo, M.S.; Cremonini, A.C. 1981. Mapa Geológico do estado de São Paulo, 1:500.000. São Paulo, IPT. V.2. (Monografias IPT, 6).

Bosence, D.W.J. \& Wilson, R.C.L. 2002..Carbonate depositional systems. In: The geological Record of environmental Change, (11): 102-233 p.

Browman, S. 1990. Radiocarbonconcentration effects. In: Radion Carbon Dating. $\mathrm{Br}$ Murs. Plubl. (pp):16-30.

Burney,D.A. 1993. Late Holocene environmental changes in arid southstern madagascar. Quaternary. Res.,40: 98-106. 
Calvert, S.E. \& Pederson, T. 1992. Organic carbon accumulation and preservation in marine sediments: How important is anoxia? In Productivity, Acumulation and Preservation of Organic Matter inrecent and ancient sediments, eds. J. Whelan and J.W. Farrington, pp. 231-263. Columbia University Press, New York.

Campanha, G.A.C. \& ENS, H.H. 1996. Estruturação geológica da Serra do Juqueriquerê, São Sebastião, SP.Bol. IG-USP, Série Científica, 27: 41-49.

Campanha, G.A.C.; ENS, H.H.; Ponçano, W.L. 1994. Análise química do Planalto do Juqueriquerê, São Sebastião. Revista Brasileira de Geociências, 24(1): 32-42.

Campos Neto, M.C. \& Figueiredo O, M.C.H. 1995. The Rio Doce Orogeny, Southeastern Brazil. Journal of South American Earth Sciences. Pergamon Press, 8(2): 143-162.

Canfield, D. 1989. Sulfate reduction and oxic respiration in marine sediments: Implications for organic matter preservation in euxinic environments. Dee-Sea Research, 36:121-138.Coleman, D.C. and Fry, B. 1991. Carbon Isotopes Tecnics. San Diego, Califórnia. Academic Press, Inc. 274p.

Corrêa, I.C.S. 1990. Lês variation du niveau de la mer durant les deniers 17.500 ans BP: I'exemple de la plateforme continentale du Rio Grande do Sul-brésil. Marine Geology, 130:163-178.

Coutinho, J.M.V.; ENS, H.H.; Rodrigues, E.P. 1992. Petrography and field features of precambrian and mesozoic mafic dykes in southeastern Brazil. In: International Geologic Congress. 29. Kyoto, Japan. p.567.

Coutinho, J.M.V.; ENS, H.H.; Rodrigues, E.P.; Tassinari, C.C.G. 1991. Mafic dyke swarms in the northern coast of São Paulo, Brazil (a preliminary report). In: International Symposium of Mafic Dykes. São Paulo, 1991. Extended Abstracts, São Paulo, SBGq/Soc.Geol. Portugal p. 111-115.

CPRM - Serviço Geológico do Brasil 1999. Projeto Integração Geológico Metalogenética, Folha Rio de Janeiro - Carta Geológica Santos (SF.23-Y-D), Escala 1:250.000.

Deffontaines, P. 1935. Regiões e paisagens do Estado de São P. Geografia, S. Paulo, 1(20): 39-53.

Dias Neto, C.M. 2001. Evolução tectono-termal do Complexo Costeiro (Faixa de Dobramentos Ribeira em São Paulo. Instituto de Geociências, Universidade Estadual Paulista, São Paulo, 160p.

Florençano, P.C. \& França, A. 1951. Paisagens do litoral norte de São Paulo. Bol. Paul. Geogr., (7):64-73.

Folland,C.K,Karl,T.R.,;Vinnikov,K.Y. 1990. Observed climate variations and change. In: Houghton, J.T;Jenkins, G.J.;Ephraunms, J.J., Climate Change: The IPPC Assesment. Cambridge. Univ. Press, Cambridge, pp. 195-238.

Furtado, V.V.; Mahiques, M.M. 1990. Distribuição de sedimentos em regiões costeiras e plataforma continental norte do Estado de São Paulo. In: Simpósio de Ecossistemas da Costa Sul e Sudeste Brasileira: estrutura, função e manejo, 2. 
Águas de Lindóia, Academia de Geociências do Estado de São Paulo. Publicação ACIESP, 71-I: 20-29.

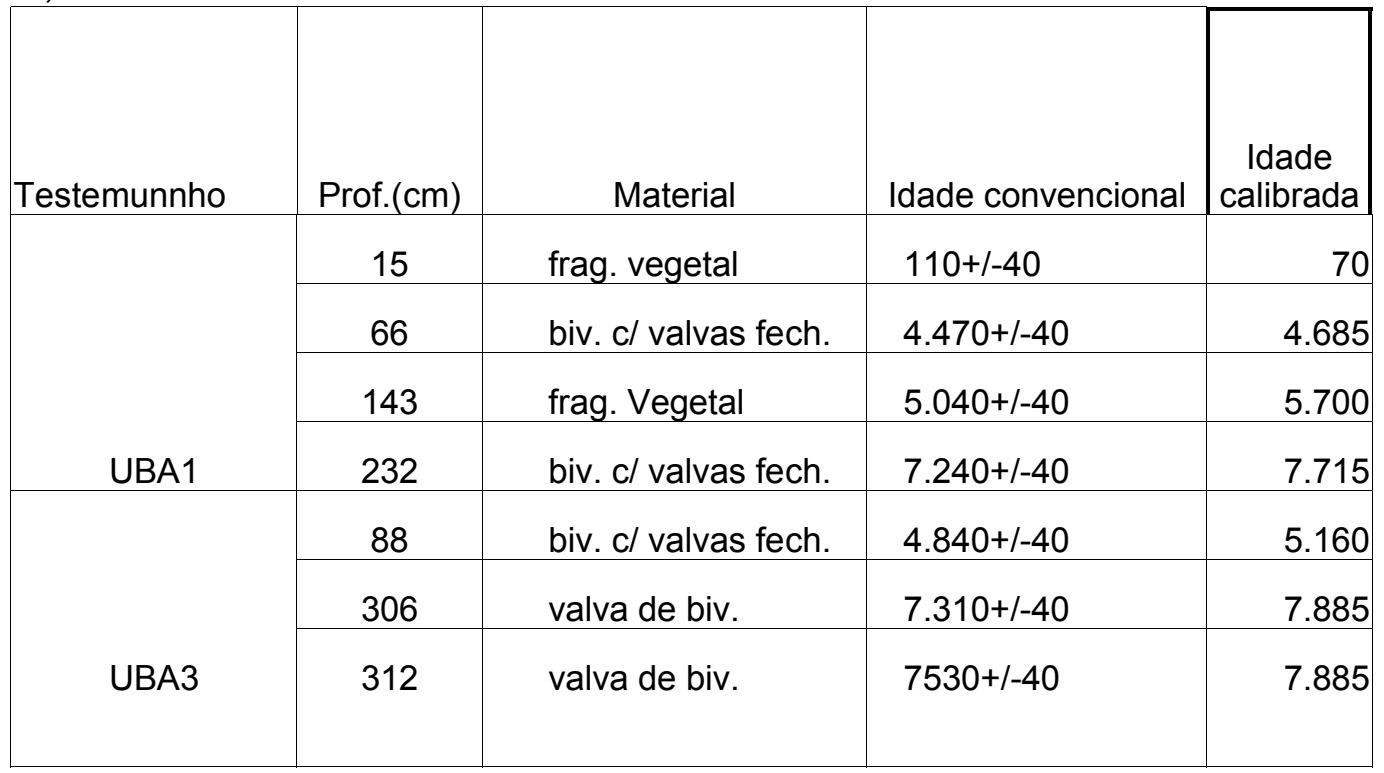

Gallagher, Hawkesworth, C.H.; Matovani, M.S.M. 1994. The denudation history of the onshore continental margin of the SE Brazil infered from apatite fission track data. Journal of Geophisical Research, 99, n. B9, p.18, 117-18, 145.

Garda, G.M.; Schorcher, H.D. 1994. Os diques máficos e ultramáficos da região costeira entre as cidades de São Sebastião e Ubatuba, São PauloSP.In:Congresso Brasileiro de Geologia, 38, 1994. Boletim de resumos... Camboriú, SBG, v. 3, p. 62-63.

Goodness,C.M.;Palutikof, J.P., Davies, T.D. 1992. The Nature and causes of Climate Changes. Lewis Publishers, 248 pp.

Hasui, Y.; Oliveira, M.A.D. 1984. Província Mantiqueira - setor central. In: Almeida, F.F.M.; Hasui,Y. (eds). O Pré-Cambriano do Brasil. São Paulo, Ed. Edgard Blucher. $378 \mathrm{p}$.

Hayes, J.M. 1993. Factors controlling ${ }^{13} \mathrm{C}$ contents of sedimentary organic compounds: Principles and evidence. Marine Geology, (113):111-125.

Hedges,J.I.; Clark, W.A.; Cowie, G.L. 1988. Fluxes and reactivities of organic matter in coastal marine bay. Limnollogy an Oceanography, 33: 1137-1152.

Klein, D.A. 2005. Registros de variações ambientais no Canal de São Sebastião (Estado de São Paulo), durante o Último Ciclo Glacial. Thesis. University of São Paulo, 1-85.

Kowalski, E.A. \& Meyers. P.A. 1997. Glacial-interglacial variations in Quaternary production of marine organic matter at DSDP Site 594. Chathan Rise, southestern New Zealand margin. Marine Geology, (140):249-263.

Kowsmann, R.O. \& M.P.A. Costa, 1979. Sedimentação quaternária da margem continental brasileira e das áreas oceânicas adjacentes (relatório final). Rio de Janeiro, Série Projeto REMAC 8. Petrobrás, 55p. 
Kowsmann, R.O .\& M.P.A. Costa, 1974. Paleolinhas de costa na Plataforma Continental das regiões sul e norte brasileira. Revista Brasileira de Geociências, 4: 215-222.

Komar, P.D. 1976. The transport of cohesionless sediments on continental shelves. In: Stanley, D.J. \& Swift, D.J.P., eds Marine sediment transport and envoronmental management. New York, John Wiley. P. 107-125.

Lowe, J.L. \& M.J.L. Walker 1997. Reconstrg Quaternary Environments. Longman, Scientific \& technical.446p.

Macedo, J.M. 1991. Evolução tectônica da Bacia de Santos e áreas continentais adjacentes. In: Gabaglia, G.P.R.; Milani. E.J. Origem e evolução de bacias sedimentares. Rio de Janeiro, Petrobrás. p. 361-374.

Machado, R. \& Endo, I. 1993. A megaestrutura em flor positiva do vale do rio Paraíba do Sul no Rio de Janeiro e suas implicações tectônicas regionais. In:Simpósio de Geologia do Sudeste, 3., Rio de Janeiro. Atas. Rio de Janeiro SBS p. 208-213.

Machado Filho, M.; Ribeirom .W; Gonzalez ,S.R.;Schenini, C.A.; Santos Neto, A.;Palmeira, R.C.B.; Pires , J.L.;Teixeira,W.; Castro, H.E.F. 1983. Geologia. In: Projeto Radambrasil. Folhas SF. 23/24. Rio de Janeiro Nitória. MME, Rio de Janeiro.27-304. (Levantamento de recursos naturais v. 32).

Maffra, C.Q.T. 2000. Geologia estrutural do embasamento cristalino na região de São Sebastião,SP: evidência de um domínio transpressivo. Inst. de Geociências, Universidade de São Paulo, São Paulo, Dissertação de Mestrado, 113p.

Mahiques, M.M. 1998. Característica da Matéria Orgânica Sedimentar da Plataforma Continental Interna e Média Entre a Baía de Guanabara (RJ) e São Francisco do Sul (SC). Inst. de Oceanografia, Universidade de São Paulo, São Paulo. Tese de Livre Docência.

Mahiques, M.M. 1992. Variações temporais na sedimentação quaternária dos embaiamentos da região de Ubatuba, Estado de São Paulo. Tese de doutorado, Universidade de São Paulo, Instituto Oceanográfico. 2v.

Mahiques, M. M. 1989. origin and evolution of isolated depressions on the coastal region of São paulo and Rio de Janeiro States. In: International Symposium on Global Changes I South America During the Quaternary: past, present and Future. Associação Brasileira de Estudo do Quaternário, São Paulo, 1:55p.

Mahiques, M.M.\& Souza, L.A.P. 1999. Shallow sismic reflectors and upper Quaternary sea level changes in Ubatuba region, South-eastern Brazil. Revista Brasileira de Oceanografia. 47(1):1-10.

Mahiques, M.M., Mishima, Y., Rodrigues, M. 1999. Characteristics of the sedimentary organic matter on the inner and middle continental shelf between Guanabara Bay and São Francisco do Sul, southeastern Brasilian Margin. Continental Shelf Research, 19 (1999) 775-798.

Mangliocca, A. \& Kutner, A.S. 1965. Sedimentos de fundo da Enseada do Flamengo. Contrções Avs Inst. Oceanográfico Universidade de São Paulo, série Oceanografia física, (8): 1-15. 
Meyers, P.A. 1997. Organic geochemical proxies of paleoceanographic,. paleolimnologic, and paleoclimatic processes. Org. Geochem. Vol. 27. No. 5/6. pp. 213-250.

Meyers, P.A. 1994. Preservation of elemental and isotopic sourse identification of sedimentary organic matter. Chemical Geology, (144):289-302.

Meyers, P.A. \& Eadie, B.J. 1993. Sourses, degradation, and resisthensis of the organic matter on sinking particles in lake Michigan. Organic Geochemistry, 20:4756.

Meyers, P.A. Leenheer, M.J.; Eadie, B.J. and Maule, S.J., 1984. Organic Geochemistry of suspended and settling particulate matter in Lake Michigan. Geochimica et Cosmochimica Acta, (48): 443-452.

Moraes Rego, L.F. 1932. Notas sobre a geomorfologia de São Paulo e sua gênesis. Instituto Astronomico e Geographico de São Paulo, 28p.

Mörner, N. 1980. Eustasy and geoid changes as a function of core/mantle changes.p. 535. In: Mörner, N. (Ed.) Earth Rheology, Isostasy and Eustasy. John Wiley \& Sons, $559 \mathrm{p}$.

Paropkari, A.L. ;Prakashi, C.B.;Mascarenhas, A. 1992. A critical evaluation of deposisional parameters controlling the variability of organic carbon in Arabian Sea sediments. Marine Geology, 107:213-226.

Pedersen, T.F.;Calvert, S.E. 1990. Anoxia versus productivity: What controls the formation of organic carbon rich sediments and sedimentary rocks?. Am. Assoc. Pet. Geol. Bull, 74:454-466.

Pereira, M.J. 1992. Considerações sobre a estratigrafia do Cenomaniano-Santoniano em algumas bacias continentais brasileiras e sua implicação na história tectônica e sedimentar da margem continental. Boletim de Geociências Petrobrás, v. 6, n. 3/4, p.171-176.

Ponçano, W.L. 1985. Sedimentação atual aplicada a portos no Brasil. Tese de doutorado. Universidade de São Paulo, Instituto de Geociências. 278p.

Ricccomini.; Pelogia, J.C.L.; Saloni, M. W.K.; Figueira, R.M. 1989. Neotectonic activity in the Serra do Mar rift system (southern Brazil). J.S. am.Earth. Sci., 2(2): 191-197.

Ruellan, F. 1944. Aspectos geomorfológicos do litoral brasileiro no trecho compreendido entre santos e o Rio Doce. Bol. Assoc. Geogr. Brasil. São Paulo, (4): 6-12.

Sampei, Y., Matsumoto E., Tokuoka, T., Inoue, D. 1997. Changes in accumulation rate of organic carbon during the last 8.000 years in sediments of Nakaumi Lagoon, Japan. Marine Chemistry, 58(1997) 39-50.

Scheel-Ybert, R. 2000. Vegetation stability in Southeastern Brazilian coastal area from $5500-1400{ }^{14} \mathrm{C}$ yr BP deduced from caracol analysis. Review of Paleobotany and Palynology, 110: 11-138.

Stein, R. 1991. Accumulation of oorganic carbon in marine sediments. Results from the DSDP/ODP, berlin, Springer-Verlag. 217p. 
Stein, R.;Rullkötter, J.;Welte, D.H. 1986. Accumulation of organic rich carbon sediments in the late Jurassic and Cretaceaus atlantic ocean: A synthesis. Chemistry Geology, 56:1-32.

Suguio, K. 1996. Papel da Neotectônica na evolução do litoral brasileiro. In: SBG/Congresso Brasileiro de Geologia, 38, Salvador 1996. Resumos expandidos, (5):473-476.

Suguio, K. 1973. Introdução à sedimentologia. São Paulo, Edgard Bücher/EDUSP, $317 p$.

Suguio, K. \& Martin 1978. Quaternary marine formations of the states of São Paulo and Southern Rio de Janeiro. In: Symposium on Coastal Evolution in the Quaternary 1978, São Paulo. Spec. Publ. 1:1-55.

Suguio, K., Martin, L.1976. Brasilian coastline quaternary formations the state of São Paulo and Bahia litoral zone evolutive schemes. Anais Acad. Brás. Cien. 48 (Suppl.), 325-334.

Suguio, K., Martin; C.S.P. Bittencourt; J.M.L. Dominguez; J.M. Flexor; A.E.G. Azevedo. 1985. Flutuações do nível relativo do mar durante o Quaternário Superior ao longo do litoral brasileiro e suas implicações na sedimentação costeira. Revista Brasileira de Geociências, 15(4): 273-286.

Suguio, K.,Martin, L.,Dominguez, J.M.L., Bittencourt, A.C.S.P.,Flexor, J.M. 1984. Quaternary emergent and subemergent coasts =comparison of the Holocene sedimentation in Brazil and southeastem USA Proc.Brazil. Acad. Sci. (An. Acad. Brasil Cienc.) 56, 163-167.

Swift, D.J.P.;Stanley, D.J.; Curray, J.R. 1971. Relict sediments on continental shelves: a reconsideration. Journal Geology. 79: 322-346.

Teixeira, C. 1980. Estudo quantitativo da produção primária, clorolfila-a e parâmetros abióticos em relação à variação temporal (lat. $23^{\circ} 30^{\prime} \mathrm{S}$ - long. $45^{\circ} 06^{\prime} \mathrm{W}$ ). Tese de livre-docência. Universidade de São Paulo, Instituto Oceanográfico.243p.

Tessler, M.G. 1988. dinâmica sedimentar quaternária no litoral sul paulista. Tese de dotourado. Universidade de São Paulo, Instituto de Geociências. 276 p.

Tomazelli, L.J. 1990. Contribuição aos estudos dos sistemas deposicionais holocênicos do nordeste da província costeira do Rio grande do Sul, com ênfase no sistema eólico. Ph. D. Thesis, Universidade Federal do Rio Grande do Sul, 270 pp.

Wakeham, S.G.; Farrington, J.W.; Gagosian, R.B.; Lee, C.; de Baar, H.; Nigrelli, G.E.; Tripp, B.W.;Smith, S.O.; Frew, N.M. 1980. Organic matter fluxes from sediment traps in the equatorial Atlantic ocean. Nature , 286: 798-800.

Villwock, J.A. \& Tomazelli, L.J., 1989. Sea-level changes and Holocene evolution in Rio Grande do Sul coastal plain, Brazil. International Symposium on Global 
Changes in South America During the Quatemary: Past-Present-Future. Special Publication No. 1, INQUA, São Paulo, 192-196

Villwock, J. A. ;L. Z. Tomazelli; E.L. Loss; E.A. Dehnhardt; N.O. Horn; F.A. Bachi \& B.A. Dehnhardt. 1986. Geology of the Rio Grande do Sul Coastal Province. In: Rabassa, J. (ed) Quaternary of South America and Antartic Peninsula. A. 4:79-97.

Ybert, J.P.;Bissa, W.M.;Catharino, E.L.M.;Kutner,M. 2003. Environmental and sea level variation on the southeastern Brazilian coast on Late Holocene with comment on prehistoric human occupation. Palaleogeography, Palaeoclimatology, Palaeoecology, 189:11-24 

Tabela 1- Amostras datadas

Tabela 2- Idades radiocarbono convencionais (conv.) e calibradas (cal.)

\begin{tabular}{|c|c|c|c|c|}
\hline Prof. (cm) & UBA1 Idade cal. (A.P.) & UBA1 Idade conv.(A.P.) & UBA3 Idade conv.(A.P.) & UBA3 Idade cal.(A.P.) \\
\hline 1 & 10 & 15,7 & 111,26 & 118,6 \\
\hline 3 & 20 & 31,4 & 222,52 & 229,86 \\
\hline 5 & 30 & 47,1 & 333,78 & 348,46 \\
\hline 7 & 40 & 62,8 & 445,04 & 467,06 \\
\hline 9 & 50 & 78,5 & 556,3 & 585,66 \\
\hline 11 & 60 & 94,2 & 667,56 & 704,26 \\
\hline 13 & 70 & 110 & 778,82 & 822,86 \\
\hline 15 & 254,6 & 284,4 & 890,08 & 941,46 \\
\hline 17 & 439,2 & 458,8 & 1001,34 & 1060,06 \\
\hline 19 & 623,8 & 633,2 & 1112,6 & 1178,66 \\
\hline 21 & 808,4 & 807,6 & 1223,86 & 1297,26 \\
\hline 23 & 993 & 982 & 1335,12 & 1415,86 \\
\hline 25 & 1177,6 & 1156,4 & 1446,38 & 1534,46 \\
\hline 27 & 1362,2 & 1330,8 & 1557,64 & 1653,06 \\
\hline 29 & 1546,8 & 1505,2 & 1668,9 & 1771,66 \\
\hline 31 & 1731,4 & 1679,6 & 1780,16 & 1890,26 \\
\hline 33 & 1916 & 1854 & 1891,42 & 2008,86 \\
\hline 35 & 2100,6 & 2028,4 & 2002,68 & 2127,46 \\
\hline 37 & 2285,2 & 2202,8 & 2113,94 & 2246,06 \\
\hline 39 & 2469,8 & 2377,2 & 2225,2 & 2364,66 \\
\hline 41 & 2654,4 & 2551,6 & 2336,46 & 2483,26 \\
\hline
\end{tabular}


Tabela 2a- Idades radiocarbono convencionais (conv.) e calibradas (cal.) (continuação)

\begin{tabular}{|c|c|c|c|c|}
\hline Prof. (cm) & UBA1 Idade cal. (A.P.) & UBA1 Idade conv.(A.P.) & UBA3 Idade conv.(A.P.) & UBA3 Idade cal.(A.P.) \\
\hline 43 & 2839 & 2726 & 2447,72 & 2601,86 \\
\hline 45 & 3023,6 & 2900,4 & 2558,98 & 2720,46 \\
\hline 47 & 3208,2 & 3074,8 & 2670,24 & 2839,06 \\
\hline 49 & 3392,8 & 3249,2 & 2781,5 & 2957,66 \\
\hline 51 & 3577,4 & 3423,6 & 2892,76 & 3076,26 \\
\hline 53 & 3762 & 3598 & 3004,02 & 3194,86 \\
\hline 55 & 3946,6 & 3772,4 & 3115,28 & 3313,46 \\
\hline 57 & 4131,2 & 3946,8 & 3226,54 & 3432,06 \\
\hline 59 & 4315,8 & 4121,2 & 3337,8 & 3550,66 \\
\hline 61 & 4500,4 & 4295,6 & 3449,06 & 3669,26 \\
\hline 63 & 4685 & 4470 & 3560,32 & 3787,86 \\
\hline 65 & 4711,7 & 4485 & 3671,58 & 3906,46 \\
\hline 67 & 4738,4 & 4500 & 3782,84 & 4025,06 \\
\hline 69 & 4765,1 & 4515 & 3894,1 & 4143,66 \\
\hline 71 & 4791,8 & 4530 & 4005,36 & 4262,26 \\
\hline 73 & 4818,5 & 4545 & 4116,62 & 4380,86 \\
\hline 75 & 4845,2 & 4560 & 4227,88 & 4499,46 \\
\hline 77 & 4871,9 & 4575 & 4339,14 & 4618,06 \\
\hline 79 & 4898,6 & 4590 & 4450,4 & 4736,66 \\
\hline 81 & 4925,3 & 4605 & 4561,66 & 4855,26 \\
\hline 83 & 4952 & 4620 & 4672,92 & 4973,86 \\
\hline 85 & 4978,7 & 4635 & 4784,18 & 5092,46 \\
\hline 87 & 5005,4 & 4650 & 4840 & 5160 \\
\hline 89 & 5032,1 & 4665 & 4862,87 & 5184,18 \\
\hline 91 & 5058,8 & 4680 & 4885,74 & 5208,44 \\
\hline 93 & 5085,5 & 4695 & 4908,61 & 5232,7 \\
\hline 95 & 5112,2 & 4710 & 4931,48 & 5256,96 \\
\hline 97 & 5138,9 & 4725 & 4954,35 & 5281,22 \\
\hline 99 & 5165,6 & 4740 & 4977,22 & 5305,48 \\
\hline 101 & 5192,3 & 4755 & 5000,09 & 5329,74 \\
\hline 103 & 5219 & 4770 & 5022,96 & 5354 \\
\hline 105 & 5245,7 & 4785 & 5045,83 & 5378,26 \\
\hline 107 & 5272,4 & 4800 & 5068,7 & 5402,52 \\
\hline 109 & 5299,1 & 4815 & 5091,57 & 5426,78 \\
\hline 111 & 5325,8 & 4830 & 5114,44 & 5451,04 \\
\hline 113 & 5352,5 & 4845 & 5137,31 & 5475,3 \\
\hline 115 & 5379,2 & 4860 & 5160,18 & 5499,56 \\
\hline 117 & 5405,9 & 4875 & 5183,05 & 5523,82 \\
\hline 119 & 5432,6 & 4890 & 5205,92 & 5548,08 \\
\hline 121 & 5459,3 & 4905 & 5228,79 & 5572,34 \\
\hline 123 & 5486 & 4920 & 5251,66 & 5596,6 \\
\hline 125 & 5512,7 & 4935 & 5274,53 & 5620,86 \\
\hline 127 & 5539,4 & 4950 & 5297,4 & 5645,12 \\
\hline 129 & 5566,1 & 4965 & 5320,27 & 5669,38 \\
\hline
\end{tabular}


Tabela 2b- Idades radiocarbono convencionais (conv.) e calibradas (cal.) (continuação)

\begin{tabular}{|c|c|c|c|c|}
\hline Prof. (cm) & UBA1 Idade cal. (A.P.) & UBA1 Idade conv.(A.P.) & UBA3 Idade conv.(A.P.) & UBA3 Idade cal.(A.P.) \\
\hline 131 & 5592,8 & 4980 & 5343,14 & 5693,64 \\
\hline 133 & 5619,5 & 4995 & 5366,01 & 5717,9 \\
\hline 135 & 5646,2 & 5010 & 5388,88 & 5742,16 \\
\hline 137 & 5672,9 & 5025 & 5411,75 & 5766,42 \\
\hline 139 & 5699,6 & 5040 & 5434,62 & 5790,68 \\
\hline 141 & 5746,28 & 5092,3 & 5457,49 & 5814,94 \\
\hline 143 & 5792,96 & 5144,6 & 5480,36 & 5839,2 \\
\hline 145 & 5839,64 & 5196,9 & 5503,23 & 5863,46 \\
\hline 147 & 5886,32 & 5249,2 & 5526,1 & 5887,72 \\
\hline 149 & 5933 & 5301,5 & 5548,97 & 5911,98 \\
\hline 151 & 5979,68 & 5353,8 & 5571,84 & 5936,24 \\
\hline 153 & 6026,36 & 5406,1 & 5594,71 & 5960,5 \\
\hline 155 & 6073,04 & 5458,4 & 5617,58 & 5984,76 \\
\hline 157 & 6119,72 & 5510,7 & 5640,45 & 6009,02 \\
\hline 159 & 6166,4 & 5563 & 5663,32 & 6033,28 \\
\hline 161 & 6213,08 & 5615,3 & 5686,19 & 6057,54 \\
\hline 163 & 6259,76 & 5667,6 & 5709,06 & 6081,8 \\
\hline 165 & 6306,44 & 5719,9 & 5731,93 & 6106,06 \\
\hline 167 & 6353,12 & 5772,2 & 5754,8 & 6130,32 \\
\hline 169 & 6399,8 & 5824,5 & 5777,67 & 6154,58 \\
\hline 171 & 6446,48 & 5876,8 & 5800,54 & 6178,84 \\
\hline 173 & 6493,16 & 5929,1 & 5823,41 & 6203,1 \\
\hline 175 & 6539,84 & 5981,4 & 5846,28 & 6227,36 \\
\hline 177 & 6586,52 & 6033,7 & 5869,15 & 6251,62 \\
\hline 179 & 6633,2 & 6086 & 5892,02 & 6275,88 \\
\hline 181 & 6679,88 & 6138,3 & 5914,89 & 6300,14 \\
\hline 183 & 6726,56 & 6190,6 & 5937,76 & 6324,4 \\
\hline 185 & 6773,24 & 6242,9 & 5960,63 & 6348,66 \\
\hline 187 & 6819,92 & 6295,2 & 5983,5 & 6372,92 \\
\hline 189 & 6866,6 & 6347,5 & 6006,37 & 6397,18 \\
\hline 191 & 6913,28 & 6399,8 & 6029,24 & 6421,44 \\
\hline 193 & 6959,96 & 6452,1 & 6052,11 & 6445,7 \\
\hline 195 & 7006,64 & 6504,4 & 6074,98 & 6469,96 \\
\hline 197 & 7053,32 & 6556,7 & 6097,85 & 6494,22 \\
\hline 199 & 7100 & 6609 & 6120,72 & 6518,48 \\
\hline 201 & 7146,68 & 6661,3 & 6143,59 & 6542,74 \\
\hline 203 & 7193,36 & 6713,6 & 6166,46 & 6567 \\
\hline 205 & 7240,04 & 6765,9 & 6189,33 & 6591,26 \\
\hline 207 & 7286,72 & 6818,2 & 6212,2 & 6615,52 \\
\hline 209 & 7333,4 & 6870,5 & 6235,07 & 6639,78 \\
\hline 211 & 7380,08 & 6922,8 & 6257,94 & 6664,04 \\
\hline 213 & 7426,76 & 6975,1 & 6280,81 & 6688,3 \\
\hline
\end{tabular}


Tabela 2c- Idades radiocarbono convencionais (conv.) e calibradas (cal.) (continuação)

\begin{tabular}{|c|c|c|c|c|}
\hline Prof. (cm) & UBA1 Idade cal. (A.P.) & UBA1 Idade conv.(A.P.) & $\begin{array}{c}\text { UBA3 Idade conv. } \\
\text { (A.P.) }\end{array}$ & UBA3 Idade cal.(A.P.) \\
\hline 217 & 7520,12 & 7079,7 & 6326,55 & 6736,82 \\
\hline 219 & 7600 & 7236 & 6349,42 & 6761,08 \\
\hline 221 & 7715 & 7290 & 6372,29 & 6785,34 \\
\hline
\end{tabular}

Tabela 3- Idades radiocarbono convencionais (conv.) e calibradas (cal.) do testemunho UBA3 (cont.)

\begin{tabular}{|c|c|c|}
\hline Prof. (cm) & UBA3 Idade conv.(A.P.) & $\begin{array}{l}\text { UBA3 Idade cal. } \\
\text { (A.P.) }\end{array}$ \\
\hline 225 & 6418,03 & 6833,86 \\
\hline 227 & 6440,9 & 6858,12 \\
\hline 229 & 6463,77 & 6882,38 \\
\hline 231 & 6486,64 & 6906,64 \\
\hline 233 & 6509,51 & 6930,9 \\
\hline 235 & 6532,38 & 6955,16 \\
\hline 237 & 6555,25 & 6979,42 \\
\hline 239 & 6578,12 & 7003,68 \\
\hline 241 & 6600,99 & 7027,94 \\
\hline 243 & 6623,86 & 7052,2 \\
\hline 245 & 6646,73 & 7076,46 \\
\hline 247 & 6669,6 & 7100,72 \\
\hline 249 & 6692,47 & 7124,98 \\
\hline 251 & 6715,34 & 7149,24 \\
\hline 253 & 6738,21 & 7173,5 \\
\hline 255 & 6761,08 & 7197,76 \\
\hline 257 & 6783,95 & 7222,02 \\
\hline 259 & 6806,82 & 7246,28 \\
\hline 261 & 6829,69 & 7270,54 \\
\hline 263 & 6852,56 & 7294,8 \\
\hline 265 & 6875,43 & 7319,06 \\
\hline 267 & 6898,3 & 7343,32 \\
\hline 269 & 6921,17 & 7367,58 \\
\hline 271 & 6944,04 & 7391,84 \\
\hline 273 & 6966,91 & 7416,1 \\
\hline 275 & 6989,78 & 7440,36 \\
\hline 277 & 7012,65 & 7464,62 \\
\hline 279 & 7035,52 & 7488,88 \\
\hline 281 & 7058,39 & 7513,14 \\
\hline 283 & 7081,26 & 7537,4 \\
\hline
\end{tabular}


Tabela 3a Idades radiocarbono convencionais (conv.) e calibradas (cal.) do testemunho UBA3 (cont.)

\begin{tabular}{|c|c|c|}
\hline Prof. (cm) & UBA3 Idade conv.(A.P.) & $\begin{array}{l}\text { UBA3 Idade cal. } \\
\text { (A.P.) }\end{array}$ \\
\hline 287 & 7127 & 7585,92 \\
\hline 289 & 7149,87 & 7610,18 \\
\hline 291 & 7172,74 & 7634,44 \\
\hline 293 & 7195,61 & 7658,7 \\
\hline 295 & 7218,48 & 7682,96 \\
\hline 297 & 7241,35 & 7707,22 \\
\hline 299 & 7264,22 & 7731,48 \\
\hline 301 & 7287,09 & 7755,74 \\
\hline 303 & 7310 & 7780 \\
\hline 305 & 7383,2 & 7815 \\
\hline 307 & 7456,4 & 7850 \\
\hline 309 & 7529,6 & 7885 \\
\hline 311 & 7602,8 & 7920 \\
\hline 313 & 7676 & 7955 \\
\hline 313 & 7676 & 7955 \\
\hline 315 & 7749,2 & 7990 \\
\hline 317 & 7822,4 & 8025 \\
\hline 319 & 7895,6 & 8060 \\
\hline 321 & 7968,8 & 8095 \\
\hline 323 & 8042 & 8130 \\
\hline 325 & 8115,2 & 8165 \\
\hline 327 & 8188,4 & 8200 \\
\hline 329 & 8261,6 & 8235 \\
\hline 331 & 8334,8 & 8270 \\
\hline 333 & 8408 & 8305 \\
\hline 335 & 8481,2 & 8340 \\
\hline 337 & 8554,4 & 8375 \\
\hline 339 & 8627,6 & 8410 \\
\hline 341 & 8700,8 & 8445 \\
\hline 343 & 8774 & 8480 \\
\hline
\end{tabular}


Tabela 4- Resultados das análises sedimentares do testemunho UBA1

\begin{tabular}{|c|c|c|c|c|c|c|c|c|c|c|}
\hline Prof. (cm) & DM & DP & $\% G R$ & $\% M G r$ & $\% G$ & $\% \mathrm{M}$ & $\% F$ & $\%$ MF & $\% \mathrm{~S}$ & $\% A r g$ \\
\hline 1 & 4,97 & 2,39 & 0,14 & 0,99548 & 4,12 & 5,16 & 10,72 & 16,52 & 48,78 & 13,57 \\
\hline 3 & 4,23 & 1,83 & 0,09 & 1,06977 & 4,23 & 6,19 & 15,49 & 17,12 & 55,81 & 0 \\
\hline 5 & 4,44 & 2,41 & 0 & 1,99005 & 7,15 & 7,01 & 11,35 & 15,11 & 48,35 & 9,05 \\
\hline 7 & 4,3 & 2,65 & 0,42 & 3,10842 & 10,46 & 9,67 & 10,12 & 12,21 & 46,44 & 7,58 \\
\hline 9 & 4,61 & 2,72 & 0,35 & 2,60256 & 8,38 & 8,38 & 11,78 & 14,47 & 43,01 & 11,03 \\
\hline 11 & 4,11 & 2,43 & 0,19 & 2,64747 & 9,29 & 9,94 & 11,15 & 14,4 & 45,42 & 6,97 \\
\hline 13 & 3,45 & 2,16 & 0,76 & 5,26316 & 12,65 & 9,63 & 9,95 & 10,27 & 51,48 & 0 \\
\hline 15 & 3,38 & 2,44 & 1,34 & 5,95878 & 12,99 & 12,23 & 13,17 & 15,99 & 36,07 & 2,24 \\
\hline 17 & 3,38 & 2,44 & 1,34 & 5,95878 & 12,99 & 12,23 & 13,17 & 15,99 & 36,07 & 2,24 \\
\hline 19 & 3,38 & 2,44 & 1,34 & 5,95878 & 12,99 & 12,23 & 13,17 & 15,99 & 36,07 & 2,24 \\
\hline 21 & 2,42 & 2,97 & 4,95 & 14,7072 & 25,02 & 15,5 & 9,09 & 4,39 & 17,56 & 8,78 \\
\hline 23 & 2,42 & 2,97 & 4,95 & 14,7072 & 25,02 & 15,5 & 9,09 & 4,39 & 17,56 & 8,78 \\
\hline 25 & 1,43 & 2,17 & 7,34 & 17,1205 & 30,53 & 18,19 & 9,82 & 4,62 & 12,38 & 0 \\
\hline 27 & 1,05 & 1,83 & 8,12 & 27,8323 & 24,17 & 14,27 & 8,21 & 8,47 & 8,92 & 0 \\
\hline 29 & 1,41 & 1,93 & 6,68 & 17,2919 & 28,2 & 17,59 & 9,53 & 9,92 & 10,78 & 0 \\
\hline 31 & 2,37 & 2,31 & 4,8 & 9,42992 & 16,67 & 15,39 & 19,5 & 17,06 & 15 & 2,14 \\
\hline 33 & 3,93 & 2,56 & 1,72 & 4,70643 & 8,57 & 7,18 & 12,91 & 20,64 & 37,28 & 6,99 \\
\hline 35 & 3,45 & 1,98 & 0,66 & 6,45325 & 7,22 & 6,3 & 19 & 19,72 & 40,65 & 0 \\
\hline 37 & 3,48 & 2 & 0,66 & 6,45325 & 7,22 & 6,3 & 19 & 19,72 & 40,65 & 0 \\
\hline 39 & 4,24 & 1,83 & 0,54 & 1,62162 & 3,84 & 3,72 & 9,55 & 29,67 & 51,05 & 0 \\
\hline 41 & 4,43 & 2,56 & 0,75 & 3,33333 & 7,15 & 5,97 & 8,01 & 21,02 & 43,01 & 10,75 \\
\hline 43 & 3,92 & 1,76 & 0,23 & 1,82753 & 4,05 & 4,63 & 17,53 & 28,9 & 42,83 & 0 \\
\hline 45 & 4,53 & 2,11 & 0,13 & 0,94458 & 1,83 & 4,41 & 26,89 & 18,58 & 47,23 & 0 \\
\hline 47 & 5,1 & 2,12 & 0,07 & 0,26578 & 1 & 1,53 & 7,31 & 26,71 & 46,51 & 16,61 \\
\hline 49 & 4,98 & 2,05 & 0,13 & 1,0589 & 1,85 & 2,25 & 5,69 & 22,83 & 56,25 & 9,93 \\
\hline 51 & 4,82 & 1,71 & 0 & 0,71942 & 1,37 & 1,51 & 5,9 & 25,76 & 61,15 & 3,6 \\
\hline 53 & 4,81 & 1,41 & 0,2 & 0,33113 & 1,19 & 1,39 & 4,9 & 22,45 & 69,54 & 0 \\
\hline 55 & 4,94 & 1,57 & 0 & 0,5102 & 1,34 & 1,91 & 4,66 & 21,43 & 70,15 & 0 \\
\hline 57 & 5,4 & 2,05 & 0,14 & 0,47265 & 1,15 & 1,22 & 4,52 & 24,98 & 57,39 & 10,13 \\
\hline 59 & 4,96 & 1,61 & 0,06 & 0,18727 & 1,12 & 1,5 & 5,24 & 23,22 & 68,66 & 0 \\
\hline 61 & 5,12 & 1,91 & 0,07 & 0,19802 & 0,99 & 2,05 & 7,19 & 20,2 & 62,71 & 6,6 \\
\hline 63 & 5,49 & 1,94 & 0 & 0,25157 & 1,13 & 1,51 & 4,28 & 17,36 & 62,89 & 12,58 \\
\hline 65 & 5,49 & 1,99 & 0,13 & 0,52493 & 1,44 & 1,38 & 3,08 & 14,7 & 68,9 & 9,84 \\
\hline 67 & 4,75 & 2,5 & 0,13 & 0,52 & 1,44 & 1,38 & 3,08 & 14,7 & 68,9 & 9,84 \\
\hline 69 & 4,75 & 2,5 & 0,98 & 3,05592 & 7,22 & 4,42 & 4,75 & 14,56 & 55,27 & 9,75 \\
\hline 71 & 5,51 & 1,86 & 0,21 & 0,42857 & 1,29 & 1,29 & 2,43 & 12,21 & 71,43 & 10,71 \\
\hline 73 & 5,2 & 2,02 & 0 & 0,74526 & 1,83 & 2,03 & 3,79 & 17,07 & 49,43 & 2 \\
\hline 75 & 4,1 & 2,96 & 0 & 0,27701 & 28,53 & 1,06 & 2,54 & 12,19 & 43,86 & 11,54 \\
\hline 77 & 5,63 & 2,25 & 0 & 1,18519 & 2,52 & 2,15 & 4 & 16,07 & 59,26 & 14,81 \\
\hline 79 & 5,31 & 2,32 & 0,05 & 0,46997 & 6,37 & 1,46 & 3,34 & 15,2 & 60,05 & 13,05 \\
\hline
\end{tabular}

Legenda: $\mathrm{DM}=$ diâmetro médio $(\varphi)$, $\mathrm{DP}=$ desvio padrão, $\mathrm{GR}=$ grânulos, $\mathrm{MGr}=$ areia muito grossa, $\mathrm{Gr}=$ areia grossa e $\mathrm{M}=$ areia média; $\mathrm{F}=$ areia fina, $\mathrm{AMF}=$ areia muito fina, . Arg=argila $\mathrm{S}=$ silte 
Tabela 4a- Continuação dos resultados das análises sedimentares do testemunho UBA1

\begin{tabular}{|c|c|c|c|c|c|c|c|c|c|c|}
\hline Prof. (cm) & DM & DP & $\%$ GR & $\% M G r$ & $\% G$ & $\% \mathrm{M}$ & $\% F$ & $\%$ MF & $\% \mathrm{~S}$ & $\%$ Arg \\
\hline 81 & 5,19 & 2,37 & 1,32 & 1,37589 & 3,08 & 2,48 & 4,24 & 18,71 & 55,04 & 13,76 \\
\hline 83 & 5,62 & 2,22 & 0,24 & 0,95238 & 1,9 & 1,37 & 3,39 & 17,74 & 56,55 & 17,86 \\
\hline 85 & 5,69 & 1,99 & 0 & 0,20587 & 0,82 & 0,98 & 2,62 & 15,59 & 64,33 & 15,44 \\
\hline 87 & 6,11 & 1,83 & 0 & 0,19166 & 0,53 & 0,48 & 1,2 & 8,96 & 71,87 & 16,77 \\
\hline 89 & 5,83 & 1,84 & 0 & 0,27012 & 0,76 & 0,92 & 2,16 & 12,16 & 72,93 & 10,8 \\
\hline 91 & 6,01 & 1,92 & 0 & 0,31915 & 0,59 & 0,69 & 1,44 & 9,2 & 69,15 & 18,62 \\
\hline 93 & 6,01 & 1,9 & 0 & 0,3 & 0,59 & 0,53 & 1,44 & 9,2 & 69,15 & 18,6 \\
\hline 95 & 6,03 & 1,91 & 0 & 0,05297 & 0,69 & 0,53 & 1,54 & 9,8 & 68,86 & 18,54 \\
\hline 97 & 5,72 & 2,04 & 0 & 0,21563 & 1,08 & 1,02 & 2,43 & 11,7 & 64,69 & 18,87 \\
\hline 99 & 6,49 & 1,59 & 0 & 0,13012 & 0,46 & 0,52 & 1,04 & 5,99 & 78,85 & 13,01 \\
\hline 101 & 6,39 & 1,81 & 0,09 & 0,13465 & 0,22 & 0,18 & 0,58 & 4,53 & 71,81 & 22,44 \\
\hline 103 & 5,13 & 2,54 & 0,34 & 2,98364 & 7,07 & 4,48 & 3,9 & 9,05 & 60,15 & 12,03 \\
\hline 105 & 5,07 & 2,53 & 0,8 & 2,44389 & 7,68 & 5,14 & 4,69 & 9,43 & 62,34 & 7,48 \\
\hline 107 & 5,64 & 2,42 & 0,46 & 1,3809 & 3,16 & 2,42 & 3,51 & 14,27 & 54,66 & 20,14 \\
\hline 109 & 6,45 & 1,62 & 0 & 0,61763 & 1,01 & 0,67 & 0,79 & 3,87 & 79 & 14,04 \\
\hline 111 & 6,22 & 1,86 & 0 & 0,23697 & 0,66 & 0,47 & 1,14 & 7,44 & 71,09 & 18,96 \\
\hline 113 & 6,38 & 1,97 & 0 & 0,44228 & 0,44 & 0,44 & 1,24 & 8,98 & 64,13 & 24,33 \\
\hline 115 & 5,92 & 1,76 & 0 & 0,0501 & 0,05 & 0,15 & 1,45 & 13,13 & 72,65 & 12,53 \\
\hline 117 & 6,34 & 1,99 & 0,39 & 0,26293 & 0,26 & 0,26 & 1,14 & 10,04 & 63,54 & 24,1 \\
\hline 119 & 6,37 & 1,94 & 0 & 0,13181 & 0,31 & 0,44 & 1,27 & 9,97 & 63,71 & 24,17 \\
\hline 121 & 6,12 & 1,87 & 0 & 0 & 0,36 & 0,45 & 1,67 & 11,86 & 67,63 & 18,03 \\
\hline 123 & 6,13 & 1,87 & 0 & 0 & 0,14 & 0,34 & 1,68 & 11,64 & 67,05 & 19,16 \\
\hline 125 & 6 & 1,83 & 0 & 0,13825 & 0,41 & 0,41 & 1,43 & 10,05 & 71,43 & 16,13 \\
\hline 127 & 6,32 & 1,93 & 0 & 0,12579 & 0,25 & 0,34 & 1,13 & 8,01 & 64,99 & 25,16 \\
\hline 129 & 6,27 & 1,71 & 0 & 0 & 0,09 & 0,13 & 0,94 & 7,4 & 74,44 & 17,01 \\
\hline 131 & 6,26 & 1,81 & 0 & 0,04562 & 0,18 & 0,18 & 1,28 & 9,35 & 70,71 & 18,25 \\
\hline 133 & 5,97 & 1,64 & 0 & 0,04721 & 0,09 & 0,24 & 1,09 & 8,83 & 77,9 & 11,8 \\
\hline 135 & 6,2 & 1,84 & 0 & 0,02375 & 0,09 & 0,24 & 1,33 & 10,45 & 68,87 & 19 \\
\hline 137 & 6,15 & 1,8 & 0 & 0 & 0,09 & 0,13 & 1,44 & 10,77 & 70,05 & 17,51 \\
\hline 139 & 5,84 & 1,77 & 0 & 0 & 0,08 & 0,29 & 1,81 & 11,75 & 73,47 & 12,59 \\
\hline 141 & 6,12 & 1,87 & 0 & 0 & 0,19 & 0,38 & 2,22 & 12,35 & 66,01 & 18,86 \\
\hline 143 & 5,87 & 1,77 & 0 & 0 & 0,18 & 0,36 & 1,83 & 12,66 & 71,56 & 13,42 \\
\hline 145 & 6 & 1,82 & 0 & 0 & 0,21 & 0,3 & 1,93 & 11,87 & 70,69 & 15 \\
\hline 147 & 6,3 & 1,83 & 0 & 0,04929 & 0,2 & 0,34 & 1,58 & 10,6 & 67,52 & 19,71 \\
\hline 149 & 6 & 1,86 & 0 & 0 & 0,16 & 0,38 & 2,11 & 13,47 & 67,64 & 16,23 \\
\hline 151 & 5,98 & 1,88 & 0 & 0,04468 & 0,45 & 0,45 & 2,19 & 11,97 & 69,26 & 15,64 \\
\hline 153 & 5,09 & 1,32 & 0 & 0,06693 & 0,67 & 0,67 & 3,28 & 18,34 & 76,97 & 0 \\
\hline 155 & 5,92 & 1,87 & 0 & 0,05018 & 0,5 & 0,5 & 2,46 & 13,7 & 67,74 & 15,05 \\
\hline 157 & 6,14 & 1,94 & 0 & 0,0478 & 0,48 & 0,48 & 2,34 & 13 & 64,53 & 19,12 \\
\hline 159 & 4,99 & 1,55 & 0 & 0 & 0,24 & 0,88 & 12,4 & 17,88 & 68,59 & 0 \\
\hline 161 & 6,11 & 1,99 & 0 & 0 & 0,21 & 0,26 & 2,82 & 14,54 & 61,63 & 20,54 \\
\hline 163 & 6,33 & 1,96 & 0 & 0 & 0,19 & 0,24 & 2,63 & 13,29 & 62,14 & 21,51 \\
\hline
\end{tabular}

Legenda: $\mathrm{DM}=$ diâmetro médio $(\varphi), \mathrm{DP}=$ desvio padrão, $\mathrm{GR}=$ grânulos, $\mathrm{MGr}=$ areia muito grossa, $\mathrm{Gr}=$ areia grossa e $\mathrm{M}=$ areia média; $\mathrm{F}=$ areia fina, $\mathrm{AMF}=$ areia muito fina,. $\mathrm{Arg}=$ argila $\mathrm{S}=$ silte 
Tabela 4b- Continuação dos resultados das análises sedimentares do testemunho UBA1

\begin{tabular}{|c|c|c|c|c|c|c|c|c|c|c|}
\hline Prof. (cm) & DM & DP & $\%$ GR & $\% M G r$ & $\% G$ & $\% \mathbf{M}$ & $\% \mathrm{~F}$ & $\%$ MF & $\% \mathrm{~S}$ & $\% A r g$ \\
\hline 165 & 5,84 & 1,8 & 0 & 0 & 0,2 & 0,24 & 2,7 & 13,5 & 71 & 12,25 \\
\hline 167 & 6,13 & 2 & 0 & 0 & 0,15 & 0,3 & 2,9 & 13 & 61 & 21,46 \\
\hline 169 & 5,99 & 2,07 & 0,13 & 0,35119 & 0,44 & 0,75 & 2,63 & 14,49 & 61,46 & 19,75 \\
\hline 171 & 5,94 & 1,88 & 0 & 0 & 0,14 & 0,29 & 2,33 & 11,73 & 68,88 & 16,63 \\
\hline 173 & 5,83 & 1,95 & 0 & 0,13812 & 0,51 & 0,69 & 2,62 & 13,17 & 66,76 & 16,11 \\
\hline 175 & 6,48 & 2,02 & 0 & 0 & 0,26 & 0,31 & 2,28 & 11,62 & 59,21 & 26,32 \\
\hline 177 & 4,22 & 4,45 & 0 & 0 & 0,15 & 0,35 & 2,04 & 10,22 & 54,84 & 12,46 \\
\hline 179 & 5,91 & 2,06 & 0,02 & 0,0717 & 0,53 & 0,81 & 4,59 & 17,5 & 59,75 & 16,73 \\
\hline 181 & 6,2 & 2,13 & 0 & 0,10701 & 0,64 & 0,8 & 3,37 & 17,5 & 53,5 & 24,08 \\
\hline 183 & 5,74 & 2 & 0 & 0,31532 & 0,95 & 1,13 & 3,92 & 14,86 & 65,32 & 13,51 \\
\hline 185 & 5,25 & 2,28 & 0 & 0,80683 & 3,94 & 4,27 & 3,27 & 18,89 & 56,95 & 11,87 \\
\hline 187 & 4,99 & 2,54 & 0 & 0,50988 & 4,72 & 5,61 & 11,22 & 26,96 & 38,24 & 12,75 \\
\hline 189 & 5,55 & 2,27 & 0,12 & 0,24927 & 0,87 & 0,91 & 4,9 & 22,31 & 47,78 & 22,85 \\
\hline 191 & 5,8 & 2,41 & 0 & 0,32693 & 1,72 & 1,96 & 6,21 & 20,31 & 44,95 & 24,52 \\
\hline 193 & 5,8 & 2,4 & 0 & 0,27162 & 1,81 & 2,26 & 7,83 & 26,71 & 47,53 & 13,58 \\
\hline 195 & 5,25 & 2,25 & 0 & 0,46431 & 3,54 & 3,42 & 8,42 & 31,92 & 40,63 & 11,61 \\
\hline 197 & 4,95 & 2,35 & 0 & 0,4 & 3,5 & 3,4 & 8,4 & 31,9 & 40 & 11,6 \\
\hline 199 & 5,33 & 2,22 & 0 & 0,26774 & 1,34 & 1,65 & 7,68 & 26,6 & 49,09 & 13,39 \\
\hline 201 & 4,9 & 2,45 & 0 & 0,60319 & 2,59 & 2,54 & 9,26 & 37,61 & 30,16 & 17,23 \\
\hline 203 & 5,21 & 2,37 & 0,26 & 0,38462 & 2,26 & 2,22 & 8,42 & 28,76 & 42,74 & 14,96 \\
\hline 205 & 5,18 & 2,33 & 0,04 & 0,39635 & 1,47 & 1,59 & 7,93 & 27,15 & 41,62 & 19,82 \\
\hline 207 & 4,7 & 2,35 & 0 & 0,48889 & 2,89 & 3,11 & 11,07 & 35,78 & 33,33 & 13,33 \\
\hline 209 & 4,7 & 2,35 & 0 & 0,48889 & 2,89 & 3,11 & 11,07 & 35,78 & 33,33 & 13,33 \\
\hline 211 & 4,44 & 2,28 & 0 & 1,11111 & 4,54 & 4,26 & 11,67 & 34,44 & 34,72 & 9,26 \\
\hline 213 & 3,37 & 1,83 & 0 & 1,99557 & 8,96 & 8,2 & 16,98 & 35,03 & 28,82 & 0 \\
\hline 215 & 4,71 & 2,83 & 0,34 & 1,56979 & 6,58 & 5,81 & 12,94 & 30,34 & 21,21 & 21,21 \\
\hline 217 & 3,7 & 2,08 & 0,46 & 1,77491 & 7,96 & 6,33 & 14,47 & 34,87 & 29,58 & 4,55 \\
\hline 219 & 4,22 & 2,83 & 0,04 & 1,9984 & 10,27 & 9,87 & 12,79 & 27,06 & 19,98 & 17,99 \\
\hline 221 & 3,87 & 2,4 & 0,28 & 1,25348 & 7,57 & 7,43 & 15,83 & 42,11 & 16,25 & 9,29 \\
\hline
\end{tabular}

Legenda: $\mathrm{DM}=$ diâmetro médio $(\varphi)$, DP=desvio padrão, $\mathrm{GR}=$ grânulos, $\mathrm{MGr}=$ areia muito grossa, $\mathrm{Gr}=\mathrm{areia}$

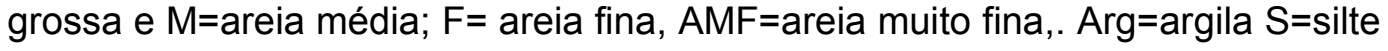


Tabela 5- Resultados das análises sedimentares do testemunho UBA3

\begin{tabular}{|c|c|c|c|c|c|c|c|c|c|c|}
\hline Prof. (cm) & DM & DV & $\%$ GR & $\% M G r$ & $\% \mathrm{Gr}$ & $\% \mathrm{M}$ & $\% F$ & \%AMF & $\%$ Arg & $\% S$ \\
\hline 1 & 5 & 1,71 & 0 & 0 & 0 & 0 & 0 & 23,41 & 15,12 & 61,46 \\
\hline 3 & 4,9 & 1,56 & 0 & 0 & 0 & 0 & 0 & 20,86 & 12,27 & 66,87 \\
\hline 5 & 5,02 & 1,79 & 0 & 0 & 0 & 0 & 0,11 & 23,58 & 16,27 & 60,04 \\
\hline 7 & 4,93 & 1,89 & 0 & 0 & 0 & 0 & 0,28 & 33,84 & 16,81 & 49,08 \\
\hline 9 & 5,16 & 1,16 & 0 & 0 & 0 & 0 & 0 & 15,04 & 5,9 & 79,06 \\
\hline 11 & 4,02 & 1,03 & 0 & 0 & 0 & 0 & 0,78 & 57,48 & 2,98 & 38,76 \\
\hline 13 & 4,85 & 2,11 & 0 & 0 & 0 & 0 & 0,98 & 52,08 & 19,76 & 27,18 \\
\hline 15 & 4,17 & 1,35 & 0 & 0 & 0,06 & 0,12 & 0,31 & 57,73 & 6,23 & 35,54 \\
\hline 17 & 4,5 & 1,32 & 0 & 0 & 0,09 & 0,18 & 1,57 & 42,67 & 4,62 & 50,86 \\
\hline 19 & 4,13 & 1,34 & 0 & 0 & 0,06 & 0,12 & 2,12 & 56,55 & 5,88 & 35,27 \\
\hline 21 & 4,31 & 1,57 & 0 & 0 & 0 & 0,12 & 1,87 & 55,82 & 9,04 & 33,15 \\
\hline 23 & 4,16 & 1,38 & 0 & 0 & 0 & 0,06 & 1,98 & 57,62 & 6,4 & 33,93 \\
\hline 25 & 4,71 & 2,02 & 0 & 0 & 0 & 0,49 & 2,81 & 54,5 & 14,06 & 28,13 \\
\hline 27 & 4,31 & 1,36 & 0 & 0 & 0 & 0 & 3,17 & 56,35 & 3,97 & 51,59 \\
\hline 29 & 4,04 & 0,83 & 0 & 0 & 0,16 & 0,08 & 3,02 & 49,13 & 0 & 47,62 \\
\hline 31 & 4,9 & 1,94 & 0 & 0 & 0,06 & 0,13 & 2,34 & 37,42 & 15,8 & 44,25 \\
\hline 33 & 5,07 & 2,09 & 0,07 & 0,2642 & 0,2 & 0,2 & 1,92 & 31,31 & 19,82 & 46,24 \\
\hline 35 & 5,2 & 1,72 & 0 & 0 & 0 & 0 & 0 & 18,18 & 15,15 & 66,67 \\
\hline 37 & 4,99 & 2,02 & 0 & 0 & 0 & 0 & 3,12 & 37,73 & 16,43 & 42,72 \\
\hline 39 & 4,9 & 1,77 & 0 & 0 & 0 & 0,18 & 2,35 & 29,95 & 11,74 & 55,78 \\
\hline 41 & 5,04 & 1,98 & 0 & 0 & 0 & 0,12 & 1,84 & 29,79 & 17,8 & 50,45 \\
\hline 43 & 4,98 & 1,99 & 0 & 0 & 0,47 & 0,36 & 3,37 & 33,67 & 14,79 & 47,34 \\
\hline 45 & 3,38 & 2,98 & 0 & 0 & 0 & 0 & 0 & 19,08 & 0 & 67,43 \\
\hline 47 & 5,12 & 1,68 & 0 & 0 & 0 & 0 & 0 & 21,88 & 13,02 & 65,1 \\
\hline 49 & 5,3 & 1,65 & 0 & 0 & 0 & 0 & 0 & 18,32 & 11,67 & 70,01 \\
\hline 51 & 5,37 & 1,8 & 0 & 0 & 0 & 0 & 0 & 8,98 & 18,83 & 72,19 \\
\hline 53 & 4,78 & 1,09 & 0 & 0 & 0 & 0 & 0 & 12,34 & 3,51 & 84,15 \\
\hline 55 & 3,75 & 0 & 0 & 0 & 0 & 0 & 0 & 100 & 0 & 0 \\
\hline 57 & 5,36 & 1,81 & 0 & 0 & 0 & 0 & 0 & 11,22 & 17,76 & 71,02 \\
\hline 59 & 5,31 & 1,74 & 0 & 0 & 0 & 0 & 0 & 13,68 & 16,6 & 69,72 \\
\hline 61 & 5,33 & 1,71 & 0 & 0 & 0 & 0 & 0 & 7,04 & 16,6 & 76,36 \\
\hline 63 & 5,42 & 1,78 & 0 & 0 & 0 & 0 & 0 & 7,8 & 17,73 & 74,47 \\
\hline 65 & 5,31 & 1,78 & 0 & 0 & 0 & 0 & 0 & 11,97 & 17,61 & 70,42 \\
\hline 67 & 5,19 & 1,57 & 0 & 0 & 0 & 0 & 0 & 6,48 & 13,36 & 80,16 \\
\hline 69 & 5,15 & 1,55 & 0 & 0 & 0 & 0 & 0 & 6,85 & 13,31 & 79,84 \\
\hline 71 & 5,2 & 1,55 & 0 & 0 & 0 & 0 & 0 & 5,84 & 12,99 & 81,17 \\
\hline 73 & 5 & 1,47 & 0 & 0 & 0 & 0 & 0 & 7,9 & 11,51 & 80,58 \\
\hline 75 & 5,39 & 1,79 & 0 & 0 & 0 & 0 & 0 & 7,41 & 18,52 & 74,07 \\
\hline 77 & 5,18 & 1,59 & 0 & 0 & 0 & 0 & 0 & 6,67 & 13,33 & 80 \\
\hline 79 & 5,15 & 1,59 & 0 & 0 & 0 & 0 & 0 & 7,17 & 12,8 & 80,03 \\
\hline 81 & 5,16 & 1,4 & 0 & 0 & 0 & 0 & 0 & 5,72 & 6,73 & 87,54 \\
\hline 83 & 5,16 & 1,49 & 0 & 0 & 0 & 0 & 0 & 6,9 & 10,34 & 82,76 \\
\hline
\end{tabular}

Legenda: $\mathrm{DM}=$ diâmetro médio $(\varphi)$, $\mathrm{DP}=$ desvio padrão, $\mathrm{GR}=$ grânulos, $\mathrm{MGr}=$ areia muito grossa, $\mathrm{Gr}=$ areia

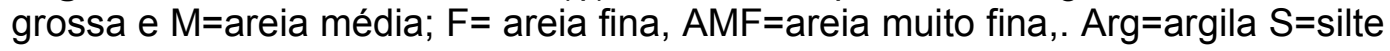


Tabela 5a- Continuação resultados das análises sedimentares do testemunho UBA3

\begin{tabular}{|c|c|c|c|c|c|c|c|c|c|c|}
\hline Prof. (cm) & DM & DV & \%GR & $\% M G r$ & $\% \mathrm{Gr}$ & $\% M$ & $\% \mathrm{~F}$ & \%AMF & \%Arg & $\% \mathrm{~S}$ \\
\hline 85 & 5,17 & 1,55 & 0 & 0 & 0 & 0 & 0 & 5,91 & 12,98 & 81,12 \\
\hline 87 & 5,08 & 1,33 & 0 & 0 & 0 & 0 & 0 & 6,05 & 6,96 & 86,99 \\
\hline 89 & 5,14 & 1,45 & 0 & 0 & 0 & 0 & 0 & 5,66 & 10,48 & 83,86 \\
\hline 91 & 5,17 & 1,45 & 0 & 0 & 0 & 0 & 0 & 5,12 & 9,49 & 85,39 \\
\hline 93 & 5,15 & 1,47 & 0 & 0 & 0 & 0 & 0 & 5,53 & 10,12 & 84,35 \\
\hline 95 & 5,35 & 1,66 & 0 & 0 & 0 & 0 & 0 & 4,83 & 13,6 & 81,58 \\
\hline 97 & 5,01 & 1,35 & 0 & 0 & 0 & 0 & 0 & 6,3 & 7,5 & 86,21 \\
\hline 99 & 5,01 & 1,35 & 0 & 0 & 0 & 0 & 0 & 6,72 & 7,46 & 85,82 \\
\hline 101 & 5,09 & 1,28 & 0 & 0 & 0 & 0 & 0 & 5,73 & 6,98 & 87,29 \\
\hline 103 & 5,02 & 1,27 & 0 & 0 & 0 & 0 & 0 & 6,74 & 7,17 & 86,08 \\
\hline 105 & 5,26 & 1,66 & 0 & 0 & 0 & 0 & 0 & 5,32 & 14,57 & 80,12 \\
\hline 107 & 5,23 & 1,44 & 0 & 0 & 0 & 0 & 0 & 5,4 & 7,01 & 87,6 \\
\hline 109 & 5,14 & 1,45 & 0 & 0 & 0 & 0 & 0 & 5,73 & 10,47 & 83,8 \\
\hline 111 & 5,21 & 1,56 & 0 & 0 & 0 & 0 & 0 & 4,9 & 10,97 & 84,13 \\
\hline 113 & 5,21 & 1,56 & 0 & 0 & 0 & 0 & 0 & 4,9 & 10,97 & 84,13 \\
\hline 115 & 5,14 & 1,5 & 0 & 0 & 0 & 0 & 0 & 4,69 & 11 & 84,31 \\
\hline 117 & 5,35 & 1,7 & 0 & 0 & 0 & 0 & 0 & 6,25 & 15,63 & 78,13 \\
\hline 119 & 5,06 & 1,21 & 0 & 0 & 0 & 0 & 0 & 4,76 & 3,4 & 91,84 \\
\hline 121 & 5,15 & 1,5 & 0 & 0 & 0 & 0 & 0 & 4,55 & 11,01 & 84,43 \\
\hline 123 & 5,32 & 1,67 & 0 & 0 & 0 & 0 & 0 & 5,81 & 15,7 & 78,49 \\
\hline 125 & 5,11 & 1,26 & 0 & 0 & 0 & 0 & 0 & 0 & 7,14 & 92,86 \\
\hline 127 & 5,04 & 1,26 & 0 & 0 & 0 & 0 & 0 & 5,28 & 6,77 & 87,96 \\
\hline 129 & 5,11 & 1,26 & 0 & 0 & 0 & 0 & 0 & 0 & 7,14 & 92,86 \\
\hline 131 & 5,12 & 1,48 & 0 & 0 & 0 & 0 & 0 & 4,26 & 10,64 & 85,11 \\
\hline 133 & 5,12 & 1,48 & 0 & 0 & 0 & 0 & 0 & 4,26 & 10,64 & 85,11 \\
\hline 135 & 5,13 & 1,47 & 0 & 0 & 0 & 0 & 0 & 6,25 & 10,42 & 83,33 \\
\hline 137 & 5,22 & 1,47 & 0 & 0 & 0 & 0 & 0 & 0 & 11,11 & 88,89 \\
\hline 139 & 5,24 & 1,51 & 0 & 0 & 0 & 0 & 0 & 3,98 & 10,29 & 85,73 \\
\hline 141 & 5,24 & 1,51 & 0 & 0 & 0 & 0 & 0 & 4,11 & 10,27 & 85,62 \\
\hline 143 & 5,12 & 1,33 & 0 & 0 & 0 & 0 & 0 & 3,57 & 7,14 & 89,29 \\
\hline 145 & 5,12 & 1,33 & 0 & 0 & 0 & 0 & 0 & 3,57 & 7,14 & 89,29 \\
\hline 147 & 5,14 & 1,41 & 0 & 0 & 0 & 0 & 0 & 2,72 & 9,73 & 87,55 \\
\hline 149 & 3,93 & 2,74 & 0 & 0 & 0 & 0 & 0 & 2,72 & 3,24 & 84,31 \\
\hline 151 & 5,19 & 1,39 & 0 & 0 & 0 & 0 & 0 & 2,39 & 9,45 & 88,16 \\
\hline 153 & 5,19 & 1,39 & 0 & 0 & 0 & 0 & 0 & 2,39 & 9,45 & 88,16 \\
\hline 155 & 5,29 & 1,52 & 0 & 0 & 0 & 0 & 0 & 2,44 & 10,45 & 87,11 \\
\hline 157 & 5,3 & 1,53 & 0 & 0 & 0 & 0 & 0 & 2,44 & 10,45 & 87,11 \\
\hline 159 & 5,19 & 1,38 & 0 & 0 & 0 & 0 & 0 & 2,85 & 10,41 & 86,75 \\
\hline 161 & 5,19 & 1,38 & 0 & 0 & 0 & 0 & 0 & 2,85 & 10,41 & 86,75 \\
\hline 163 & 5,85 & 1,92 & 0 & 0 & 0 & 0 & 0 & 3,36 & 20,35 & 76,3 \\
\hline 165 & 5,87 & 1,92 & 0 & 0 & 0 & 0 & 0 & 2,36 & 20,55 & 77,08 \\
\hline 189 & 5,24 & 1,37 & 0 & 0 & 0 & 0 & 0 & 2,22 & 8,89 & 88,89 \\
\hline
\end{tabular}

Legenda: $\mathrm{DM}=$ diâmetro médio $(\varphi)$, DP=desvio padrão, $G R=$ grânulos, $M G r=a r e i a$ muito grossa, $G r=a r e i a$

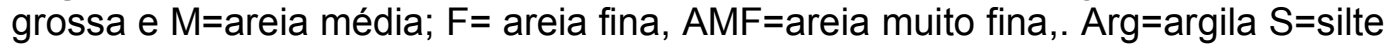


Tabela 5b- Continuação resultados das análises sedimentares do testemunho UBA3

\begin{tabular}{|c|c|c|c|c|c|c|c|c|c|c|}
\hline Prof. (cm) & DM & DV & $\%$ GR & $\% M G r$ & $\% \mathrm{Gr}$ & $\% \mathrm{M}$ & $\% F$ & \%AMF & \%Arg & $\% S$ \\
\hline 191 & 5,24 & 1,37 & 0 & 0 & 0 & 0 & 0 & 2,05 & 8,9 & 89,05 \\
\hline 193 & 5,54 & 1,68 & 0 & 0 & 0 & 0 & 0 & 2,38 & 16,98 & 80,65 \\
\hline 195 & 5,54 & 1,68 & 0 & 0 & 0 & 0 & 0 & 2,38 & 16,98 & 80,65 \\
\hline 197 & 5,55 & 1,69 & 0 & 0 & 0 & 0 & 0 & 2,14 & 17,79 & 80,07 \\
\hline 199 & 5,55 & 1,69 & 0 & 0 & 0 & 0 & 0 & 2,14 & 17,79 & 80,07 \\
\hline 201 & 5,55 & 1,69 & 0 & 0 & 0 & 0 & 0 & 2,14 & 17,79 & 80,07 \\
\hline 205 & 5,56 & 1,68 & 0 & 0 & 0 & 0 & 0 & 1,71 & 17,09 & 81,2 \\
\hline 207 & 5,56 & 1,68 & 0 & 0 & 0 & 0 & 0 & 1,71 & 17,09 & 81,2 \\
\hline 209 & 5,8 & 1,64 & 0 & 0 & 0 & 0 & 0 & 1,48 & 16,42 & 82,1 \\
\hline 211 & 5,74 & 1,7 & 0 & 0 & 0 & 0 & 0 & 1,61 & 17,89 & 80,5 \\
\hline 213 & 5,68 & 1,55 & 0 & 0 & 0 & 0 & 0 & 2,17 & 10,87 & 86,96 \\
\hline 223 & 5,71 & 1,82 & 0 & 0 & 0 & 0 & 0 & 1,71 & 21,37 & 76,92 \\
\hline 225 & 5,74 & 1,62 & 0 & 0 & 0 & 0 & 0 & 1,96 & 14,71 & 83,33 \\
\hline 227 & 5,44 & 1,66 & 0 & 0 & 0 & 0 & 0 & 16,67 & 12,5 & 70,83 \\
\hline 229 & 5,69 & 1,76 & 0 & 0 & 0 & 0 & 0 & 2,04 & 20,41 & 77,55 \\
\hline 231 & 5,69 & 1,76 & 0 & 0 & 0 & 0 & 0 & 2,04 & 20,41 & 77,55 \\
\hline 233 & 5,72 & 1,72 & 0 & 0 & 0 & 0 & 0 & 2,21 & 17,01 & 80,78 \\
\hline 235 & 5,72 & 1,72 & 0 & 0 & 0 & 0 & 0 & 2,21 & 17,01 & 80,78 \\
\hline 237 & 5,75 & 1,59 & 0 & 0 & 0 & 0 & 0 & 2,28 & 16,29 & 81,43 \\
\hline 239 & 5,75 & 1,59 & 0 & 0 & 0 & 0 & 0 & 2,28 & 16,29 & 81,43 \\
\hline 255 & 5,96 & 1,73 & 0 & 0 & 0 & 0 & 0 & 5,54 & 19,54 & 74,92 \\
\hline 257 & 5,49 & 1,37 & 0 & 0 & 0 & 0 & 0 & 6,98 & 3,32 & 89,7 \\
\hline 259 & 5,49 & 1,37 & 0 & 0 & 0 & 0 & 0 & 6,98 & 3,32 & 89,7 \\
\hline 261 & 5,95 & 1,79 & 0 & 0 & 0 & 0 & 0 & 7,68 & 20,85 & 71,47 \\
\hline 263 & 5,94 & 1,79 & 0 & 0 & 0 & 0 & 0 & 7,74 & 20,83 & 71,43 \\
\hline 265 & 5,72 & 1,63 & 0 & 0 & 0 & 0 & 0 & 9,68 & 12,9 & 77,42 \\
\hline 267 & 5,93 & 1,58 & 0 & 0 & 0 & 0 & 0 & 0 & 14,29 & 85,71 \\
\hline 269 & 5,74 & 1,73 & 0 & 0 & 0 & 0 & 0 & 10,66 & 15,95 & 73,39 \\
\hline 271 & 5,74 & 1,73 & 0 & 0 & 0 & 0 & 0 & 10,83 & 15,92 & 73,25 \\
\hline 273 & 5,94 & 1,76 & 0 & 0 & 0 & 0 & 0 & 13,62 & 16,61 & 69,77 \\
\hline
\end{tabular}

Legenda: $\mathrm{DM}=$ diâmetro médio $(\varphi)$, $\mathrm{DP}=$ desvio padrão, $\mathrm{GR}=$ grânulos, $\mathrm{MGr}=$ areia muito grossa, $\mathrm{Gr}=$ areia grossa e $M=$ areia média; $F=$ areia fina, $A M F=$ areia muito fina,. Arg=argila $S=$ silte

Tabela 5c- Continuação resultados das análises sedimentares do testemunho UBA3 


\begin{tabular}{|c|c|c|c|c|c|c|c|c|c|c|}
\hline $\begin{array}{l}\text { Prof. } \\
\text { (cm) }\end{array}$ & DM & DV & $\%$ GR & $\% M G r$ & $\% \mathrm{Gr}$ & $\% \mathrm{M}$ & $\% F$ & \%AMF & $\%$ Arg & $\% \mathrm{~S}$ \\
\hline 275 & 5,94 & 1,76 & 0,00 & 0 & 0,00 & 0,00 & 0,00 & 13,62 & 16,61 & 69,77 \\
\hline 277 & 5,33 & 1,36 & 0,00 & 0 & 0,32 & 0,37 & 0,67 & 18,40 & 2,87 & 77,38 \\
\hline 279 & 5,33 & 1,36 & 0,00 & 0 & 0,32 & 0,37 & 0,67 & 18,40 & 2,87 & 77,38 \\
\hline 281 & 5,17 & 1,58 & 0,07 & $\begin{array}{c}0,0034 \\
1\end{array}$ & 0,20 & 0,97 & $\begin{array}{c}16,7 \\
8 \\
\end{array}$ & 2,33 & 2,80 & 76,70 \\
\hline 283 & 5,17 & 1,58 & 0,07 & $\begin{array}{c}0,0034 \\
1 \\
\end{array}$ & 0,20 & 0,97 & $\begin{array}{c}16,7 \\
8 \\
\end{array}$ & 2,33 & 2,84 & 76,80 \\
\hline 285 & 4,69 & 1,44 & 0,00 & $\begin{array}{c}0,1543 \\
2\end{array}$ & 1,00 & 0,77 & 1,85 & 30,63 & 0,00 & 65,59 \\
\hline 287 & 4,69 & 1,44 & 0,00 & $\begin{array}{c}0,1543 \\
2\end{array}$ & 1,00 & 0,77 & 1,85 & 30,63 & 0,00 & 65,59 \\
\hline 289 & 4,88 & 1,50 & 0,00 & $\begin{array}{c}0,0894 \\
9\end{array}$ & 0,70 & 0,77 & 4,41 & 26,91 & 0,00 & 67,12 \\
\hline 291 & 4,88 & 1,50 & 0,00 & $\begin{array}{c}0,0894 \\
9 \\
\end{array}$ & 0,70 & 0,77 & 4,41 & 26,91 & 0,00 & 67,12 \\
\hline 293 & 4,45 & 1,50 & 0,00 & $\begin{array}{c}0,2502 \\
1\end{array}$ & 2,34 & 1,42 & 1,83 & 44,12 & 0,00 & 50,04 \\
\hline 295 & 4,45 & 1,50 & 0,00 & $\begin{array}{c}0,2502 \\
1\end{array}$ & 2,34 & 1,42 & 1,83 & 44,12 & 0,00 & 50,04 \\
\hline 297 & 4,45 & 1,50 & 0,00 & $\begin{array}{c}0,2502 \\
1\end{array}$ & 2,34 & 1,42 & 1,83 & 44,12 & 0,00 & 50,04 \\
\hline 299 & 4,45 & 1,50 & 0,00 & $\begin{array}{c}0,2502 \\
1\end{array}$ & 2,34 & 1,42 & 1,83 & 44,12 & 0,00 & 50,04 \\
\hline 301 & 4,18 & 1,45 & 0,00 & $\begin{array}{c}0,1562 \\
5\end{array}$ & 1,25 & 0,86 & 7,73 & 50,94 & 0,00 & 39,06 \\
\hline 303 & 4,18 & 1,45 & 0,00 & $\begin{array}{c}0,1562 \\
5\end{array}$ & 1,25 & 0,86 & 7,73 & 50,94 & 0,00 & 39,06 \\
\hline 305 & 4,27 & 1,50 & 0,00 & $\begin{array}{c}0,1898 \\
5\end{array}$ & 0,82 & 0,70 & 2,90 & 57,42 & 0,00 & 37,97 \\
\hline 307 & 4,27 & 1,50 & 0,00 & $\begin{array}{c}0,1898 \\
5\end{array}$ & 0,82 & 0,70 & 2,90 & 57,42 & 0,00 & 37,97 \\
\hline 309 & 4,21 & 1,61 & 0,00 & $\begin{array}{c}0,0585 \\
7\end{array}$ & 0,76 & 0,73 & $\begin{array}{c}15,4 \\
6\end{array}$ & 46,09 & 0,00 & 36,90 \\
\hline 311 & 4,21 & 1,61 & 0,00 & $\begin{array}{c}0,0585 \\
7\end{array}$ & 0,76 & 0,73 & $\begin{array}{c}15,4 \\
6\end{array}$ & 46,09 & 0,00 & 36,90 \\
\hline 313 & 3,94 & 1,61 & 0,00 & $\begin{array}{c}0,2137 \\
2 \\
\end{array}$ & 1,24 & 1,06 & 9,51 & 63,93 & 0,00 & 24,04 \\
\hline 315 & 3,94 & 1,61 & 0,00 & $\begin{array}{c}0,2137 \\
2 \\
\end{array}$ & 1,24 & 1,06 & 9,51 & 63,93 & 0,00 & 24,04 \\
\hline 317 & 4,27 & 1,37 & 0,00 & 0 & 0,48 & 1,70 & 0,42 & 72,65 & 3,54 & 21,21 \\
\hline 319 & 4,27 & 1,37 & 0,00 & 0 & 0,48 & 1,70 & 0,42 & 72,65 & 3,54 & 21,21 \\
\hline 321 & 3,58 & 1,07 & 0,07 & 0,2451 & 1,50 & 0,70 & 5,50 & 74,48 & 0,00 & 17,51 \\
\hline 323 & 3,58 & 1,07 & 0,07 & 0,2451 & 1,50 & 0,70 & 5,50 & 74,48 & 0,00 & 17,51 \\
\hline 325 & 3,35 & 0,55 & 0,00 & $\begin{array}{c}0,5302 \\
3\end{array}$ & 0,42 & 0,36 & 5,67 & 82,11 & 0,00 & 10,92 \\
\hline 327 & 3,35 & 0,55 & 0,00 & $\begin{array}{c}0,5302 \\
3\end{array}$ & 0,42 & 0,36 & 5,67 & 82,11 & 0,00 & 10,92 \\
\hline 329 & 2,90 & 0,49 & 0,00 & $\begin{array}{c}0,0516 \\
8\end{array}$ & 0,26 & 0,26 & $\begin{array}{c}80,5 \\
3\end{array}$ & 12,24 & 0,00 & 6,67 \\
\hline 331 & 2,90 & 0,49 & 0,00 & $\begin{array}{c}0,0516 \\
8 \\
\end{array}$ & 0,26 & 0,26 & $\begin{array}{c}80,5 \\
3 \\
\end{array}$ & 12,24 & 0,00 & 6,67 \\
\hline 333 & 3,35 & 0,42 & 0,00 & 0,1022 & 0,36 & 0,20 & 3,73 & 88,86 & 0,00 & 6,75 \\
\hline 335 & 3,35 & 0,42 & 0,00 & 0,1022 & 0,36 & 0,20 & 3,73 & 88,86 & 0,00 & 6,75 \\
\hline 337 & 3,28 & 0,21 & 0,00 & 0 & 0,03 & 0,10 & 4,01 & 95,85 & 0,00 & 0,00 \\
\hline 339 & 3,27 & 0,51 & 0,00 & 0 & 1,33 & 1,63 & 4,90 & 87,28 & 0,00 & 4,85 \\
\hline 341 & 2,28 & 0,27 & 0,00 & $\begin{array}{c}0,0930 \\
3 \\
\end{array}$ & 0,78 & 1,91 & $\begin{array}{c}97,0 \\
1\end{array}$ & 0,21 & 0,00 & 0,00 \\
\hline 343 & 3,21 & 0,86 & 0,18 & $\begin{array}{c}1,2239 \\
9\end{array}$ & 3,67 & 1,65 & 7,02 & 75,61 & 0,00 & 10,64 \\
\hline
\end{tabular}


Legenda: $\mathrm{DM}=$ diâmetro médio $(\varphi)$, DP=desvio padrão, $\mathrm{GR}=$ grânulos, $\mathrm{MGr}=$ areia muito grossa, $\mathrm{Gr}=$ areia grossa e $\mathrm{M}=$ areia média; $\mathrm{F}=$ areia fina, $\mathrm{AMF}=$ areia muito fina,. Arg=argila $\mathrm{S}=$ silte 

Tabela 6- Teor de $\mathrm{CaCO}_{3}$ e das análises da matéria orgânica sedimentar do testemunho UBA1

\begin{tabular}{|c|c|c|c|c|c|c|c|c|c|}
\hline $\begin{array}{l}\text { Prof. } \\
\text { (cm) }\end{array}$ & $\begin{array}{c}\mathrm{CaCO} 3 \\
(\%)\end{array}$ & $\begin{array}{c}\text { T.A.M. } \\
\text { (g/mªno) }\end{array}$ & $\begin{array}{c}\text { T.A.C. } \\
\text { (g/mªno) }\end{array}$ & $\% \mathrm{C}$ & $\% \mathrm{~N}$ & $\% \mathrm{~S}$ & $\mathrm{C} / \mathrm{S}$ & $\mathrm{C} / \mathrm{N}$ & $\begin{array}{r}\delta^{13} \mathrm{C} \\
(\mathrm{ppm})\end{array}$ \\
\hline 1 & 13,32 & 193,8257977 & 2,477868998 & 1 & $\begin{array}{c}0,1346 \\
6\end{array}$ & $\begin{array}{c}0,2167 \\
4\end{array}$ & 5,8983113 & 9,4935393 & $-22,1$ \\
\hline 3 & 12,08 & 170,54994 & 2,255011307 & 1,3222 & $\begin{array}{c}0,1272 \\
5\end{array}$ & $\begin{array}{c}0,2300 \\
9\end{array}$ & 5,746447 & 10,39057 & \\
\hline 5 & 9,8 & 161,247684 & 2,034784525 & 1,2619 & $\begin{array}{c}0,1246 \\
7 \\
\end{array}$ & $\begin{array}{c}0,2119 \\
1\end{array}$ & 5,9548865 & 10,121922 & $-22,4$ \\
\hline 7 & 9,44 & 164,2357922 & 1,770626076 & 1,0781 & $\begin{array}{c}0,1078 \\
3\end{array}$ & $\begin{array}{c}0,2013 \\
9\end{array}$ & 5,3532946 & 9,9981452 & \\
\hline 9 & 3,16 & 172,8690684 & 2,118337564 & 1,2254 & $\begin{array}{c}0,1178 \\
7\end{array}$ & $\begin{array}{c}0,2080 \\
5 \\
\end{array}$ & 5,8899303 & 10,396199 & $-22,4$ \\
\hline 11 & 17,2 & 162,7416439 & 1,821078995 & 1,119 & $\begin{array}{c}0,1024 \\
3 \\
\end{array}$ & $\begin{array}{c}0,1906 \\
1\end{array}$ & 5,8706259 & 10,924534 & \\
\hline 13 & 17,32 & 151,6784701 & 1,385582825 & 0,9135 & 0,0831 & $\begin{array}{c}0,1835 \\
3\end{array}$ & 4,9773879 & 10,99278 & $-22,1$ \\
\hline 15 & 9,8 & 154,2376708 & 0 & $\begin{array}{c}0,9852 \\
7\end{array}$ & $\begin{array}{c}0,0824 \\
1\end{array}$ & 0,2471 & 3,9873331 & 11,955709 & \\
\hline 17 & 9,56 & 170,7330114 & 1,682181142 & $\begin{array}{c}0,6434 \\
5\end{array}$ & $\begin{array}{c}0,0622 \\
5\end{array}$ & $\begin{array}{c}0,2109 \\
5\end{array}$ & 3,0502489 & 10,336546 & $-22,5$ \\
\hline 19 & 8 & 177,6920033 & 1,143359195 & 0,5098 & $\begin{array}{c}0,0491 \\
3 \\
\end{array}$ & $\begin{array}{c}0,2566 \\
7 \\
\end{array}$ & 1,986208 & 10,376552 & \\
\hline 21 & 7,4 & 168,0787696 & 0,856865567 & $\begin{array}{c}0,4194 \\
7\end{array}$ & $\begin{array}{c}0,0336 \\
5\end{array}$ & $\begin{array}{c}0,3456 \\
4\end{array}$ & 1,2136037 & 12,465676 & $-22,8$ \\
\hline 23 & 17,24 & 214,3403195 & 0,899093338 & $\begin{array}{c}0,4110 \\
7\end{array}$ & $\begin{array}{c}0,0309 \\
9\end{array}$ & $\begin{array}{c}0,3069 \\
6\end{array}$ & 1,3391647 & 13,264601 & \\
\hline 25 & 4,36 & 200,8930741 & 0,82581116 & $\begin{array}{c}0,4798 \\
9\end{array}$ & $\begin{array}{c}0,0354 \\
2\end{array}$ & $\begin{array}{c}0,5288 \\
4\end{array}$ & 0,9074389 & 13,54856 & $-24,8$ \\
\hline 27 & 4,2 & 213,144769 & 1,022860432 & $\begin{array}{c}0,2740 \\
2\end{array}$ & 0,0213 & 0,2795 & 0,9803936 & 12,864789 & \\
\hline 29 & 5,32 & 214,4016348 & 0,58750336 & $\begin{array}{c}0,5146 \\
2\end{array}$ & $\begin{array}{c}0,0364 \\
3 \\
\end{array}$ & $\begin{array}{c}0,5517 \\
8 \\
\end{array}$ & 0,9326543 & 14,12627 & -25 \\
\hline 31 & 6,84 & 191,5018438 & 0,985506789 & $\begin{array}{c}0,6912 \\
7\end{array}$ & $\begin{array}{c}0,0559 \\
7\end{array}$ & $\begin{array}{c}0,3015 \\
3\end{array}$ & 2,2925414 & 12,350724 & \\
\hline 33 & 13,04 & 133,7777019 & 0,92476512 & $\begin{array}{c}0,7857 \\
8 \\
\end{array}$ & $\begin{array}{c}0,0654 \\
2 \\
\end{array}$ & $\begin{array}{c}0,3897 \\
6\end{array}$ & 2,0160612 & 12,011312 & $-22,8$ \\
\hline 35 & 18,76 & 161,1257364 & 1,266093811 & 1,151 & $\begin{array}{c}0,0890 \\
1\end{array}$ & $\begin{array}{c}0,5036 \\
6\end{array}$ & 2,2852718 & 12,931131 & \\
\hline 37 & 18,76 & 161,18671 & 1,855259032 & 1,1462 & $\begin{array}{c}0,0840 \\
2\end{array}$ & $\begin{array}{c}0,5282 \\
3\end{array}$ & 2,1698881 & 13,64199 & $-23,1$ \\
\hline 39 & 25 & 129,3060061 & 1,482105442 & 1,0512 & $\begin{array}{c}0,0933 \\
3\end{array}$ & $\begin{array}{c}0,5667 \\
5\end{array}$ & 1,8547861 & 11,263259 & \\
\hline 41 & 24,08 & 176,3792164 & 1,854098323 & $\begin{array}{c}0,8787 \\
8\end{array}$ & $\begin{array}{c}0,0724 \\
1\end{array}$ & $\begin{array}{c}0,4634 \\
2\end{array}$ & 1,8962928 & 12,136169 & $-22,5$ \\
\hline 43 & 28,16 & 160,6684437 & 1,411922149 & $\begin{array}{c}0,7291 \\
5\end{array}$ & $\begin{array}{c}0,0642 \\
1\end{array}$ & $\begin{array}{c}0,3673 \\
4\end{array}$ & 1,9849458 & 11,355708 & \\
\hline 45 & 31,48 & 169,5736102 & 1,236445978 & 1,017 & $\begin{array}{c}0,0826 \\
6\end{array}$ & $\begin{array}{c}0,5380 \\
4\end{array}$ & 1,890194 & 12,303412 & $-22,2$ \\
\hline
\end{tabular}




\begin{tabular}{|c|c|c|c|c|c|c|c|c|c|}
\hline 47 & 19,64 & 159,357634 & 1,620667138 & 1,0798 & $\begin{array}{c}0,0856 \\
8\end{array}$ & $\begin{array}{c}0,5351 \\
5\end{array}$ & 2,017752 & 12,602708 & \\
\hline 49 & 38,68 & 167,1026536 & 1,804374453 & 1,1592 & $\begin{array}{c}0,0910 \\
3\end{array}$ & $\begin{array}{c}0,6174 \\
5\end{array}$ & 1,877399 & 12,734263 & $-22,7$ \\
\hline 51 & 40,36 & 161,2781711 & 1,86953656 & 1,0805 & $\begin{array}{c}0,0878 \\
4\end{array}$ & $\begin{array}{c}0,4905 \\
7 \\
\end{array}$ & 2,2025399 & 12,300774 & \\
\hline 53 & 29,92 & 147,7187977 & 1,596101609 & $\begin{array}{c}0,9982 \\
5\end{array}$ & $\begin{array}{c}0,0819 \\
4\end{array}$ & $\begin{array}{c}0,4605 \\
2\end{array}$ & 2,1676583 & 12,182695 & -23 \\
\hline 55 & 33,28 & 164,9676894 & 1,646789959 & 1,1833 & $\begin{array}{c}0,0934 \\
2 \\
\end{array}$ & $\begin{array}{c}0,5309 \\
6 \\
\end{array}$ & 2,2286048 & 12,666453 & \\
\hline 57 & 25,64 & 139,2246561 & 1,647445356 & 1,0762 & $\begin{array}{c}0,0763 \\
7 \\
\end{array}$ & $\begin{array}{c}0,5530 \\
6 \\
\end{array}$ & 1,945901 & 14,091921 & $-22,9$ \\
\hline 59 & 31,12 & 151,9221816 & 1,634986518 & 0,9875 & $\begin{array}{c}0,0791 \\
4\end{array}$ & $\begin{array}{c}0,5822 \\
1\end{array}$ & 1,6961234 & 12,477887 & \\
\hline
\end{tabular}

Legenda: T.A.M. =taxa de acúmulo de massa e T.A.C. $=$ taxa de acúmulo carbono ( $\mathrm{g} \cdot \mathrm{m}^{-2}$ ano-1) 

Tabela 6a-. Teor de $\mathrm{CaCO}_{3}$ e das análises da matéria orgânica sedimentar do testemunho UBA1 (cont.)

\begin{tabular}{|c|c|c|c|c|c|c|c|c|c|}
\hline Prof.(cm) & $\mathrm{CaCO} 3(\%)$ & $\begin{array}{c}\text { T.A.M. } \\
\text { (g/m²/ano) }\end{array}$ & $\begin{array}{l}\text { T.A.C. } \\
\text { (g/m²/ano } \\
)^{2}\end{array}$ & $\% \mathrm{C}$ & $\% \mathrm{~N}$ & $\% S$ & $\mathrm{C} / \mathrm{S}$ & $\mathrm{C} / \mathrm{N}$ & $\delta^{13} \mathrm{C}$ (ppm) \\
\hline 61 & 37,84 & 168,99395 & 1,6688153 & 1,0352 & 0,07397 & 0,60418 & 1,7133967 & 13,994863 & $-23,8$ \\
\hline 63 & 35,88 & 141,69016 & 1,4667765 & 1,0796 & 0,06861 & 0,69318 & 1,5574598 & 15,735316 & \\
\hline 65 & 39,52 & 143,09052 & 1,5448052 & 1,095 & 0,07537 & 0,63781 & 1,7168122 & 14,528327 & $-23,8$ \\
\hline 67 & 37,76 & 727,0507 & 7,9612052 & 1,1793 & 0,11365 & 0,67564 & 1,7454562 & 10,376595 & \\
\hline 69 & 42,44 & 645,96074 & 7,617815 & 1,1012 & 0,07487 & 0,64083 & 1,7183965 & 14,708161 & -24 \\
\hline 71 & 42,44 & 659,88034 & 7,2666023 & 1,0409 & 0,07481 & 0,64331 & 1,618038 & 13,913915 & \\
\hline 73 & 43,12 & 600,87243 & 6,2544811 & 0,86807 & 0,06372 & 0,61085 & 1,4210854 & 13,623195 & $-23,6$ \\
\hline 75 & 37,84 & 660,87474 & 5,7368554 & 0,96934 & 0,07495 & 0,6459 & 1,5007586 & 12,933155 & \\
\hline 77 & 44,4 & 685,74168 & 6,6471684 & 0,99808 & 0,07113 & 0,63625 & 1,5686916 & 14,031773 & -24 \\
\hline 79 & 26,32 & 621,73491 & 6,2054117 & 1,1755 & 0,07514 & 0,67815 & 1,7333923 & 15,644131 & \\
\hline 81 & 27,92 & 652,42292 & 7,6692314 & 1,1963 & 0,07903 & 0,7544 & 1,5857635 & 15,13729 & $-23,3$ \\
\hline 83 & 34,24 & 591,56142 & 7,0768493 & 1,1842 & 0,07889 & 0,78082 & 1,5166107 & 15,010774 & \\
\hline 85 & 23,96 & 640,12064 & 7,5803086 & 1,4216 & 0,0754 & 0,78215 & 1,8175542 & 18,854111 & $-23,9$ \\
\hline 87 & 18,24 & 648,94318 & 9,2253762 & 1,0398 & 0,0598 & 0,81154 & 1,2812677 & 17,38796 & \\
\hline 89 & 26,92 & 562,89322 & 5,8529637 & 1,2224 & 0,07461 & 1 & 1,0741652 & 16,383863 & -24 \\
\hline 91 & 26,56 & 496,92173 & 6,0743712 & 1,0964 & 0,06268 & 0,84662 & 1,295032 & 17,492023 & \\
\hline 93 & 24,8 & 636,26902 & 6,9760536 & 1,32 & 0,07016 & 1 & 1,1136421 & 18,814139 & $-23,7$ \\
\hline 95 & 30,2 & 537,71158 & 7,0977928 & 1,3696 & 0,07686 & 1 & 1,2087194 & 17,819412 & \\
\hline 97 & 20,8 & 528,90667 & 7,2439058 & 1,3139 & 0,07582 & 1 & 1,2232567 & 17,329201 & $-24,1$ \\
\hline 99 & 15,96 & 616,39433 & 8,0988051 & 1,0774 & 0,06224 & 0,97395 & 1,106217 & 17,310411 & \\
\hline 101 & 21,92 & 569,59359 & 6,1368013 & 0,8136 & 0,04558 & 0,84477 & 0,9631024 & 17,849934 & $-24,4$ \\
\hline 103 & 17,44 & 571,95131 & 4,6533959 & 1,1045 & 0,05792 & 1 & 1,063963 & 19,069406 & \\
\hline 105 & 21,76 & 567,60821 & 6,2692327 & 1,059 & 0,05725 & 1 & 0,9729879 & 18,497817 & $-24,4$ \\
\hline 107 & 9,56 & 503,86284 & 5,3359075 & 1,0677 & 0,06249 & 1 & 0,9300523 & 17,085934 & \\
\hline 109 & 14,56 & 451,20257 & 4,8174898 & 1,0771 & 0,0588 & 1 & 0,8519339 & 18,318027 & $-23,3$ \\
\hline 111 & 13,6 & 518,24324 & 5,581998 & 1,1501 & 0,06626 & 0,99115 & 1,1603693 & 17,35738 & \\
\hline 113 & 14 & 517,25139 & 5,9489082 & 1,0992 & 0,06017 & 0,96132 & 1,1434278 & 18,26824 & $-23,4$ \\
\hline 115 & 14,12 & 430,52101 & 4,7322869 & 1,1634 & 0,07052 & 1 & 0,9826843 & 16,497448 & \\
\hline 117 & 12,04 & 523,57473 & 6,0912684 & 0,92339 & 0,05885 & 0,652 & 1,4162423 & 15,690569 & $-23,4$ \\
\hline 119 & 11,76 & 704,1518 & 6,5020673 & 1,1929 & 0,06477 & 0,86602 & 1,3774509 & 18,417477 & \\
\hline 121 & 13,84 & 395,23936 & 4,7148103 & 1,1367 & 0,07042 & 0,88875 & 1,2789873 & 16,141721 & $-23,3$ \\
\hline 123 & 15,6 & 485,76788 & 5,5217235 & 1,1364 & 0,0621 & 0,81866 & 1,3881221 & 18,299517 & \\
\hline 125 & 12,92 & 555,44926 & 6,3121254 & 1,2348 & 0,07587 & 0,86027 & 1,4353633 & 16,275208 & $-23,3$ \\
\hline 127 & 11,2 & 569,4695 & 7,0318094 & 1,2071 & 0,07362 & 0,90866 & 1,3284397 & 16,39636 & \\
\hline 129 & 12,28 & 595,40978 & 7,1871914 & 1,1488 & 0,07558 & 0,85547 & 1,3428875 & 15,199788 & $-23,4$ \\
\hline 131 & 12 & 518,98714 & 5,9621243 & 1,1027 & 0,07096 & 0,94682 & 1,1646353 & 15,539741 & \\
\hline 133 & 8,44 & 502,3754 & 5,5396935 & 1,2245 & 0,07522 & 0,79609 & 1,5381427 & 16,278915 & $-23,8$ \\
\hline 135 & 11,52 & 533,49499 & 6,5326461 & 1,1255 & 0,07956 & 1 & 0,994258 & 14,146556 & \\
\hline 137 & 11,36 & 534,4871 & 6,0156523 & 1,2464 & 0,08199 & 1 & 1,0573465 & 15,201854 & $-23,4$ \\
\hline 139 & 15,08 & 677,78284 & 8,4478853 & 1,3183 & 0,07731 & 0,9453 & 1,3945837 & 17,052128 & \\
\hline 141 & 14,32 & 372,71697 & 4,9135278 & 1,3125 & 0,08498 & 0,94799 & 1,3845083 & 15,444811 & $-23,4$ \\
\hline 143 & 15,44 & 379,39878 & 4,979609 & 1,2493 & 0,08555 & 1 & 1,1124666 & 14,603156 & \\
\hline
\end{tabular}

Legenda: T.A.M. =taxa de acúmulo de massa e T.A.C. $=$ taxa de acúmulo carbono $\left(\mathrm{g} \cdot \mathrm{m}^{-2}\right.$ ano-1 $\left.^{-1}\right)$ 
Tabela 6b-. Teor de $\mathrm{CaCO}_{3}$ e das análises da matéria orgânica sedimentar do testemunho UBA1 (cont.)

\begin{tabular}{|c|c|c|c|c|c|c|c|c|c|}
\hline Prof.(cm) & CaCO3 (\%) & $\begin{array}{c}\text { T.A.M. } \\
\text { (g/m²/ano) }\end{array}$ & $\begin{array}{c}\text { T.A.C. } \\
\left(\mathrm{g} / \mathrm{m}^{2} / \text { ano }\right. \\
)^{(2)}\end{array}$ & $\% \mathrm{C}$ & $\% \mathrm{~N}$ & $\% \mathrm{~S}$ & $\mathrm{C} / \mathrm{S}$ & $\mathrm{C} / \mathrm{N}$ & $\delta^{13} \mathrm{C}(\mathrm{ppm})$ \\
\hline 145 & 17,6 & 380,8837 & 4,7583801 & 1,2086 & 0,0723 & 1 & 1,2046247 & 16,716459 & $-23,1$ \\
\hline 147 & 13,44 & 484,15693 & 5,8515206 & 1,2987 & 0,07634 & 0,98638 & 1,3166325 & 17,012051 & \\
\hline 149 & 13,44 & 504,73054 & 6,5549355 & 1,433 & 0,08215 & 0,98027 & 1,4618421 & 17,443701 & $-23,5$ \\
\hline 151 & 14,92 & 429,03513 & 6,1480734 & 1,4084 & 0,08708 & 1 & 1,346334 & 16,173633 & \\
\hline 153 & 11,8 & 510,30883 & 7,1871896 & 1,3704 & 0,10215 & 0,96647 & 1,4179437 & 13,415565 & $-23,5$ \\
\hline 155 & 20,04 & 521,96284 & 7,1529787 & 1,4245 & 0,09221 & 1 & 1,3488306 & 15,448433 & \\
\hline 157 & 11,16 & 829,0095 & 11,80924 & 1,2355 & 0,08114 & 0,9669 & 1,277795 & 15,226769 & $-23,2$ \\
\hline 159 & 17,2 & 482,42209 & 5,960325 & 1,2492 & 0,1238 & 0,77089 & 1,6204647 & 10,090468 & \\
\hline 161 & 20,08 & 469,53614 & 5,8654455 & 1,5905 & 0,14047 & 1,0904 & 1,458639 & 11,322702 & $-23,4$ \\
\hline 163 & 13,72 & 598,88595 & 9,525281 & 1,5739 & 0,13023 & 1,1169 & 1,4091682 & 12,085541 & \\
\hline 165 & 16,72 & 323,23874 & 5,0874546 & 1,5332 & 0,12837 & 1,2715 & 1,2058199 & 11,943601 & $-23,5$ \\
\hline 167 & 17,12 & 423,58718 & 6,4944386 & 1,5778 & 0,12894 & 1,5205 & 1,037685 & 12,236699 & \\
\hline 169 & 15,8 & 576,66705 & 9,0986527 & 1,5574 & 0,13217 & 1,2574 & 1,2385876 & 11,783309 & $-23,5$ \\
\hline 171 & 14,24 & 605,83895 & 9,4353358 & 1,6945 & 0,13119 & 0,97917 & 1,7305473 & 12,916381 & \\
\hline 173 & 15,44 & 639,37514 & 10,834212 & 1,6122 & 0,12487 & 1,6437 & 0,9808359 & 12,911027 & $-23,1$ \\
\hline 175 & 20,8 & 549,37072 & 8,8569548 & 1,5785 & 0,13743 & 0,95911 & 1,6457966 & 11,485847 & \\
\hline 177 & 21,04 & 615,2766 & 9,7121411 & 1,5741 & 0,14761 & 0,91074 & 1,7283747 & 10,663912 & $-23,3$ \\
\hline 179 & 12,92 & 611,30265 & 9,622515 & 1,5429 & 0,12727 & 1,0371 & 1,4877061 & 12,123045 & \\
\hline 181 & 11,96 & 523,82272 & 8,0820607 & 1,4674 & 0,10082 & 1,1662 & 1,2582747 & 14,554652 & $-23,1$ \\
\hline 183 & 11,92 & 586,84444 & 8,6113553 & 1,4039 & 0,08639 & 1,0831 & 1,2961869 & 16,250723 & \\
\hline 185 & 10,8 & 471,51844 & 6,6196474 & 1,4246 & 0,09005 & 1,2246 & 1,1633186 & 15,8201 & -23 \\
\hline 187 & 13,2 & 427,30165 & 6,0873393 & 1,2402 & 0,09005 & 0,85108 & 1,4572073 & 13,772349 & \\
\hline 189 & 13,2 & 561,90064 & 8,0048365 & 1,2402 & 0,09127 & 0,85108 & 1,4572073 & 13,588255 & $-23,1$ \\
\hline 191 & 16 & 538,70376 & 6,681004 & 1,0201 & 0,0748 & 0,73413 & 1,3895359 & 13,637701 & \\
\hline 193 & 14,8 & 573,31635 & 5,8484001 & 1,792 & 0,10012 & 0,77171 & 2,3221158 & 17,898522 & $-23,4$ \\
\hline 195 & 8,4 & 672,93358 & 7,9352328 & 1,2271 & 0,12816 & 0,82865 & 1,4808423 & 9,5747503 & \\
\hline 197 & 7,8 & 543,54087 & 6,66979 & 1,3027 & 0,11417 & 1,1323 & 1,1504902 & 11,410178 & $-22,9$ \\
\hline 199 & 7,6 & 625,08857 & 8,1430288 & 1,1906 & 0,09197 & 0,75673 & 1,5733485 & 12,945526 & \\
\hline 201 & 6,8 & 564,63028 & 6,7224881 & 1,2557 & 0,09734 & 0,87033 & 1,4427861 & 12,900144 & $-23,3$ \\
\hline 203 & 7,44 & 654,9086 & 8,2236873 & 1,13 & 0,08981 & 0,93663 & 1,2064529 & 12,582118 & \\
\hline 205 & 10,84 & 652,05008 & 7,3681659 & 1,2057 & 0,09175 & 0,80723 & 1,4936264 & 13,141144 & $-23,3$ \\
\hline 207 & 9,28 & 520,47497 & 6,2753667 & 1,1742 & 0,0912 & 0,74032 & 1,5860709 & 12,875 & \\
\hline 209 & 9,28 & 581,75551 & 6,8309732 & 0,9606 & 0,0766 & 0,71771 & 1,3384236 & 12,54047 & $-23,5$ \\
\hline 211 & 13,04 & 576,66705 & 5,5394636 & 0,96752 & 0,08503 & 0,57322 & 1,6878685 & 11,378572 & \\
\hline 213 & 8,76 & 640,99039 & 6,2017103 & 0,95024 & 0,13336 & 0,64738 & 1,4678242 & 7,1253749 & -24 \\
\hline 215 & 12,56 & 723,44083 & 6,8744242 & 0,93141 & 0,10091 & 0,50178 & 1,8562119 & 9,230106 & \\
\hline 217 & 10,12 & 693,20434 & 6,4565746 & 0,7145 & 0,06893 & 0,64738 & 1,1036794 & 10,365588 & $-23,7$ \\
\hline 219 & 13,2 & 669,82534 & 4,7859021 & 0,77539 & 0,05961 & 0,6938 & 1,1175987 & 13,007717 & \\
\hline 221 & 8,72 & 676,53939 & 5,2458188 & 0,77539 & 0,05961 & 0,6938 & 1,1175987 & 13,007717 & $-23,8$ \\
\hline
\end{tabular}

Legenda: T.A.M. =taxa de acúmulo de massa e T.A.C. $=$ taxa de acúmulo carbono $\left(\mathrm{g} \cdot \mathrm{m}^{-2}\right.$ ano-1 $\left.^{-1}\right)$ 
Tabela 7- Teor de $\mathrm{CaCO}_{3}$ e das análises da matéria orgânica sedimentar do testemunho UBA3

\begin{tabular}{|c|c|c|c|c|c|c|c|c|c|}
\hline Prof. (cm) & $\mathrm{CaCO} 3(\%)$ & $\begin{array}{c}\text { T.A.M. } \\
\text { (g/m²/ano) }\end{array}$ & $\begin{array}{c}\text { T.A.C. } \\
\text { (g/mªno) }\end{array}$ & $\% \mathrm{C}$ & $\% \mathrm{~N}$ & $\% S$ & $\mathrm{C} / \mathrm{S}$ & $\mathrm{C} / \mathrm{N}$ & $\delta^{13} \mathrm{C}(\mathrm{ppm})$ \\
\hline 1 & 17,5 & 292,48642 & 0,7829277 & 0,26768 & 0,0135 & 0,12951 & 2,0668674 & 19,828148 & $-22,8$ \\
\hline 3 & 16,75 & 331,83879 & 1,03245 & 0,31113 & 0,00895 & 0,1164 & 2,6729381 & 34,763128 & \\
\hline 5 & 13,75 & 340,55873 & 1,1283392 & 0,33132 & 0,01416 & 0,11366 & 2,9150097 & 23,398305 & $-23,5$ \\
\hline 7 & 13 & 329,45894 & 1,9734261 & 0,59899 & 0,0652 & 0,36193 & 1,6549885 & 9,1869632 & \\
\hline 9 & 14,35 & 331,03197 & 1,0959144 & 0,33106 & 0,00941 & 0,10064 & 3,2895469 & 35,181722 & $-24,2$ \\
\hline 11 & 11,2 & 313,94881 & 0,9263688 & 0,29507 & 0,01301 & 0,10492 & 2,8123332 & 22,680246 & \\
\hline 13 & 17,6 & 245,38878 & 0,9261218 & 0,37741 & 0,00651 & 0,06484 & 5,8206354 & 57,973886 & $-21,8$ \\
\hline 15 & 18,5 & 250,14562 & 1,3170917 & 0,52653 & 0,00313 & 0,5619 & 0,9370529 & 168,22045 & \\
\hline 17 & 15,6 & 255,34428 & 1,5112041 & 0,59183 & 0,01314 & 0,09938 & 5,9552224 & 45,040335 & $-23,9$ \\
\hline 19 & 14,25 & 253,62447 & 1,548276 & 0,61046 & 0,0209 & 0,11095 & 5,5021181 & 29,208612 & \\
\hline 21 & 19,3 & 246,06822 & 1,3216078 & 0,53709 & 0,008 & 0,10545 & 5,0933144 & 67,13625 & $-23,7$ \\
\hline 23 & 19,3 & 262,58626 & 1,4293358 & 0,54433 & 0,202 & 0,154 & 3,5346104 & 2,694703 & \\
\hline 25 & 24,75 & 268,27106 & 1,5426391 & 0,57503 & 0,01778 & 0,16272 & 3,5338618 & 32,341395 & $-23,4$ \\
\hline 27 & 22,85 & 264,62765 & 1,4525147 & 0,54889 & 0,03353 & 0,18454 & 2,9743687 & 16,370116 & \\
\hline 29 & 25,6 & 248,94624 & 1,2572034 & 0,50501 & 0,01786 & 0,19342 & 2,6109503 & 28,276036 & -23 \\
\hline 31 & 20,5 & 257,26436 & 1,2866563 & 0,50013 & 0,00481 & 0,20206 & 2,4751559 & 103,97713 & \\
\hline 33 & 20 & 248,86629 & 1,1690494 & 0,46975 & 0,00185 & 0,24081 & 1,950708 & 253,91892 & -23 \\
\hline 35 & 20,5 & 249,98569 & 1,2617778 & 0,50474 & 0,00242 & 0,19229 & 2,6248895 & 208,57025 & \\
\hline 37 & 21 & 260,22511 & 1,2737499 & 0,48948 & 0,00529 & 0,19355 & 2,5289589 & 92,529301 & $-23,1$ \\
\hline 39 & 19,2 & 254,58434 & 1,1060416 & 0,43445 & 0,01307 & 0,19326 & 2,2480079 & 33,240245 & \\
\hline 41 & 16,9 & 266,8696 & 1,1543978 & 0,43257 & 0,0109 & 0,18674 & 2,3164293 & 39,685321 & $-23,6$ \\
\hline 43 & 16 & 268,43124 & 1,1216399 & 0,41785 & 0,00385 & 0,2032 & 2,0563484 & 108,53247 & \\
\hline 45 & 22,6 & 267,71046 & 1,0128825 & 0,37835 & 0,01578 & 0,23025 & 1,6432139 & 23,976553 & $-23,5$ \\
\hline 47 & 21,75 & 250,26556 & 1,1320512 & 0,45234 & 0,00866 & 0,23868 & 1,8951735 & 52,233256 & \\
\hline 49 & 22,1 & 253,42451 & 1,2202137 & 0,48149 & 0,01126 & 0,24095 & 1,9982984 & 42,761101 & $-23,2$ \\
\hline 51 & 20,25 & 267,0698 & 1,1623412 & 0,43522 & 0,01478 & 0,22126 & 1,9670071 & 29,446549 & \\
\hline 53 & 21,25 & 257,5044 & 1,1025823 & 0,42818 & 0,02411 & 0,21393 & 2,0014958 & 17,759436 & $-23,4$ \\
\hline 121 & 13,84 & 395,23936 & 4,7148103 & 1,1367 & 0,07042 & 0,88875 & 1,2789873 & 16,141721 & $-23,3$ \\
\hline 123 & 15,6 & 485,76788 & 5,5217235 & 1,1364 & 0,0621 & 0,81866 & 1,3881221 & 18,299517 & \\
\hline 125 & 12,92 & 555,44926 & 6,3121254 & 1,2348 & 0,07587 & 0,86027 & 1,4353633 & 16,275208 & $-23,3$ \\
\hline 127 & 11,2 & 569,4695 & 7,0318094 & 1,2071 & 0,07362 & 0,90866 & 1,3284397 & 16,39636 & \\
\hline 129 & 12,28 & 595,40978 & 7,1871914 & 1,1488 & 0,07558 & 0,85547 & 1,3428875 & 15,199788 & $-23,4$ \\
\hline 131 & 12 & 518,98714 & 5,9621243 & 1,1027 & 0,07096 & 0,94682 & 1,1646353 & 15,539741 & \\
\hline 133 & 8,44 & 502,3754 & 5,5396935 & 1,2245 & 0,07522 & 0,79609 & 1,5381427 & 16,278915 & $-23,8$ \\
\hline 135 & 11,52 & 533,49499 & 6,5326461 & 1,1255 & 0,07956 & 1 & 0,994258 & 14,146556 & \\
\hline 137 & 11,36 & 534,4871 & 6,0156523 & 1,2464 & 0,08199 & 1 & 1,0573465 & 15,201854 & $-23,4$ \\
\hline 139 & 15,08 & 677,78284 & 8,4478853 & 1,3183 & 0,07731 & 0,9453 & 1,3945837 & 17,052128 & \\
\hline 141 & 14,32 & 372,71697 & 4,9135278 & 1,3125 & 0,08498 & 0,94799 & 1,3845083 & 15,444811 & $-23,4$ \\
\hline 143 & 15,44 & 379,39878 & 4,979609 & 1,2493 & 0,08555 & 1 & 1,1124666 & 14,603156 & \\
\hline 145 & 17,6 & 380,8837 & 4,7583801 & 1,2086 & 0,0723 & 1 & 1,2046247 & 16,716459 & $-23,1$ \\
\hline 147 & 13,44 & 484,15693 & 5,8515206 & 1,2987 & 0,07634 & 0,98638 & 1,3166325 & 17,012051 & \\
\hline 149 & 13,44 & 504,73054 & 6,5549355 & 1,433 & 0,08215 & 0,98027 & 1,4618421 & 17,443701 & $-23,5$ \\
\hline
\end{tabular}

Legenda: T.A.M. =taxa de acúmulo de massa e T.A.C. $=$ taxa de acúmulo carbono $\left(\mathrm{g} \cdot \mathrm{m}^{-2}\right.$ ano $\left.^{-1}\right)$ 
Tabela 7a- Teor de $\mathrm{CaCO}_{3}$ e das análises da matéria orgânica sedimentar do testemunho UBA3 (cont.)

\begin{tabular}{|c|c|c|c|c|c|c|c|c|c|}
\hline Prof. (cm) & $\mathrm{CaCO} 3(\%)$ & $\begin{array}{c}\text { T.A.M. } \\
\text { (g/m²/ano) }\end{array}$ & $\begin{array}{c}\text { T.A.C. } \\
\text { (g/m²/ano) }\end{array}$ & $\% \mathrm{C}$ & $\% \mathbf{N}$ & $\% S$ & $\mathrm{C} / \mathrm{S}$ & $\mathrm{C} / \mathrm{N}$ & $\delta^{13} \mathrm{Cppm}$ \\
\hline 151 & 27,35 & 1158,8663 & 1200,6113 & 0,72156 & 0,05545 & 0,34296 & 2,1039188 & 13,012804 & \\
\hline 153 & 27,35 & 1113,8353 & 1100,0005 & 2 & 0,06672 & 0,41002 & 4,5436808 & 27,922662 & $-23,3$ \\
\hline 155 & 30,75 & 1200,6113 & 1255,4695 & 0,70028 & 0,06016 & 0,31668 & 2,2113174 & 11,640293 & \\
\hline 157 & 26,4 & 1100,0005 & 1205,0996 & 0,64156 & 0,06025 & 0,29624 & 2,1656765 & 10,648299 & $-22,7$ \\
\hline 159 & 1,8666667 & 1255,4695 & 1155,7463 & 0,71969 & 0,08403 & 0,33805 & 2,1289454 & 8,5646793 & \\
\hline 161 & 29,2 & 1205,0996 & 1162,5716 & 0,6705 & 0,07057 & 0,3356 & 1,9979142 & 9,5012045 & $-22,8$ \\
\hline 163 & 29,2 & 1155,7463 & 1336,7814 & 0,61203 & 0,05014 & 0,3515 & 1,7411949 & 12,206422 & \\
\hline 165 & 28,666667 & 1162,5716 & 1119,292 & 0,60966 & 0,04859 & 0,33736 & 1,8071496 & 12,547026 & $-22,7$ \\
\hline 167 & 30,266667 & 1336,7814 & 1157,3063 & 0,70907 & 0,04961 & 0,31695 & 2,2371667 & 14,292884 & \\
\hline 169 & 29,866667 & 1119,292 & 1212,5157 & 0,68853 & 0,04705 & 0,32833 & 2,097067 & 14,634006 & $-22,9$ \\
\hline 171 & 28,133333 & 1157,3063 & 1166,277 & 0,72196 & 0,04703 & 0,33912 & 2,1289219 & 15,351053 & \\
\hline 173 & 29,8 & 1212,5157 & 1127,4778 & 0,78362 & 0,04932 & 0,37508 & 2,0892076 & 15,888483 & $-23,1$ \\
\hline 175 & 29,266667 & 1166,277 & 1202,7579 & 0,75777 & 0,05396 & 0,37299 & 2,0316094 & 14,04318 & \\
\hline 177 & 29,4 & 1127,4778 & 1123,1899 & 0,75252 & 0,07113 & 0,32891 & 2,2879207 & 10,579502 & $-23,1$ \\
\hline 179 & 29,533333 & 1202,7579 & 1132,5458 & 0,75592 & 0,07959 & 0,3471 & 2,1778162 & 9,4976756 & \\
\hline 181 & 27,2 & 1123,1899 & 1123,3848 & 0,79589 & 0,0782 & 0,40123 & 1,9836254 & 10,177621 & $-23,2$ \\
\hline 183 & 27,2 & 1132,5458 & 1130,0118 & 0,85318 & 0,07332 & 0,45935 & 1,8573637 & 11,636388 & \\
\hline 185 & 28,466667 & 1123,3848 & 1094,1557 & 1 & 0,09415 & 0,5586 & 1,811672 & 10,748805 & $-22,9$ \\
\hline 187 & 28,4 & 1130,0118 & 1083,831 & 0,80374 & 0,06912 & 0,39239 & 2,0483193 & 11,628183 & \\
\hline 189 & 27,266667 & 1094,1557 & 1126,5033 & 0,77961 & 0,06968 & 0,36431 & 2,1399632 & 11,188433 & $-22,8$ \\
\hline 191 & 29,333333 & 1083,831 & 1137,0293 & 0,88417 & 0,05623 & 0,28295 & 3,1248213 & 15,724136 & \\
\hline 193 & 29,333333 & 1126,5033 & 1105,4562 & 0,89964 & 0,08658 & 0,38588 & 2,3313972 & 10,390847 & $-22,7$ \\
\hline 195 & 28,513333 & 1137,0293 & 1164,9118 & 0,91511 & 0,09442 & 0,36205 & 2,5275816 & 9,6919181 & \\
\hline 197 & 28,513333 & 1105,4562 & 1175,639 & 0,93058 & 0,08752 & 0,36886 & 2,5228604 & 10,632796 & $-23,1$ \\
\hline 199 & 29 & 1164,9118 & 1170,9578 & 0,94605 & 0,05781 & 0,33305 & 2,8405754 & 16,364879 & \\
\hline 201 & 29 & 1175,639 & 1104,4819 & 0,96152 & 0,06112 & 0,41103 & 2,3393061 & 15,731757 & $-23,1$ \\
\hline 203 & 26,666667 & 1170,9578 & 1119,292 & 0,977 & 0,0613 & 0,47488 & 2,0573542 & 15,93795 & \\
\hline 205 & 26,666667 & 1104,4819 & 1128,2575 & 0,99247 & 0,07363 & 0,43912 & 2,2601287 & 13,479122 & $-22,9$ \\
\hline 207 & 29,066667 & 1119,292 & 1126,6982 & 1 & 0,06266 & 0,47412 & 2,1259156 & 16,085846 & \\
\hline 209 & 29,066667 & 1128,2575 & 1118,9022 & 1,02341 & 0,06979 & 0,48639 & 2,1040944 & 14,664142 & -23 \\
\hline 211 & 28,8 & 1126,6982 & 1193,1966 & 1,03888 & 0,07513 & 0,45998 & 2,2585369 & 13,827789 & \\
\hline 213 & 28,8 & 1118,9022 & 1167,4472 & 1,05435 & 0,10152 & 0,43136 & 2,4442535 & 10,38567 & $-23,2$ \\
\hline 215 & 29,133333 & 1193,1966 & 1152,4314 & 1,06982 & 0,08409 & 0,49444 & 2,1637095 & 12,722375 & \\
\hline 217 & 29,133333 & 1167,4472 & 1078,7666 & 1,0853 & 0,06225 & 0,4516 & 2,4032239 & 17,434472 & $-22,6$ \\
\hline 219 & 28,666667 & 1152,4314 & 1106,8201 & 1,10077 & 0,05596 & 0,49495 & 2,2239969 & 19,670609 & \\
\hline 221 & 28,666667 & 1078,7666 & 1138,5888 & 1,11624 & 0,05848 & 0,46698 & 2,390335 & 19,087528 & $-22,8$ \\
\hline 223 & 26,066667 & 1106,8201 & 1126,6982 & 1,13171 & 0,05898 & 0,47561 & 2,3794916 & 19,18803 & \\
\hline 225 & 26,066667 & 1138,5888 & 1132,5458 & 1,14718 & 0,05367 & 0,46585 & 2,4625553 & 21,374723 & $-23,1$ \\
\hline 227 & 24,266667 & 1126,6982 & 1107,7944 & 1,16265 & 0,06357 & 0,49822 & 2,3336131 & 18,28933 & \\
\hline 229 & 24,266667 & 1132,5458 & 1161,0114 & 1 & 0,05927 & 0,51993 & 2,2659283 & 19,877241 & $-22,8$ \\
\hline 231 & 26,733333 & 1107,7944 & 1133,1306 & 1,1936 & 0,06589 & 0,55455 & 2,1523676 & 18,114971 & \\
\hline
\end{tabular}

Legenda: T.A.M. =taxa de acúmulo de massa e T.A.C.= taxa de acúmulo carbono $\left(\mathrm{g} \cdot \mathrm{m}^{-2}\right.$ ano-1 $\left.^{-1}\right)$ 
Tabela 7b- Teor de $\mathrm{CaCO}_{3}$ e das análises da matéria orgânica sedimentar do testemunho UBA3 (cont.)

\begin{tabular}{|c|c|c|c|c|c|c|c|c|c|}
\hline Prof. (cm) & $\mathrm{CaCO} 3(\%)$ & $\begin{array}{c}\text { T.A.M. } \\
\text { (g/mªno) }\end{array}$ & $\begin{array}{c}\text { T.A.C. } \\
\text { (g/mªno) }\end{array}$ & $\% \mathrm{C}$ & $\% \mathrm{~N}$ & $\% \mathrm{~S}$ & $\mathrm{C} / \mathrm{S}$ & $\mathrm{C} / \mathrm{N}$ & $\delta^{13} \mathrm{C}$ (ppm) \\
\hline 233 & 26,733333 & 1161,0114 & 1116,5636 & 0,9712 & 0,09435 & 0,53904 & 1,8017216 & 10,293588 & $-22,7$ \\
\hline 235 & 27,333333 & 1133,1306 & 1291,2238 & 2 & 0,10504 & 0,4847 & 3,5960388 & 16,593679 & \\
\hline 237 & 27,333333 & 1116,5636 & 1008,2907 & 1 & 0,08383 & 0,59153 & 1,9380251 & 13,675295 & $-22,9$ \\
\hline 241 & 30,933333 & 1291,2238 & 1021,135 & 1 & 0,08543 & 0,63852 & 1,725083 & 12,893597 & \\
\hline 243 & 30,933333 & 1008,2907 & 1036,5121 & 1 & 0,08415 & 0,64256 & 1,7593688 & 13,434343 & $-22,7$ \\
\hline 245 & 30,933333 & 1036,5121 & 1057,1495 & 1 & 0,09043 & 0,62519 & 1,7181977 & 11,878801 & \\
\hline 247 & 22,9 & 1057,1495 & 1064,5493 & 1 & 0,09043 & 0,62519 & 1,7181977 & 11,878801 & $-23,2$ \\
\hline 249 & 22,9 & 1064,5493 & 1076,2346 & 1 & 0,09181 & 0,69884 & 1,5853414 & 12,067313 & \\
\hline 251 & 22,9 & 1076,2346 & 1027,558 & 1 & 0,09993 & 0,93122 & 1,3064582 & 12,174522 & $-23,2$ \\
\hline 253 & 21,55 & 1027,558 & 1016,4641 & 1 & 0,09854 & 0,7811 & 1,4564076 & 11,54455 & \\
\hline 255 & 21,55 & 1016,4641 & 1054,4235 & 1 & 0,11245 & 0,78725 & 1,4727215 & 10,31036 & $-23,2$ \\
\hline 257 & 21,55 & 1054,4235 & 970,93721 & 1 & 0,12276 & 0,72073 & 1,5542575 & 9,1251222 & \\
\hline 259 & 22,35 & 970,93721 & 896,66901 & 1 & 0,09857 & 0,71524 & 1,5951289 & 11,574516 & $-22,5$ \\
\hline 261 & 22,35 & 896,66901 & 939,62786 & 1 & 0,10227 & $0 ., 0150$ & \#VALOR! & 11,257456 & \\
\hline 263 & 22,35 & 939,62786 & 993,89199 & 1 & 0,09137 & 0,58659 & 1,8472869 & 11,859472 & -23 \\
\hline 265 & 25,45 & 993,89199 & 1023,276 & 1 & 0,08935 & 0,5968 & 1,8813673 & 12,566312 & \\
\hline 267 & 25,45 & 1023,276 & 960,8236 & 1 & 0,08758 & 0,52464 & 1,9441903 & 11,646495 & $-22,9$ \\
\hline 269 & 25,45 & 960,8236 & 1012,1827 & 1 & 0,10555 & 0,58249 & 1,9547117 & 10,787305 & \\
\hline 271 & 21,4 & 1012,1827 & 1033,2029 & 1 & 0,08909 & 0,70592 & 1,7469402 & 13,842182 & $-23,1$ \\
\hline 273 & 21,4 & 1033,2029 & 994,86479 & 1 & 0,08144 & 0,62966 & 1,915637 & 14,810904 & \\
\hline 275 & 20,3 & 994,86479 & 1012,5719 & 1 & 0,08144 & 0,62966 & 1,915637 & 14,810904 & -23 \\
\hline 277 & 20,3 & 1012,5719 & 1026,9741 & 1 & 0,08063 & 0,57036 & 1,9359703 & 13,694655 & \\
\hline 279 & 22,2 & 1026,9741 & 998,36698 & 1,12165 & 0,08108 & 0,55672 & 2,0147506 & 13,833892 & $-23,4$ \\
\hline 281 & 22,2 & 998,36698 & 923,49152 & 1 & 0,09886 & 0,57383 & 1,9497627 & 11,317341 & \\
\hline 283 & 23,725 & 923,49152 & 986,6936 & 1 & 0,09922 & 0,54842 & 2,03496 & 11,247861 & $-23,2$ \\
\hline 285 & 23,725 & 986,6936 & 1037,6801 & 1 & 0,08806 & 0,66641 & 1,6704329 & 12,641303 & \\
\hline 287 & 17,2 & 1037,6801 & 1088,5062 & 1 & 0,07268 & 0,60864 & 1,824352 & 15,277567 & $-22,5$ \\
\hline 289 & 17,2 & 1088,5062 & 1033,9815 & 1 & 0,06873 & 0,51374 & 2,1558648 & 16,114564 & \\
\hline 291 & 29,57 & 1033,9815 & 1011,7935 & 1 & 0,07683 & 0,59819 & 1,8467951 & 14,378946 & $-22,4$ \\
\hline 293 & 29,57 & 1011,7935 & 1009,6529 & 1 & 0,08992 & 0,48884 & 2,254142 & 12,254391 & \\
\hline 295 & 25,5 & 1009,6529 & 1041,9629 & 1 & 0,0817 & 0,49711 & 2,2109698 & 13,452818 & $-22,1$ \\
\hline 297 & 25,5 & 1041,9629 & 1035,5388 & 1 & 0,0956 & 0,52295 & 2,0963297 & 11,467318 & \\
\hline 299 & 20,7 & 1035,5388 & 1062,0177 & 0,98082 & 0,08728 & 0,43408 & 2,2595374 & 11,237626 & $-22,3$ \\
\hline
\end{tabular}

Legenda: T.A.M. =taxa de acúmulo de massa e T.A.C.= taxa de acúmulo carbono (g. $\mathrm{m}^{-2}$ $\mathrm{ano}^{-1}$ ) 
Tabela 7c- Teor de $\mathrm{CaCO}_{3}$ e das análises da matéria orgânica sedimentar do testemunho UBA3 (cont.)

\begin{tabular}{|c|c|c|c|c|c|c|c|c|c|}
\hline Prof. (cm) & CaCO3 (\%) & $\begin{array}{c}\text { T.A.M. } \\
\text { (g/m²/ano) }\end{array}$ & $\begin{array}{c}\text { T.A.C. } \\
\text { (g/mªno) }\end{array}$ & $\% \mathrm{C}$ & $\% \mathrm{~N}$ & $\% \mathrm{~S}$ & $\mathrm{C} / \mathrm{S}$ & $\mathrm{C} / \mathrm{N}$ & $\delta^{13} \mathrm{Cppm}$ \\
\hline 301 & 20,7 & 1062,0177 & 1097,2729 & 1 & 0,09513 & 0,50363 & 2,1529694 & 11,398087 & \\
\hline 303 & 6,85 & 1097,2729 & 1023,276 & 0,93576 & 0,07421 & 0,51052 & 1,8329546 & 12,609621 & -23 \\
\hline 305 & 6,85 & 702,73168 & 1142,4879 & 1 & 0,07971 & 0,43969 & 2,4210239 & 13,354661 & \\
\hline 307 & 7,85 & 784,6001 & 1117,9277 & 0,90742 & 0,07802 & 0,37547 & 2,4167577 & 11,630608 & $-23,1$ \\
\hline 309 & 7,85 & 767,73351 & 1226,5699 & 0,56222 & 0,03868 & 0,21655 & 2,5962595 & 14,53516 & \\
\hline 311 & 8,2 & 842,34317 & 878,02081 & 0,55241 & 0,04685 & 0,23493 & 2,3513813 & 11,791035 & $-22,5$ \\
\hline 313 & 8,2 & 878,02081 & 920,71739 & 0,42653 & 0,03943 & 0,17097 & 2,4947652 & 10,817398 & \\
\hline 315 & 8,35 & 920,71739 & 983,92019 & 0,34854 & 0,03155 & 0,12136 & 2,8719512 & 11,047227 & $-23,2$ \\
\hline 317 & 8,35 & 983,92019 & 1002,2325 & 0,37319 & 0,02994 & 0,14126 & 2,6418661 & 12,464596 & \\
\hline 319 & 4 & 1002,2325 & 961,31434 & 0,40734 & 0,03035 & 0,16309 & 2,4976393 & 13,421417 & $-23,2$ \\
\hline 321 & 4 & 961,31434 & 937,51477 & 0,43145 & 0,0335 & 0,1805 & 2,3903047 & 12,879104 & \\
\hline 323 & 2,85 & 937,51477 & 895,06658 & 0,37262 & 0,03046 & 0,12309 & 3,0272159 & 12,233093 & $-22,8$ \\
\hline 325 & 2,85 & 895,06658 & 969,78962 & 0,29182 & 0,02538 & 0,07783 & 3,7494539 & 11,49803 & \\
\hline 327 & 2,15 & 969,78962 & 971,53877 & 0,50969 & 0,02197 & 0,10749 & 4,7417434 & 23,199363 & $-23,3$ \\
\hline 329 & 2,15 & 971,53877 & 975,97936 & 0,28646 & 0,01632 & 0,07468 & 3,8358329 & 17,552696 & \\
\hline 331 & 1,3 & 975,97936 & 957,1448 & 0,35412 & 0,01525 & 0,09282 & 3,8151261 & 23,220984 & $-22,5$ \\
\hline 333 & 1,3 & 957,1448 & 935,90187 & 0,50992 & 0,03356 & 0,19133 & 2,6651335 & 15,194279 & \\
\hline 335 & 2,25 & 935,90187 & 925,28546 & 0,40905 & 0,02365 & 0,13971 & 2,9278505 & 17,295983 & $-22,6$ \\
\hline 337 & 2,25 & 925,28546 & 950,82426 & 0,28269 & 0,00886 & 0,07996 & 3,5353927 & 31,906321 & \\
\hline 339 & 2 & 950 & 968 & 0,3 & 0,01 & 0,1012 & 2,96 & 29,01 & $-23,8$ \\
\hline 341 & 2 & 968,57872 & 894,66383 & 0,44113 & 0,0188 & 0,16003 & 2,7565456 & 23,464362 & \\
\hline 343 & 4,425 & 894,66383 & 1032,4191 & 0,42724 & 0,02629 & 0,15316 & 2,7895012 & 16,251046 & $-23,7$ \\
\hline
\end{tabular}

Legenda: T.A.M. =taxa de acúmulo de massa e T.A.C.= taxa de acúmulo carbono (g. $\mathrm{m}^{-2}$ ano $^{-1}$ ) (cont.) 

